Universidad de Lima

Facultad de Comunicaciones

Carrera de Psicología

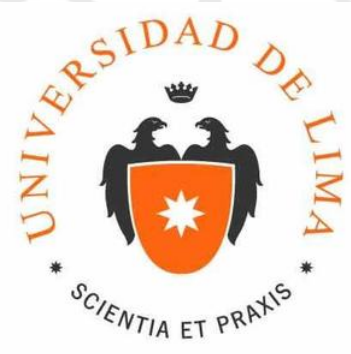

EL ROL PREDICTOR DE LA REGULACIÓN EMOCIONAL, LA EMPATÍA Y LA ALEXITIMIA EN EL CONTROL INTENCIONAL DE NIÑOS Y NIÑAS DE EDUCACIÓN INICIAL

Tesis para optar el título profesional de Licenciado en Psicología

Benjamin Lira Luttges

Código 20092009

Asesora

Carolina Camino

Lima - Perú

Enero del 2017 


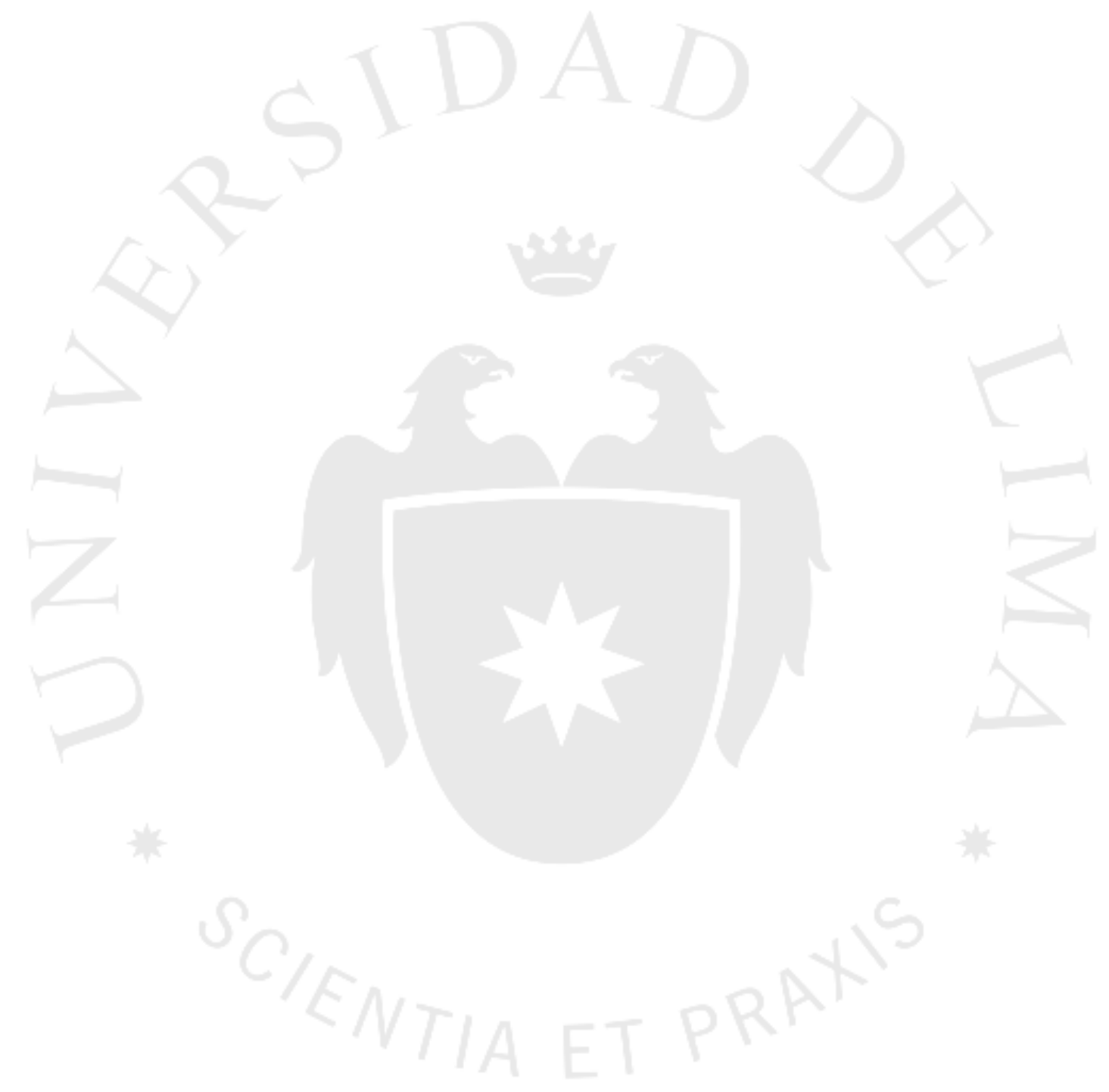




\section{EL ROL PREDICTOR DE LA REGULACIÓN EMOCIONAL, LA EMPATÍA Y LA ALEXITIMIA EN EL CONTROL INTENCIONAL DE NIÑOS Y NIÑAS DE EDUCACIÓN INICIAL}




\section{RESUMEN Y ABSTRACT}

Estudios recientes, han demostrado que el apego y el clima emocional del ambiente de desarrollo pueden ser predictores del temperamento infantil. El presente estudio evaluó el rol predictor de la empatía, regulación emocional y alexitimia de los padres en el control intencional de 326 niños. Los resultados indican que el distrés personal en la madre predice al control inhibitorio, y que la preocupación empática del padre predice la sensibilidad perceptual, sin embargo los efectos son pequeños. Se reportan análisis suplementarios como la correlación del control intencional con la edad (no se observa la correlación esperada) y diferencias de sexo (se observan diferencias a favor de las mujeres); así como una evaluación psicométrica de todos los instrumentos empleados. Los resultados sugieren que determinadas características del ajuste emocional de los padres tienen un rol, aunque pequeño, en el desarrollo del control intencional. Esto es consistente con el hecho de que en la literatura la mayoría de los efectos reportados no son directos. Se presentan las limitaciones del estudio, y recomendaciones para estudios futuros.

Palabras clave: Temperamento; Control intencional; Empatía; Regulación emocional.

Recent studies have shown that secure attachment and the emotional climate of the place where infants develop can be predictive of their temperament. The present study evaluated the predictive role of parental empathy, emotional regulation and alexithymia in effortful control of 326 children. Results show that personal distress in mothers predicts inhibitory control and that fathers' empathic concern predicts perceptual sensibility, however, effects are mild. Supplemental analyses are also reported, such as the relation between age and effortful control (the expected correlation is not replicated) and sex differences (in favor of girls); as well as psychometric evaluation of the tests used. Results suggest that certain parental emotional adjustment characteristics can have a role, although mild, in the development of effortful control. This is consistent with the fact that most effects in the literature are not direct. Limitations of the study and recommendations for future research are presented.

Keywords: Temperament; Effortful Control; Empathy; Emotion Regulation. 


\section{AGRADECIMIENTOS}

Son muchas las personas a quienes debo gratitud por la realización de este trabajo. Siendo el perfeccionista que soy, no deja de ser difícil para mí buscar palabras que hagan justicia a lo que debo a las muchas personas que me han acompañado en este proceso.

Debo agradecer a Carolina Camino, mi asesora de tesis, que me recomendó lecturas interesantes, y me ayudó mucho con la revisión del trabajo.

Además, agradezco al profesor Andrés Burga y Luis Miguel Escurra, que fueron mis asesores en temas estadísticos y metodológicos, y dedicaron muchas horas, incluso fuera de horario, para guiarme con sus conocimientos. Les agradezco además, por inspirarme a seguir aprendiendo y motivarme para tratar de comprender un poco más.

No puedo dejar de agradecer a María Teresa Uriarte, quien debe haber recibido más de 500 correos míos, los cuales siempre respondió de manera rápida, eficiente y con mucha paciencia.

Le debo sinceros agradecimientos a Lennia Matos y a Sandra Inurritegui, dos de mis profesoras. A ambas por el cariño e interés de acompañarme en la tesis. A Sandra por el apoyo que me dio durante el curso de Seminario de Tesis II, curso en el que surgió la primera versión de este trabajo, y a Lennia por las buenas ideas y la ayuda y por darme una motivación para terminar la tesis (“¡Benji, de una vez! Se me va acabar el soporte a la autonomía"). Muchas gracias por todo el cariño.

Agradezco también a varios investigadores extranjeros que, por alguna razón que aún no logro comprender, se tomaron el tiempo de responder a un tesista que escribía consultas desde Perú. Mis agradecimientos a Sam Putnam, que respondió dudas acerca de una de las pruebas usadas en la tesis, y me dio buenas explicaciones para resultados aparentemente contradictorios y a Michael Posner, quien me dio ánimos y artículos interesantes en la realización del trabajo. Además, agradezco a Erin Buchanan, profesora de estadística de la Michigan State University que comparte clases y tutoriales mediante YouTube. Agradezco a quienes trabajan por hacer que la información sea abierto y esté disponible a todos, las iniciativas de Open Science y Open Access, y tantos que trabajan por democratizar el acceso al conocimiento. 
No puedo dejar de agradecer a mi jefa, Anna Lucía Campos, quién generosamente me permitió usar estos datos para realizar la investigación, me alentó durante el camino y me permitió tiempo para dedicarme por completo a la tesis por una semana.

Tengo inmensa gratitud y admiración por mis padres, por darme las oportunidades que me han dado a lo largo de mi vida, y por insistirme, presionarme, empujarme y alentarme a sacar el máximo provecho de ellas. Mi inmensa admiración y agradecimiento a mis papás por enseñarme el valor del trabajo duro mediante el ejemplo y por siempre alentarme a hacer las cosas de la mejor manera. Les agradezco por no permitirme dar menos del máximo ("Las matemáticas son un año más difíciles, pero tu eres un año mayor, así que ¡a estudiar!”). Todo lo que soy se los debo a ellos.

Finalmente, quiero agradecer a María Fernanda Flores por darme fuerza cuando estaba más cansado, más triste, más decepcionado y más desanimado. Por todas las horas en las que nos acompañamos mutuamente para hacer nuestras tesis.

Sé que probablemente hay muchas más personas a las que debería mencionar, y mucho más podría decirse de los mencionados; pero sería iluso pensar que estas páginas son suficientes para expresar mi gratitud. Estoy muy feliz de haber podido contar con el apoyo y la amistad de tantas personas durante este proceso. 


\section{TABLA DE CONTENIDO}

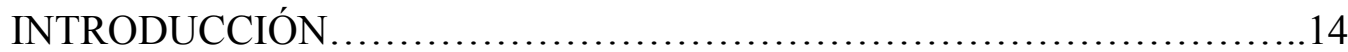

CAPÍTULO I. PLANTEAMIENTO DEL PROBLEMA ….............................. 14

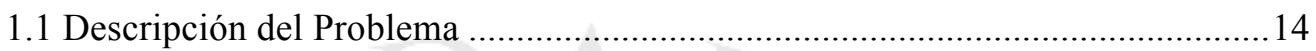

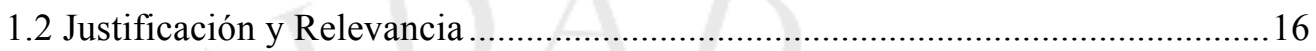

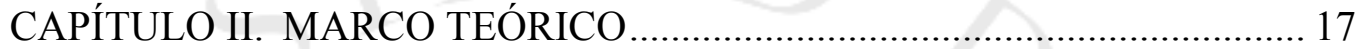

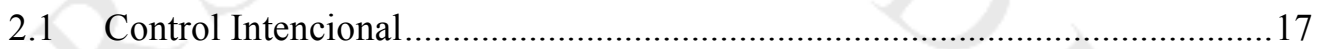

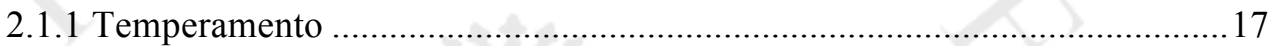

2.1.2 El modelo neurobiológico evolutivo del temperamento ...............................21

2.1.3 Definición de control intencional..............................................................23

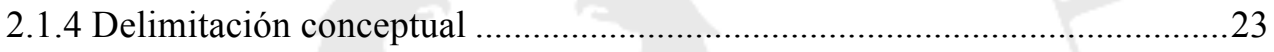

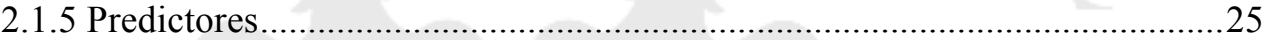

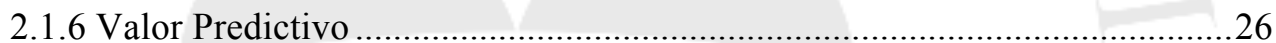

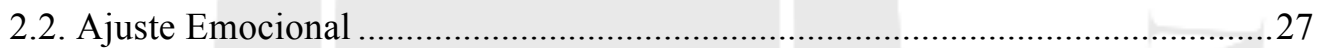

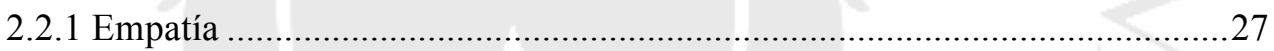

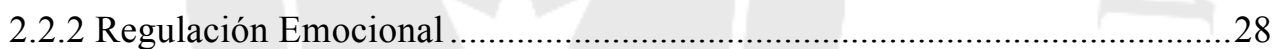

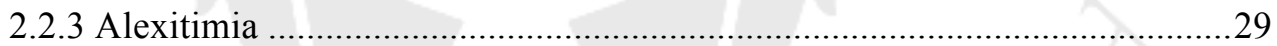

CAPÍTULO III. Objetivos, hipótesis y definición de variables.......................... 31

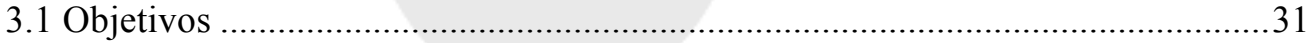

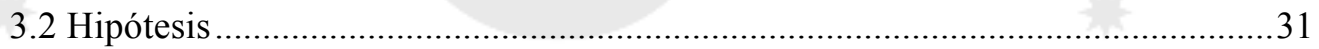

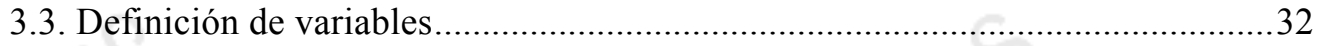

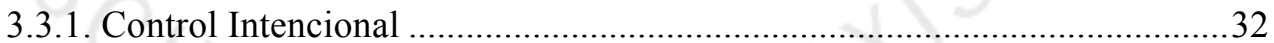

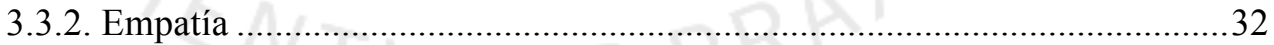

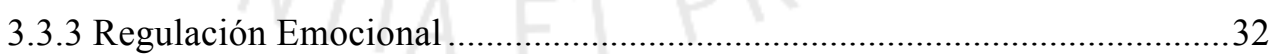

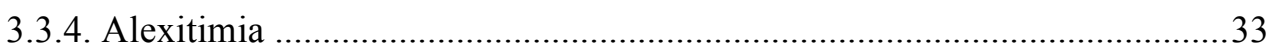

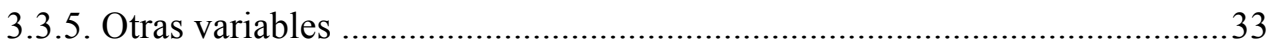

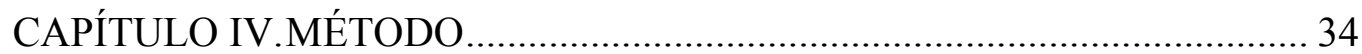

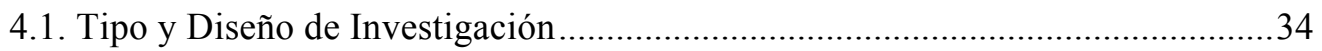

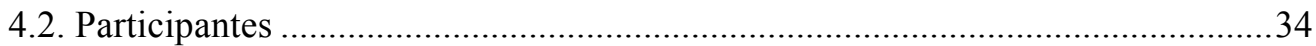

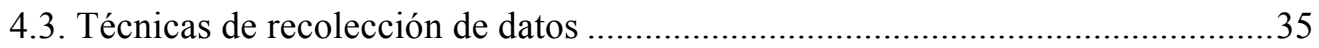

4.4. Procedimiento de recolección de datos ................................................................. 


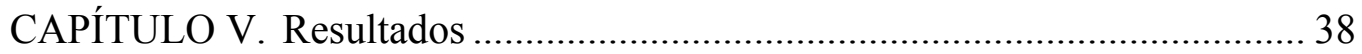

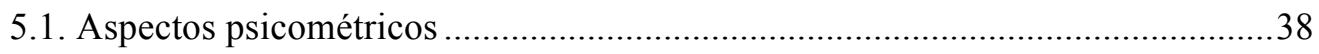

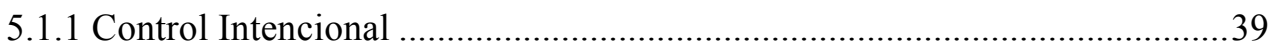

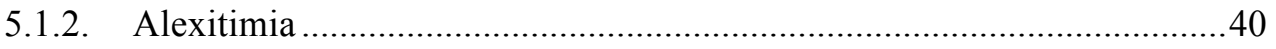

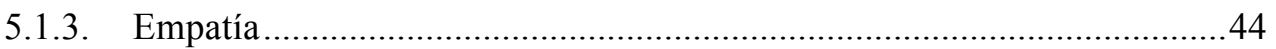

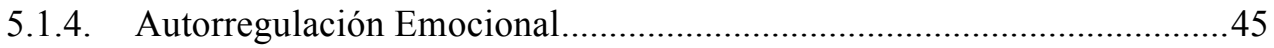

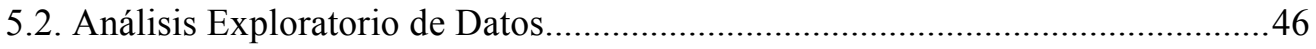

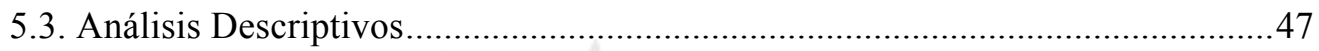

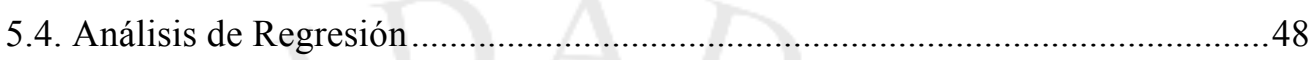

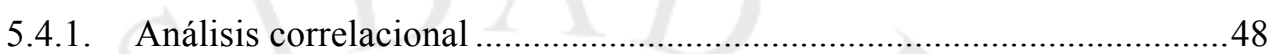

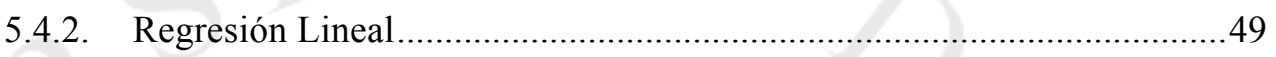

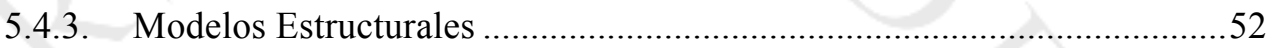

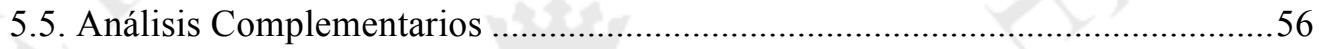

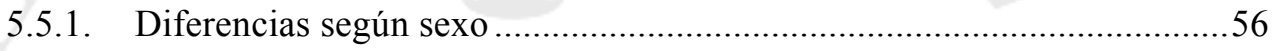

5.5.2. Relación entre la edad y el control intencional .......................................57

5.5.3. Diferencias en control intencional según grado ......................................58

5.5.4. Diferencias en control intencional según salud psicológica de los

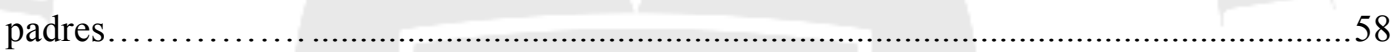

5.5.5. Relaciones entre la alexitimia, la empatía y la regulación emocional......59

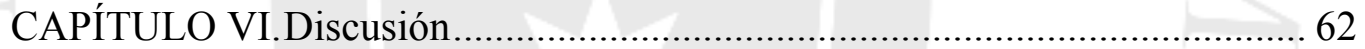

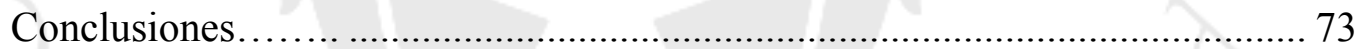

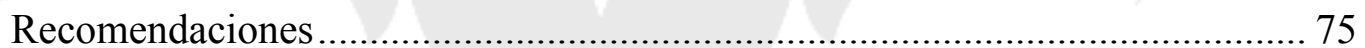




\section{INDICE DE FIGURAS}

Figura 1. El modelo modal de la emoción y las posibilidades de regulación emocional. Adaptado de Ochsner y Gross (2011) ................................................................ 29

Figura 2. Análisis factorial confirmatorio de la prueba ERQ .................................. 40

Figura 3. Análisis factorial confirmatorio inicial de la prueba TAS ........................... 41

Figura 4. Gráfico de sedimentación para la prueba TAS .......................................... 42

Figura 5. Análisis factorial confirmatorio de la prueba TAS ..................................... 44

Figura 6. Análisis factorial confirmatorio de la prueba IRI ..................................... 45

Figura 7. Análisis factorial confirmatorio de la prueba ERQ ...................................... 46

Figura 8. Diagnóstico del modelo de regresión para el control inhibitorio ................... 50

Figura 9. Diagnóstico del modelo de regresión para el control atencional .................... 51

Figura 10. Diagnóstico del modelo de regresión para el placer de baja intensidad....... 52

Figura 11. Diagnóstico del modelo de regresión para el placer de baja intensidad ....... 52

Figura 12. Modelo inicial para la predicción del control intencional a partir de las variables con correlaciones estadísticamente significativas ...............................5 53

Figura 13. Modelo final de predicción del control intencional ................................... 54

Figura 14. Diferencias de medias en las puntuaciones promedio (1-7) de las escalas de control intencional según sexo. 56

Figura 15. Relación entre la edad del niño y su nivel de control intencional. La línea muestra la tendencia de asociación lineal entre ambas variables. 58

Figura 16. Gráfico de red de correlaciones entre los predictores parentales. Se omiten las correlaciones menores a .2 debido a que este valor es menor al mínimo recomendado. 


\section{INDICE DE TABLAS}

Tabla 1. Confiabilidad ordinal de las subescalas de la prueba CBQ 40

Tabla 2. Cargas factoriales de la prueba TAS ......................................................... 42

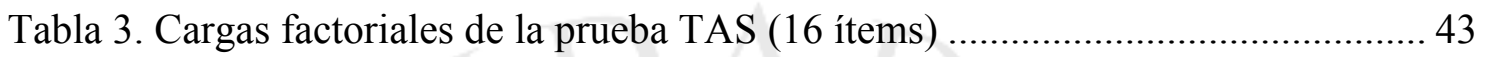

Tabla 4. Confiabilidad ordinal de las subescalas de la prueba IRI ............................. 45

Tabla 5. Estadísticos descriptivos y análisis de normalidad de las variables del estudio

Tabla 6. Correlacioens entre el control intencional de los niños y el ajuste emocional de

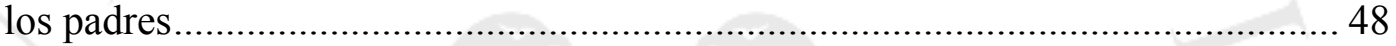

Tabla 7. Modelo de regresión lineal para el control inhibitorio ....................................49

Tabla 8. Modelo de regresión lineal para el control atencional ....................................50

Tabla 9. Modelo de regresión lineal para el placer de baja intensidad ......................... 51

Tabla 10. Modelo de regresión lineal para la sensibilidad perceptual ........................... 52

Tabla 11. Parámetros del modelo de senderos inicial para la predicción del control intencional

Tabla 12. Parámetros del modelo de senderos final para la predicción del control intencional

Tabla 13. Comparación entre el rol predictor de padres y madres sobre el control intencional

Tabla 14. Diferencias entre las subescalas de control intencional según sexo 56

Tabla 15. Matriz de correlaciones entre la edad y las subescalas de control intencional

Tabla 16. Diferencias en el control intencional de niños cuyas madres han o no han recibido tratamiento farmacológico para la ansiedad en el pasado 
Tabla 17. Matriz de correlaciones entre las variables de ajsute emocional de los padres y madres 60 


\section{INDICE DE ANEXOS}

Anexo 1.Instrumentos de evaluación y consentimiento informado

86 


\section{INTRODUCCIÓN}

Tradicionalmente, el temperamento se ha comprendido como una característica personal que no puede ser modificada por el ambiente al ser completamente dependiente de los genes. Estudios recientes determinan que la heredabilidad del temperamento no es diferente a la de otras características psicológicas. Así, se plantea la pregunta de qué factores ambientales pueden estar relacionados con el desarrollo del temperamento; comprendido ahora no como el centro hereditario de la personalidad, sino como el núcleo emocional-atencional-activacional de la personalidad.

Uno de las características temperamentales, se denomina control intencional, y ha sido definido, en resumidas cuentas, como el predictor temperamental de las funciones ejecutivas. Por esta razón, está asociado a una serie de resultados positivos posteriores, como el ajuste a la escuela, menor riesgo para algunas psicopatologías, menores problemas de conducta, mayor desarrollo de la conciencia moral y la prosocialidad, entre muchos otros. Por esta razón, es relevante preguntarnos que estrategias podemos llevar a cabo para desarrollar el control intencional de los niños.

Sin embargo, los predictores del control intencional no han sido estudiados a profundidad en la literatura, existiendo solo indicios de que el clima emocional en el ambiente de desarrollo del niño tiene un impacto importante. Así, este estudio buscó analizar el rol predictor de algunas variables de ajuste emocional de los padres en el control intencional de sus hijos. Estas variables fueron la empatía, la regulación emocional y la alexitimia.

Los resultados indicaron efectos pequeños, pero estadísticamente significativos para el distrés personal de la madre y la preocupación empática del padre sobre el control inhibitorio y la sensibilidad perceptual, respectivamente. Esto nos lleva a plantear estrategias centradas en los padres para el desarrollo del control intencional de los niños; y a replantear las definiciones tradicionales que tenemos sobre el temperamento. 


\section{CAPÍtUlO I. PLANTEAMIENTO DEL PROBLEMA}

\subsection{Descripción del Problema}

El temperamento se refiere a una serie de diferencias individuales en los campos de la emocionalidad, el control intencional y el nivel de actividad. Tradicionalmente, su estudio se ha centrado en evaluar su rol predictor. Es decir, se ha centrado en buscar cómo determinadas características temperamentales se vinculan a resultados futuros, como el éxito académico, tanto temprano (Blair y Razza, 2007; Coplan, Barber y Lagacé-Séguin, 1999) como posterior (Guerin, Gottfried, Oliver y Thomas, 1994), el desarrollo de la prosocialidad (Luengo Kanacri, Pastorelli, Eisenberg, Zuffianò y Caprara, 2013), la conciencia moral (Kochanska y Knaack, 2003) y la empatía (Rothbart y Rueda, 2005). Así, determinadas dimensiones del temperamento parecen ser determinantes para el éxito escolar, definido tanto como el desempeño académico como el ajuste socioemocional a la escuela.

Si bien las diferencias temperamentales se muestran desde temprano en la vida y se consideran constitucionales, existen evidencias para señalar que estas son influenciadas por el ambiente temprano de desarrollo (Eisenberg, Smith y Spinrad, 2011), lo que ha determinado que una serie de estudios comiencen a buscar predictores de características temperamentales, en lugar de conceptualizarlo como una característica fija. En gran medida, el ambiente temprano de desarrollo está determinado por la presencia de los padres. Es de esperar que sean sus características las que expliquen el cambio en las trayectorias de desarrollo y se ha observado el rol moderador de las características parentales (especialmente de la madre) en las relaciones entre temperamento como variable predictora y otras variables criterio como adaptación socioemocional y éxito académico (Rothbart y Bates, 2007; Rothbart y Rueda, 2005; Zentner y Bates, 2008).

Asimismo, estudios longitudinales han comprobado la importancia del control intencional, específicamente el rasgo de temperamento, que será estudiado en esta tesis, para el rendimiento académico inicialmente (Blair y Razza, 2007) y posteriormente, para una serie de resultados posteriores positivos hasta la adultez. Estos incluyen el nivel socioeconómico, el ingreso, planificación y responsabilidad financiera, así como 
la salud física y el uso de sustancias, la planificación familiar y la conducta criminal (Moffitt et al., 2011).

El vínculo entre control intencional y desempeño académico resulta especialmente relevante, dados los problemas de calidad y equidad en los sistemas educativos de América Latina evidenciados en estudios diagnósticos (Cueto, 2007; Organización para la Cooperación y el Desarrollo Económico, 2014).

Sin embargo, un aspecto que no ha sido estudiado a profundidad en la literatura corresponde a cómo determinadas características de los adultos significativos para los niños (e.g. padres y madres) se relacionan con el desarrollo del control intencional en ellos. Tradicionalmente, el control intencional es estudiado como una variable predictora y rara vez se estudia como una variable criterio: es decir los estudios predictivos del temperamento son escasos (Gartstein, Bridgett, Young, Panksepp y Power, 2013). Así, resulta importante esclarecer el rol de los padres en el desarrollo del control intencional.

De haber un vínculo claro, las implicancias para el desarrollo de habilidades socioemocionales y del cuidado de salud mental en adultos serían importantes, especialmente en adultos que se encargan del cuidado temprano de niños (e.g: adultos que atienden a niños en programas de intervención temprana estatal como Cuna Más). Esta vía de intervención puede resultar ser muy útil para lograr cambios positivos y desarrollo social y económico, especialmente para las poblaciones más vulnerables, que suelen ser las usuarias de estos programas.

A partir de la información señalada, se configura la pregunta de este estudio como: ¿cuál es el rol predictor del ajuste emocional de los padres (regulación emocional, empatía y alexitimia) en el control intencional de un grupo de niños de educación inicial (pre-kínder a segundo grado) en un colegio en Rancagua, Chile? 


\subsection{Justificación y Relevancia}

La justificación de esta investigación se sustenta a diversos niveles. Desde el punto de vista práctico, busca informar a servicios privados y estatales que buscan resolver la problemática social de los países de América Latina a través de la intervención educativa temprana (e.g: Cuna Más ${ }^{1}$ en Perú o Buen Comienzo ${ }^{2}$ en Medellín). Asimismo, se espera que la investigación resalte la importancia de la salud emocional de los padres para el desarrollo de sus hijos, basándose en la premisa de que padres que desarrollan resiliencia, entendida como ajuste social y emocional, son capaces de dar una crianza que brinda más soporte (Gavidia-Payne, Denny, Davis, Francis y Jackson, 2015), lo cual ha demostrado ser un efecto moderador entre los rasgos temperamentales infantiles y los resultados posteriores en la vida, así como tener una influencia directa en el desarrollo del control intencional (Li et al., 2016).

A nivel teórico, se busca ofrecer luces sobre las líneas de investigación en el desarrollo de características temperamentales en la niñez, específicamente en lo relativo a cómo determinadas características de los padres podrían influenciar en las características temperamentales de sus hijos.

Desde el punto de vista metodológico, la investigación aportará evidencias de confiabilidad y validez a las interpretaciones derivadas de las aplicación de los instrumentos de medición que se emplean en la presente investigación. Esto es importante dado que la ausencia de instrumentos de evaluación en Latinoamérica con adecuadas evidencias de confiabilidad y validez impiden un apropiado diagnóstico e intervención. Así, presentando dichas evidencias se espera contribuir a lograr un argumento de validez y confiabilidad que permita el uso adecuado, responsable y justificado de estas herramientas de medición.

\footnotetext{
${ }^{1}$ http://www.cunamas.gob.pe

2 http://www.medellin.edu.co/index.php/buen-comienzo
} 


\section{CAPÍTULO II. MARCO TEÓRICO}

A continuación, se expone el sustento teórico conceptual del presente estudio. Se comenzará con una presentación del control intencional, para luego discutir la literatura relevante en lo referente a la empatía y la reactividad interpersonal y finalmente, argumentar los aspectos de regulación emocional y alexitimia.

\subsection{Control Intencional}

El control intencional se refiere a la capacidad temperamental para regular el propio comportamiento, para inhibir una respuesta dominante en favor de una respuesta sub-dominante que esta al servicio de metas intencionales, la capacidad para planificar y detectar errores (Rothbart y Bates, 2007; Yan, 2016; Zentner y Bates, 2008). Al ser una variable temperamental, se explicará primero el temperamento y el modelo teórico específico en el que se basa esta tesis, para luego explicar con precisión el control intencional.

\subsubsection{Temperamento}

El temperamento se refiere a las diferencias individuales de tipo constitucional en la reactividad y la autorregulación, en los dominios de los afectos-emocionalidad, la actividad y la atención. El término constitucional hace referencia a las bases biológicas del temperamento, que son influenciadas a través del tiempo por la herencia (influencia genética), la maduración (cambios en la estructura del sistema nervioso después del nacimiento como producto de programas de cambio genético que interactúan con la experiencia) y las experiencias en relación al ambiente. Los términos reactividad y autorregulación son términos generales empleados para resumir el dominio temperamental. Por un lado, la reactividad se refiere a las diferencias en la intensidad, duración, latencia (tiempo entre el estímulo y la respuesta) de las respuestas al cambio en el ambiente externo e interno. Dentro de su definición, también se incluyen las tendencias de acción relacionadas (e.g. El miedo inhibe la acción). Por otro lado, la autorregulación se refiere a cualquier función involucrada en los procesos que modulen o modifiquen esta reactividad (Rothbart y Bates, 2007).

Se afirma que para que la reactividad y los procesos autorregulatorios sean temperamentales deben estar relacionados a alguna de las siguientes tres grandes áreas: (1) la emocionalidad, sea positiva o negativa, caracterizada como procesos afectivos 
relacionados a evaluaciones primarias acerca del posible carácter aversivo o apetitivo de un estímulo; (2) la atención, vinculada tempranamente a la orientación de la atención y la persistencia o capacidad de focalizar (e.g. tiempo de fijación en un estímulo) y más adelante al uso regulatorio de la atención como mecanismo autorregulatorio $\mathrm{y}$, finalmente (3), los aspectos motores vinculados a la cantidad total de locomoción y el nivel de actividad (Rothbart y Bates, 2007).

Es importante notar que las tendencias temperamentales no se expresan de manera continua, sino que requieren de condiciones elicitantes apropiadas. Así, un niño con miedo no estará constantemente asustado, sino únicamente en la presencia de estímulos poco familiares que sean evaluados como potencialmente peligrosos o dañinos por el niño.

\section{Criterios de inclusión y heredabilidad}

Si bien no existe un consenso, en la literatura clásica sobre el temperamento, para definir qué características personales forman parte del temperamento y cuáles no, Zentner y Bates (2008) ofrecen un set tentativo de criterios sintetizando la literatura reciente. A continuación, se presentan estos criterios y se discute por qué la heredabilidad no es uno de ellos.

- Dominios. Los dominios acordados como aspectos básicos, biológicos y compartidos con los animales se configuran como la afectividad (tanto positiva como negativa), el nivel de actividad, los aspectos básicos atencionales y la sensibilidad perceptual.

- Expresión cuantificable. El temperamento ha de expresarse en parámetros cuantificables. La intensidad de la respuesta (e.g. cantidad de decibeles del llanto), la latencia (i.e. tiempo entre la presentación del estímulo y la aparición de la respuesta), la duración (e.g. duración de la conducta de aproximación), el umbral (i.e. la intensidad mínima del estímulo para que se produzca una respuesta) y el tiempo de recuperación (i.e. cantidad de tiempo que demora una persona en volver a un estado emocional neutral después de haber sido perturbada).

- Manifestación temprana. Las características temperamentales deben ser observadas desde temprano en la vida. Si es que no lo son, se puede presumir que no están inscritas constitucionalmente (en el make-up biológico del individuo) y 
que por lo tanto, no son características básicas, sino producto de un aprendizaje posterior.

- Continuidad filogenética. Las características temperamentales han de ser observables en otros primates u otros animales sociales. Esto se debe a que las características temperamentales son producto de la evolución y por tanto, deben estar presentes de manera comparable, aunque rudimentaria, en otros mamíferos superiores con los que compartimos antepasados comunes y por tanto, material genético

- Mecanismos biológicos. Al igual que el resto de las variables psicológicas, el temperamento está sustentado biológicamente (i.e. es producto del funcionamiento del cerebro). Así, debe existir una continuidad entre la explicación biológica y el temperamento; $\mathrm{y}$, de hecho, se está trabajando para esclarecer los mecanismos neurales que explican las diferentes dimensiones temperamentales, así como los vínculos a nivel de genética molecular (qué polimorfismos genéticos contribuyen a explicar las diferencias temperamentales).

- Predicción. Al igual que en el caso de la personalidad, se exige cierta continuidad en el temperamento de la persona. Si es que estas diferencias están inscritas biológicamente, se espera que se mantengan estables. Así, el temperamento de un niño debe ser predictivo de los estilos temperamentales de ese niño durante la adultez.

La heredabilidad no ha sido seleccionada como un criterio útil o necesario para delimitar a las dimensiones temperamentales. Esto no se debe a que el temperamento no sea heredable; por el contrario, existe evidencia de que gran cantidad de las dimensiones temperamentales tienen un importante componente genético. Sin embargo, la influencia de los genes en el comportamiento no es específica al temperamento, sino a todo el funcionamiento psicológico de la persona. Así, existe una gran cantidad de otras variables psicológicas que son tanto o más heredables que el temperamento. Ejemplos como la inteligencia, la habilidad perceptual y otros sustentan la razón por la que se deshecha la heredabilidad como criterio. Asimismo, estudios al respecto de la heredabilidad del temperamento solo atribuyen un cociente de heredabilidad de 0.5 (Rothbart y Bates, 2007). 


\section{Temperamento y Personalidad}

Es importante desambiguar los términos de temperamento y personalidad para delimitar adecuadamente esta tesis. Tradicionalmente, se ha enfatizado al temperamento como hereditario y genético y a la personalidad como los aspectos que son moldeados por el ambiente. Esta concepción está basada en la separación tradicional entre la mente como aquello modificable, la personalidad, y el cerebro determinado biológicamente, el temperamento (Damasio, 2005).

Actualmente, se plantea una distinción algo más elaborada, que ha de fundamentarse en criterios que asuman la posibilidad de la explicación naturalista para ambos constructos. Rothbart y Bates (2007) y Zentner y Bates (2008) ofrecen algunos criterios útiles para esto.

La principal diferencia es que el temperamento se refiere a procesos básicos del funcionamiento del sistema nervioso, mientras que la personalidad se refiere a la integración de procesos más complejos. Así, mientras que el temperamento se relaciona con las tendencias de aproximación-inhibición; la personalidad como constructo se refiere a diferencias más complejas, relacionadas a patrones de pensamiento, emoción y conducta, valores, actitudes, estilos interpersonales, cognición social y la percepción del yo (Rothbart y Bates, 2007).

De esta manera, las características de personalidad serían exclusivas a los humanos mientras que las características temperamentales son compartidas con los animales, dado el hecho de que son producto de una historia evolucionaria compartida. Por ello, se puede afirmar que el temperamento es observable desde la infancia, mientras que la personalidad se va construyendo progresivamente y no se considera estable hasta la adultez temprana.

Así, Rothbart y Bates (2007) señalan que el temperamento sería el centro afectivo-activacional-atencional de la personalidad y por tanto, programas actuales del estudio de determinados rasgos de personalidad, como los 'grandes 3' (Eysenck, 1950) o los 'grandes 5' (Digman, 1990; McCrae y Costa, 1987), que buscan encontrar los rasgos fundamentales de la personalidad con bases biológicas, explicaciones genéticas y presencia en animales y de aparición temprana, son equivalentes al estudio del temperamento (Zentner y Bates, 2008). 
Es importante recalcar que sigue siendo necesaria una clara diferenciación o integración de los dos conceptos, de manera que el lenguaje sea unívoco. En parte, este problema se debe, también, a la falta de consenso en las definiciones y a que, con frecuencia, un mismo fenómeno es estudiado desde dos tradiciones o enfoques diferentes. Un ejemplo de esto último es el caso del control intencional, estudiado desde una perspectiva de temperamento, y las funciones ejecutivas, estudiadas desde una perspectiva cognitiva o de neurociencias (Liew, 2012).

\subsubsection{El modelo neurobiológico evolutivo del temperamento}

El modelo temperamental de Rothbart (1981) se basa en el principio de que las diferencias constitucionales en reactividad y regulación son causadas por diferentes mecanismos de funcionamiento del sistema nervioso y por tanto, están asociadas a procesos neurobiológicos. Así, es importante aclarar el funcionamiento temperamental a partir de estudios anatómicos y neuroquímicos (Zentner y Bates, 2008).

A continuación se presenta más detalladamente las dimensiones temperamentales extraídas en estudios de análisis factorial (Rothbart, Ahadi, Hershey y Fisher, 2001). Posteriormente se tratan los vínculos directos y moderados entre el temperamento y otras variables.

\section{Afectos Negativos}

En general, los afectos negativos son un mecanismo de evitación de posibles peligros (Fernández-Vilar y Carranza, 2013), probablemente explicable evolucionariamente como un mecanismo para evitar predadores. Así, los estudios factoriales atribuyen cuatro subdimensiones a este factor: el discomfort, el miedo, la ira y la tristeza. Se ilustrará este componente con el miedo.

El miedo estaría relacionado a una reacción de inhibición comportamental relacionada ante estímulos desconocidos, que pueden ser interpretados como potencialmente dañinos. Está vinculado fisiológicamente a la amígdala, que se encarga de responder ante estímulos poco usuales ${ }^{3}$ (Zentner y Bates, 2008).

Así, el miedo recién puede diferenciarse del distrés general infantil a los 7 a 10 meses de edad (Rothbart, Sheese y Posner, 2007) y genera un programa motor de

\footnotetext{
3 Anteriormente se consideraba que la amígdala estaba relacionada únicamente al miedo. Actualmente, se ha evidenciado que la amígdala se activa en presencia de estímulos inesperados o inusuales, independientemente de su valencia emocional.
} 
preparación para respuestas ante esta situación, como el ataque, la huida, el congelamiento o el escondite (Rothbart y Bates, 2007). Probablemente, la demora entre el nacimiento y la aparición del miedo es tal, debido a que requiere de un proceso computacional complejo para estimar la valencia del estímulo como neutra, agradable o potencialmente dañina.

Numerosos estudios han vinculado el miedo con variables criterio posteriormente (Rothbart y Bates, 2007; Rothbart et al., 2007; Zentner y Bates, 2008). Así, niños con altos niveles de miedo en la infancia tienden a sentir mayores niveles de empatía, culpabilidad y baja agresión a los 6 o 7 años (Rothbart, 2007). Asimismo, otros estudios vinculan el miedo a la aparición más temprana de la consciencia moral (Kochanska, Aksan y Joy, 2007), especialmente cuando las madres usan disciplina gentil (Posner y Rothbart, 2007). Por otro lado, la falta de miedo en la infancia es predictiva de mayor agresividad y conducta criminal (Rothbart, Ellis y Posner, 2011).

De esta manera, tanto el miedo como el control intencional cumplen un rol inhibitorio y ambas estarían relacionadas con la conducta moral y la aparición de la consciencia (Posner y Rothbart, 2007). No obstante, la diferencia entre ambas es que el miedo es un mecanismo regulatorio reactivo, mientras que el control intencional tiene una forma más autorregulatoria o voluntaria. Adicionalmente, se afirma que niveles excesivos de miedo podrían estar relacionados a un sobre-control muy rígido de la conducta (Rothbart, Ellis, et al., 2011).

\section{Extraversión y Surgencia}

Las tendencias a la extraversión y la surgencia están relacionadas con la aproximación hacia los estímulos, y por tanto serían, en resumidas cuentas, un sistema de aproximación para buscar potenciales recompensas (Fernández-Vilar y Carranza, 2013) probablemente fundamentable evolutivamente como un mecanismo promotor de la caza y la conquista de nuevos territorios. Así, neuroquímicamente, estaría relacionado principalmente a circuitos dopaminérgicos (Rothbart, Sheese y Posner, 2014).

De este modo, mientras que el miedo es un mecanismo de control regulatorio, que potencia la retirada o la inhibición comportamental; la aproximación se opone a esta, potenciando un acercamiento rápido y energético hacia los estímulos (Rothbart, Ellis, et al., 2011; Rothbart, Sheese, Rueda y Posner, 2011). 
La ira está positivamente relacionada con la aproximación (extraversiónsurgencia, Rothbart et al., 2014) y estaría relacionada principalmente con problemas de externalización (i.e. agresividad, Rothbart y Bates, 2007).

Altos niveles de aproximación aunados bajos niveles de miedo o control intencional pueden ser predictivos de altos niveles de impulsividad (Deyoung, 2011). Es así como la alta aproximación explica la tendencia a actuar y esa actuación no está limitada por los mecanismos regulatorios del miedo o el control intencional (Zentner y Bates, 2008).

\subsubsection{Definición de control intencional}

El control intencional es una manera de dar nombre a los rasgos temperamentales de autorregulación (Eisenberg et al., 2011). Es entendido como la eficiencia de la red de atención ejecutiva (Petersen y Posner, 1990, 2012), relacionada con la habilidad para inhibir una respuesta dominante para dar una respuesta subdominante, para planear y detectar errores (Rothbart y Bates, 2007). Si bien tanto el miedo como el control intencional son "frenos" para la conducta, el miedo es un mecanismo reactivo, mientras que el control intencional es un mecanismo autorregulatorio y voluntario (Fernández-Vilar y Carranza, 2013).

Eisenberg et al. (2011) plantean que la medida de control intencional suele incluir aspectos de regulación de la atención, es decir, la habilidad para voluntariamente enfocar o dirigir la atención según sea necesario; regulación comportamental, referida a la habilidad de suprimir el comportamiento impulsivo o automático y también de control de la activación, definida como la habilidad para activar el comportamiento cuando es necesario, aún en situaciones en las que uno preferiría desistir de una tarea.

Rothbart y Rueda (2005) plantean que si bien el control intencional nos permite mantener un control sobre la conducta, aún en situaciones cargadas emocionalmente, la eficiencia de este control, sin embargo, también dependerá de la intensidad del proceso emocional al que se enfrenta la persona.

\subsubsection{Delimitación conceptual}

La delimitación conceptual del control intencional es un asunto complejo dado que son fácilmente confundibles con conceptos como las funciones ejecutivas (Davidson, Amso, Cruess Anderson y Diamond, 2006; Diamond, 2013; Miyake et al., 
2000), la autorregulación (Posner, Rothbart y Tang, 2013) y la red de atención ejecutiva en los trabajos de Petersen y Posner (1990, 2012). Es necesario un esfuerzo para esclarecer conceptualmente estos términos y definir hasta dónde son equivalentes, dónde se encuentran las fronteras de cada concepto y qué subcomponentes podrían ser comunes. Recientemente, se están dando algunos esfuerzos para consolidar las definiciones de los conceptos, para evitar la confusión conceptual y tener un lenguaje más científico, unívoco y menos redundante (Diamond, 2013; Liew, 2012).

Así, Diamond (2013) discute las relaciones entre las funciones ejecutivas y constructos relacionados como la autorregulación, el control inhibitorio y la atención ejecutiva. Plantea al control inhibitorio como parte integral del constructo de autorregulación (con la salvedad de que la autorregulación incluiría aspectos de mantenimiento del arousal óptimo). Adicionalmente, identificaría al control intencional como el componente temperamental de la autorregulación.

Por otro lado, Liew (2012) señala que el control intencional y las funciones ejecutivas no son incompatibles, sino que son el resultado de diferentes corrientes que estudian fenómenos similares con distintos métodos (neurocogntivos vs. reportes de conducta). Así, el control intencional sería muy similar al componente de control inhibitorio de las funciones ejecutivas, pero no estaría relacionado a la flexibilidad cognitiva o a la memoria de trabajo.

Dos estudios que han examinado el control intencional en el ámbito chileno fueron los de Barata (2011) y Barra (2009); aunque desde una perspectiva más de neuropsicología que de una perspectiva temperamental. Barata (2011) comprobó la estructura factorial de las funciones ejecutivas y la influencia de estas en el éxito académico posterior: principalmente para el éxito en matemáticas, más que en lectura. Por otro lado, Barra (2009) vinculó las funciones ejecutivas en niños de edad preescolar con la habilidad de narración oral.

Gonzáles-Salinas et al. (2014) analizaron la relación entre el control intencional de niños ligeramente mayores a los de este estudio y encontró vínculos significativos con escalas del BRIEF (Behavior Rating Inventory of Executive Function - Inventario conductual para la medición de la función ejecutiva) encontrando correlaciones de entre .6 y .65 , así como correlaciones significativas aunque menores $(r=.29)$ con tareas relacionadas a memoria de trabajo (dígitos inversos). Esto es consistente con la 
precisión que hacen Diamond (2013) y Liew (2012) sobre la falta de relación entre memoria de trabajo y control intencional.

\subsubsection{Predictores}

El predictor más evidente del desarrollo del control intencional es la edad (Gartstein et al., 2013), dado que el control intencional está vinculado a la red atencional ejecutiva (Petersen y Posner, 2012), que sigue un patrón madurativo establecido (Posner y Rothbart, 2007).

El sexo, por otro lado, no juega un papel predictor relevante (Gartstein et al., 2013), aunque en un metanálisis de 205 estudios y 1758 tamaños del efecto, Else-Quest, Hyde, Goldsmith y Van Hulle (2006) encontraron diferencias relevantes entre hombres y mujeres. Otras variables como el nivel socioeconómico de la familia y la educación total de la madre no alcanzan valores significativos (Gartstein et al., 2013).

Se ha observado que la calidad de los padres tiene un rol sobre el control intencional. Li et al. (2016) recopilan posibles explicaciones sobre este mecanismo: por un lado, madres más gentiles tienden a expresar más emociones positivas en el contexto familiar y así, pueden modelar métodos efectivos de regulación de las emociones y el comportamiento y de manejo del estrés. Además, es más probable que estas madres modulen el arousal de los niños al discutir las emociones verbalmente, lo que permite respuestas más adaptativas a la socialización de los padres.

Adicionalmente, la actitud positiva de la madre estaría relacionada con que los niños sean mas atentos y receptivos a las metas de socialización de la madre, incluyendo las relacionadas a la autorregulación. Asimismo, los mecanismos de apego seguro entre madre y niño, están relacionados con la internalización y aceptación infantil de las expectativas y metas de socialización de la madre para ese niño. De esta manera, el apego sería un predictor de la aparición del control intencional en los niños (Viddal et al., 2015).

Además, se ha observado que la respuesta de los padres a las emociones de los niños tiene efectos en el desarrollo de control intencional. Así, los padres que responden apropiadamente a las emociones de sus hijos modelan la respuesta ante situaciones emocionalmente cargadas. Se han observado cómo las respuestas positivas (enfocarse en el problema, enfocarse en la emoción y expresar la emoción) en contraposición a 
estrategias negativas (minimizar, castigar o reacciones de distrés) se relacionan con un mayor nivel de control intencional (Eisenberg et al., 2011).

Además, Kochanska y Knaack (2003) indican que ciertas características temperamentales en los primeros meses de vida serían predictivos del control intencional durante la edad preescolar. Así, la emocionalidad en términos de ira o alegría serían predictores negativos del control intencional, mientras que el miedo sería un predictor positivo. De esta manera, estos resultados son consistentes con la idea del control intencional como un mecanismo regulatorio de las tendencias conductuales producidas por la ira y la irritabilidad (Rothbart y Bates, 2007). Asimismo, otras tendencias conductuales en la infancia como la latencia para retirar la mirada de un objeto (i.e. tiempo de mirada a un estímulo) y la dirección de la atención en la infancia son también predictores significativos (Gartstein et al., 2013). Sin embargo, podría argüirse que estas mediciones atencionales son mediciones de control intencional en sí y por tanto, no son predictores en sentido estricto, sino dos mediciones de un mismo constructo.

Gartstein et al. (2013) han identificado factores maternales predictores del desarrollo del control intencional en niños, encontrando como únicos predictores de la madre relevantes la extraversión (como predictor positivo) y el estrés parental (como predictor negativo).

\subsubsection{Valor Predictivo}

Kochanska y Knaack (2003) han estudiado profundamente la relación entre el control intencional y la posterior aparición de la consciencia moral, encontrando un vínculo bastante robusto entre ambas variables. Además, se ha observado que estos vínculos predictivos son duraderos en el tiempo, llegando a predecir la conducta prosocial en la adultez (Luengo Kanacri et al., 2013)

Rothbart y Rueda (2005) plantean que el control inhibitorio puede permitir la empatía, al permitirle a una persona dirigir la atención a los pensamientos y emociones de los otros (respuesta subdominante) sin ser sobrepasados por el propio distrés (respuesta dominante). La red ejecutiva interactuaría con el sistema límbico para ajustar respuestas de afectos positivos (i.e. extraversión) y negativos y alinearlos a las expectativas de las normas culturales (Rothbart, Sheese, et al., 2011). 
Por otro lado, en el campo escolar, se ha estudiado el rol que cumple el control intencional en el aprestamiento escolar para kindergarten, prediciendo logros en lenguaje y matemáticas (Blair y Razza, 2007). No obstante, estudios similares en Chile solo han logrado replicar la relación con las matemáticas, pero no con lenguaje (Barata, 2011).

\subsection{Ajuste Emocional}

Para efectos de este estudio, se analizan tres indicadores de ajuste emocional: la empatía, la regulación emocional y la alexitimia. A continuación se presenta un breve sustento teórico para cada uno de ellos.

\subsubsection{Empatía}

La empatía se conceptualiza como la capacidad para compartir los sentimientos de los demás (Singer, 2006). Incluye la capacidad para representar los estados afectivos de los otros, comprendiendo sus sentimientos, motivaciones y acciones (Bernhardt y Singer, 2012). Así, en ocasiones, se separa en un componente afectivo (compartir la emoción) y en uno cognitivo (representar las intenciones y creencias de los otros teoría de la mente) (Singer, 2006). Aparentemente, en estudios factoriales, esta estructura que separa componentes afectivas y cognitivas parece replicarse en los datos (Fernández, Dufey y Kramp, 2011).

En cuanto a los correlatos físicos, estudios basados en resonancia magnética funcional (fMRI) han identificado algunas áreas cerebrales vinculadas a esto, destacando, principalmente, la ínsula y la corteza anterior cingulada. Neuroquímicamente, la oxitocina sería el neurotransmisor más relacionado con este patrón conductual (Bernhardt y Singer, 2012).

Asimismo, se han observado vínculos entre la alexitimia y la activación cerebral característica de la empatía, demostrándose una relación inversa entre la empatía y la alexitimia (Bernhardt y Singer, 2012).

\section{Componentes de la empatía}

Como fue discutido anteriormente, las medidas de empatía suelen separar los componentes afectivos de los cognitivos (Davis, 1983). Estos componentes reciben el nombre de preocupación empática y toma de perspectiva para la capacidad de compartir 
la emoción del otro y para representar los estados mentales de los demás, respectivamente.

Adicionalmente, se suele incluir una tercera escala referida a la respuesta aversiva dirigida internamente ante el estado o condición emocional de otro. Esta recibe el nombre de distrés personal y se suele dar en situaciones de una sobreactivación empática, que es experimentada como aversiva, que genera una focalización y preocupación autodirigidas (Eisenberg et al., 2011). A su vez, el dirigir la atención hacia el interior impide prestar atención a la otra persona, lo cual impide una respuesta eficiente.

La experiencia de distrés personal podría vincularse a bajos niveles de control intencional. Se ha evidenciado que altas puntuaciones de control intencional se relacionan con experiencia de simpatía en el contexto de la exposición a un video emocionalmente cargado. Por otro lado, menores niveles de control intencional se relacionan análogamente con menores niveles de simpatía y por una respuesta de distrés personal que la reemplaza (Eisenberg et al., 2011). Esto tiene sentido dado que poder inhibir esta respuesta de preocupación requeriría del control pre-frontal del comportamiento y de las representaciones y emociones.

\subsubsection{Regulación Emocional}

La regulación emocional se refiere a la capacidad para modificar (i.e. escoger) las emociones que uno experimenta, cuándo uno las experimenta y cómo uno experimenta o expresa estas emociones (Gross, 2014). Dicho de otro modo, es cualquier proceso que influencie el inicio, la finalización, la magnitud, duración o intensidad de una respuesta emocional (Ochsner y Gross, 2011).

\section{Modelo Modal de la Emoción}

Gross (2014) propone un modelo en el que la emoción sigue un proceso secuencial y cíclico que puede ser útil para comprender diferentes tipos de regulación emocional. Así, el proceso de la emoción responde a una secuencia: (1) la persona se encuentra en una situación determinada y estando en esta situación (2) dirige su atención a determinados aspectos de esta. Los aspectos atendidos son interpretados cognitivamente (3) y producto de esa evaluación cognitiva se da una respuesta (4). 


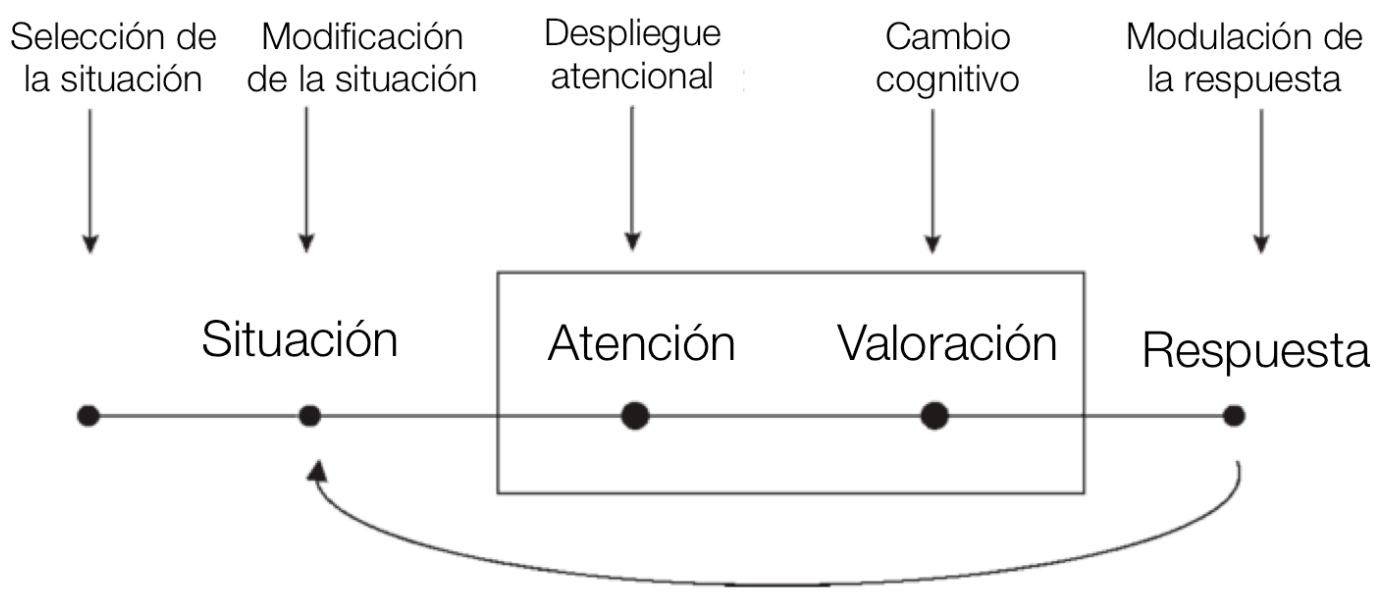

Figura 1. El modelo modal de la emoción y las posibilidades de regulación emocional. Adaptado de Ochsner y Gross (2011)

La regulación de la emoción puede darse en diferentes etapas de este proceso. (1) La selección de las situaciones a las que uno se expone es una manera de regular la emoción (e.g. un niño no asiste a la clase en la que tiene que exponer oralmente un trabajo delante de la clase). Ya estando en la situación, se puede modular la emoción (2) modificando dicha situación. El control voluntario de la atención (3), puede ser otra manera de controlar las respuestas emocionales; así, si se dirige la atención lejos de los aspectos desagradables de la situación se puede evitar una reacción emocional. (4) El cambio cognitivo (i.e. reevaluación cognitiva) se refiere a cambiar el significado de la interpretación del contenido de la situación atendido. Finalmente, (5) puede modificarse la expresión emocional modulando la respuesta (e.g. haciendo la mueca de la sonrisa, a pesar de que no se esté sintiendo alegría). La Figura 1 muestra tanto el proceso de la emoción como las diferentes formas de regulación en las distintas etapas.

\subsubsection{Alexitimia}

La alexitimia se refiere a las dificultades en la identificación y expresión de las emociones (Bernhardt y Singer, 2012). Esta denota un déficit tanto a nivel cognitivo como afectivo. Cognitivamente, implica un estilo de pensamiento concreto y práctico, mientras que afectivamente, implica una conciencia emocional disminuida e indiferenciada (Timoney y Holder, 2013). 
Grabe, Spitzer, y Freyberger (2001) plantean que el 51\% de la varianza en alexitimia es explicable a partir de variables de temperamento y personalidad, lo que sugiere que la alexitimia es una característica estable y no un estado temporal.

\section{Correlatos de la alexitimia}

Asimismo, se ha estudiado el vínculo entre la alexitimia y el razonamiento moral en pacientes con esclerosis múltiple, encontrándose una relación inversa: a mayor nivel de alexitimia, menor calidad en el juicio moral (Sinay, Manes y Gleichgerrcht, 2012). Estos resultados son comprensibles dado que la identificación con las emociones ajenas y la comprensión de los estados de los otros (i.e. empatía) está relacionado con el razonamiento moral (Luengo Kanacri et al., 2013). 


\section{CAPÍTULO III. OBJETIVOS, HIPÓTESIS Y DEFINICIÓN DE VARIABLES}

\subsection{Objetivos}

- Construir un modelo para la predicción del control intencional de estudiantes de primaria en base a la regulación emocional, alexitimia y empatía de sus padres en el contexto de un colegio privado en Rancagua, Chile.

- Evaluar las características psicométricas de las pruebas.

- Comparar los niveles de control intencional según sexo y grado.

- Evaluar la relación entre edad y control intencional.

- Comparar las diferencias en el control intencional de los niños según la presencia de trastornos de ansiedad en los padres.

- Comparar el poder predictivo de padres y madres en el control intencional de sus hijos

- Evaluar las relaciones entre las variables de ajuste emocional de los padres

\subsection{Hipótesis}

Numerosos estudios (para una revisión ver: Rothbart y Bates, [2007]; Zentner y Bates, [2008]) postulan que el rol de la madre (principalmente y no del padre) está relacionado en los niveles de control intencional en los niños. Especialmente en términos del apego (Viddal et al., 2015), la calidez y sensibilidad materna (Li et al., 2016). Así, se espera que las variables emocionales de la madre que permitan un mejor apego y calidez serán predictores de mayores niveles de control intencional en los niños. Específicamente: la empatía y la reevaluación cognitiva serán predictores positivos, mientras que la alexitimia y la supresión emocional serán predictores negativos.

Asimismo, basado en el hecho de que los estudios consideran casi íntegramente el rol de la madre y no el del padre, se espera que el padre no explicará varianza adicional a la explicada por las características maternales. 
En cuanto a los análisis complementarios, se espera encontrar diferencias en el control intencional según género, consistente con lo reportado en Else-Quest et al. (2006). Además, se espera encontrar una relación positiva entre la edad y el control intencional, y menores niveles de control intencional en niños cuyos padres reciban o hayan recibido tratamiento para la ansiedad y en niños cuyos padres tomen pastillas para dormir.

\subsection{Definición de variables}

\subsubsection{Control Intencional}

El control intencional se refiere a la habilidad para dar una respuesta subdominante mientras se inhibe una respuesta dominante; implica así detectar errores y planear (Kochanska y Knaack, 2003). Se relaciona con la eficiencia de la red neuronal de la atención ejecutiva (Petersen y Posner, 1990, 2012) y se entiende como la característica temperamental de la autorregulación (Diamond, 2013). Para efectos de este estudio, será definida operacionalmente como los puntajes derivados del reporte de ambos padres de las características conductuales de sus hijos según la aplicación del instrumento CBQ (Rothbart et al., 2001).

\subsubsection{Empatía}

La empatía se define como la habilidad para compartir los sentimientos de los otros (Singer, 2006), y estaría relacionada a la capacidad para representar las intenciones y las creencias de los otros (i.e. teoría de la mente). Operacionalmente, se define como las puntuaciones derivadas de la aplicación del Interpersonal Reactivity Index - IRI (Davis, 1983) en su versión adaptada al contexto chileno (Fernández et al., 2011).

\subsubsection{Regulación Emocional}

La regulación emocional se define como los procesos que modulan, ascendente o descendentemente la respuesta emocional de una persona (Gross, 2014). Para efectos de esta investigación, se estudian dos estrategias específicas: la reevaluación cognitiva, definida como la modificación de la respuesta emocional mediante la re-significación de un estímulo; y la supresión emocional, definida como el control en la manifestación y expresión interna y externa de la respuesta emocional (Ochsner y Gross, 2011). Para efectos de esta tesis, estas variables se definen operacionalmente como los puntajes 
derivados de la aplicación de la prueba ERQ (Gross y John, 2003), en su versión traducida al español (Gargurevich y Matos, 2010).

\subsubsection{Alexitimia}

Adicionalmente, otra variable relevante para esta tesis es la alexitimia, definida como la dificultad para identificar y expresar emociones, vinculado a un estilo de pensamiento vinculado al exterior (Bagby, Parker y Taylor, 1994). Para el presente estudio, la alexitimia se define operacionalmente como los puntajes derivados de la aplicación de la escala TAS-20 Toronto Alexythimia scale (Bagby, Parker, et al., 1994; Bagby, Taylor y Parker, 1994) en su versión traducida y adaptada al contexto chileno (Sáez Vilches y Tiznado Cerda, 2012).

\subsubsection{Otras variables}

Sexo

En todos los casos el sexo fue reportado por los padres de los niños, quienes lo marcaron en una encuesta sociodemográfica.

\section{Edad}

La edad de los padres será escrita por ellos mismo en cantidad de años. Ambos padres reportaron por escrito la edad de sus hijos(as) en años y meses. Las edades de los niños serán transformadas a número de meses para realizar los análisis

\section{Presencia de trastornos de ansiedad}

La presencia/ausencia de trastornos de ansiedad se evaluará mediante una pregunta en el cuestionario sobre el uso actual o anterior de pastillas para dormir (que requieren de una receta médica en Chile) y si ha tenido actual o anteriormente tratamiento farmacológico o psicoterapéutico para la ansiedad. 


\section{CAPÍTULO IV. MÉTODO}

\subsection{Tipo y Diseño de Investigación}

Se trata de una investigación cuantitativa - dado que los datos serán analizados estadísticamente, transeccional - debido a que los datos serán recogidos en un solo momento, de tipo no experimental y diseño correlacional - ya que no se manipulará ninguna variable, solo se analizarán las relaciones entre estas (Hernández, Fernández y Baptista, 2014). Debido a este último punto, la investigación no poseerá el poder explicativo para plantear que las características emocionales adultas causan los niveles del control intencional infantil. Se propone analizar el rol predictor de la empatía, la alexitimia y la regulación emocional de los padres en el control intencional infantil.

\subsection{Participantes}

Los participantes para el estudio son alumnos y alumnas de un colegio chileno de pre-kínder a segundo grado. Se trata de un colegio tradicional, mixto y privado en la ciudad de Rancagua, ubicada 100 kilómetros al sur de Santiago. Estos provienen de una base de datos secundaria, que se generó en el marco de una prestación de servicios para esta escuela, para lo cual se evaluaron a todos los alumnos de ese colegio y de esos grados. El objetivo de la recolección de estos datos fue la construcción de perfiles en el marco de una intervención para desarrollar habilidades de autorregulación en los niños. Los datos fueron recogidos antes del inicio del programa, por lo que no han sido influidos por éste.

El tamaño de la muestra es de 326 alumnos y sus padres. Criterios estadísticos señalan que con una muestra de ese tamaño es viable realizar análisis factoriales, dado que el predictor más importante para la calidad de los análisis es el tamaño de la muestra y que con muestras superiores a 300 personas, el criterio de 10 participantes por ítem deja de ser significativo (Field, Miles y Field, 2012).

Además, una muestra de este tamaño, permite una sensibilidad (Faul, Erdfelder, Buchner y Lang, 2009) al estudio suficiente como para lograr detectar correlaciones de hasta $r=.09$ (considerado un efecto de tamaño pequeño (Cohen, 1992; Ferguson, 2009) y un modelo de regresión múltiple con cuatro predictores con un tamaño del efecto $f^{2}=0.059$ (consideradas como efectos entre pequeños, y medianos [Cohen, 1992]). 
En cuanto a las características de la muestra, tras la eliminación de participantes con más del 40\% de los cuestionarios en blanco, se conformó por 322 niños y 500 padres. La edad promedio de los niños (51\% femenino) fue de 78 meses (6 años y medio, $\mathrm{DE}=13.71$ ), y la mayor proporción de estos pertenecían al primero y segundo grado de educación básica (29\% y 32\% respectivamente) más que a pre kínder y kínder (20\% y 19\% respectivamente). Con relación a los padres (59\% femenino), su edad promedio fue de 39.05 años $(\mathrm{DE}=5.89)$, y tenían en promedio 2.18 hijos.

\subsection{Técnicas de recolección de datos}

Para la medición del temperamento infantil se empleó el Child Behaviour Questionnaire - CBQ (Rothbart et al., 2001) en su versión corta de 94 ítems (Putnam y Rothbart, 2006) en su versión en español (Carranza, González y Hidalgo, 2000). La prueba se responde mediante una escala Likert de 7 niveles (extremadamente falso a extremadamente cierto). Esta mide 15 subdimensiones de temperamento agrupadas en tres superfactores extraídos mediante el análisis factorial de las sumas de los puntajes de las subdimensiones. Los superfactores son afectividad negativa, compuesta de 31 ítems (e.g. Llora desconsoladamente cuando uno de sus juguetes favoritos se pierde o se rompe); control intencional, compuesta de 26 ítems (e.g. Puede esperar a emprender una nueva actividad si se le pide); y extraversión-surgencia, compuesta de 37 ítems (e.g. Normalmente se lanza a una actividad sin pensarlo). En cuanto a las evidencias de validez respecto a la relación con otras variables, se obtuvieron correlaciones entre la versión corta y larga de la prueba de entre .62 y .88 (en las 15 subdimensiones). Con respecto a las evidencias de confiabilidad, se obtuvieron alfas de entre .69 y .79 para las subdimensiones (Putnam y Rothbart, 2006).

Para la medición de la empatía se empleó el Interpersonal Reactivity Index índice de reactividad interpersonal - que cuenta con 28 ítems distribuidos en cuatro componentes de 7 ítems cada uno: identificación con la fantasía (e.g. Cuando estoy leyendo una novela o cuento interesante, imagino cómo me sentiría si los sucesos de la historia me estuviesen ocurriendo a mi), distrés personal (e.g. Tiendo a perder el control durante las emergencias), preocupación empática (e.g. A menudo tengo sentimientos de ternura y preocupación por la gente menos afortunada que yo) y toma de perspectiva (e.g. Trato de considerar las perspectivas de todas las partes en un desacuerdo antes de tomar una decisión) de las cuales, las dos últimas corresponden directamente a la empatía, vinculándose principalmente con aspectos afectivos $\mathrm{y}$ cognitivos 
respectivamente (Davis, 1983). El formato de respuesta es una escala de tipo Likert de 5 niveles (No me describe bien - Me describe muy bien). Recientemente, estudios han proporcionado evidencias de validez mediante la relación entre los puntajes derivados de la prueba y el nivel de activación en áreas cerebrales relacionadas a la empatía (Bernhardt y Singer, 2012). Se empleó la versión traducida al español y adaptada al contexto chileno (Fernández et al., 2011) en la que se ha replicado la estructura factorial mediante análisis factorial confirmatorio, en la que se obtuvieron índices de ajuste satisfactorios $(R M S E A=0.054, C F I=0.813)$. En cuanto a las evidencias de confiabilidad, se han obtenido niveles de consistencia interna por alfa de Cronbach satisfactorios (entre .66 y .76) así como una adecuada estabilidad temporal tras 60 días $(r=.67-.89)$.

La medición de la alexitimia se recogió mediante el cuestionario TAS-20 (Bagby, Parker, et al., 1994; Bagby, Taylor, et al., 1994) de 20 ítems que mide la dificultad para reconocer emociones ( 7 ítems, e.g. A menudo estoy confundido con las emociones que estoy sintiendo), la dificultad para expresar emociones (5 ítems, e.g. Me es difícil expresar lo que siento acerca de las personas) y un patrón de pensamiento dirigido hacia el exterior ( 8 ítems, e.g. Prefiero hablar con la gente de sus actividades diarias a hablar sobre sus sentimientos). Se responde a la prueba mediante una escala Likert de 5 niveles (totalmente en desacuerdo - totalmente de acuerdo). En una tesis, Sáez Vilches y Tiznado Cerda (2012) obtuvieron evidencias de confiabilidad por consistencia interna de $\alpha=.77$ y una estructura de 7 componentes. Para cada uno de los factores de la prueba original, los investigadores hallaron dos o tres componentes que los representan ${ }^{4}$. Esta prueba (y su estructura de tres factores) es la más ampliamente usada y la que cuenta con mayores evidencias de validez (Timoney y Holder, 2013).

Para la medición de la regulación emocional se empleó el cuestionario de regulación emocional (ERQ) de 10 ítems (Gross y John, 2003). Se responde a esta prueba mediante una escala de tipo Likert de 7 niveles (Totalmente en desacuerdo Totalmente de acuerdo). Posee una subescala de 6 ítems que mide la estrategia de reevaluación cognitiva (e.g. Cuando quiero sentir una emoción positiva con mayor intensidad (por ejemplo, más alegría), modifico lo que pienso para hacerlo) y una subescala de 4 ítems que mide la estrategia de supresión emocional (e.g. Controlo mis

\footnotetext{
${ }^{4}$ Probablemente debido a que se empleó únicamente del criterio de autovalores mayores a uno. Es probable que usando métodos más precisos para determinar el número de factores a extraer se hubiera conseguido una solución más similar a la original
} 
emociones no expresándolas). Se usó la versión en español, de la cual se tiene evidencia psicométrica para el contexto peruano (Gargurevich y Matos, 2010). En un análisis factorial exploratorio se replicó la solución bifactorial original, explicando el 50.3\% de la varianza; que luego fue corroborado en un análisis factorial confirmatorio en el que se obtuvieron índices de ajuste aceptables $(R M S E A=.073, C F I=.90)$. Con respecto a las evidencias de validez provenientes de las relaciones con otras variables, se obtuvieron correlaciones positivas entre la reevaluación cognitiva y una medida de afecto positivo $(r=.14)$, y entre la supresión emocional y una medida de afecto negativo $(r=32)$. En cuanto a las evidencias de confiabilidad, se obtuvieron alfas de Cronbach de .72 y .74 para las dos subescalas.

\subsection{Procedimiento de recolección de datos}

Para recoger los datos, se contactó a la escuela mediante una carta de presentación elaborada por el centro de trabajo. Los padres recibieron sobres con las pruebas las cuales fueron respondidas individualmente para el caso de la regulación emocional, empatía y alexitimia y en conjunto para reportar el temperamento de sus hijos. Adicionalmente, llenaron cuestionarios de datos sociodemográficos. Los padres los devolvieron a la escuela en sobres cerrados. 


\section{CAPÍTULO V. RESULTADOS}

\subsection{Aspectos psicométricos}

A continuación se presenta un resumen de las evidencias de confiabilidad y validez de las interpretaciones de los puntajes obtenidos de las pruebas. Se presentan evidencias de validez por la estructura interna de la prueba. En todos los casos se realizó análisis factorial confirmatorio (AFC) usando el método de estimación de mínimos cuadrados ponderados con corrección de medias y varianzas (Weighted Least Squares Mean and Variance Corrected - WLSMV por sus siglas en inglés) replicando las estructuras originales planteadas por los autores de las pruebas. Este estimador es el más usado para datos ordinales como las respuestas Likert. Métodos tradicionales como el de máxima verosimilitud (ML) sobreestiman o subestiman los parámetros, según estudios de simulación; por lo que las opciones para usar con datos ordinales son el WLSMV (el más usado en la literatura) y el MML que, al a no estar implementado en muchos programas, permanece impopular fuera de quienes no usan modelos basados en teoría de respuesta al ítem (Brown, 2015). Este estimador es adecuado además porque estima los parámetros del modelo en base a las correlaciones policóricas que son adecuadas para este tipo de datos (Rosseel, 2014).

En todos los casos, se presentan índices de ajuste diferentes al $X^{2}$ tradicional, debido a que este ha sido considerado demasiado exigente. Para todos los modelos, se presentan dos índices de ajuste: el índice de ajuste comparativo en su versión normal (CFI) y robusta (CFIr), y el índice de ajuste Tucker-Lewis, también en su versión normal (TLI) y robusta (TLIr). Además, se presenta la aproximación a la raíz cuadrada promedio de los errores cuadrados, en su versión estándar (RMSEA) y robusta (RMSEAr). No se presenta la raíz media del residual cuadrado estandarizada (SRMR) debido a que esta no es apropiada para ser usada con el estimador WLSMV. Se buscan valores mayores a .9 en los índices de ajuste (idealmente mayores a .95), y menores a .1 para los índices de residuales (idealmente menores a .09) de acuerdo con las recomendaciones de $\mathrm{Hu}$ y Bentler (1999).

Posteriormente, se estimó la confiabilidad de las puntuaciones derivadas de los ítems de las pruebas mediante el cálculo del coeficiente alfa de Cronbach basado en correlaciones policóricas (alfa ordinal). Se prefirió este coeficiente, debido a que el alfa 
tradicional, al estar basado en correlaciones de Pearson o en la varianza, no es apropiado para datos ordinales (Gadermann, Guhn, y Zumbo, 2012).

Previo a estos análisis, se eliminaron los participantes que hubieran contestado menos del 40\% de los ítems; y se completaron los datos faltantes usando la técnica de imputación múltiple por ecuaciones encadenadas (MICE). Este es un procedimiento estadístico complejo que usa la información multivariada de cada sujeto para predecir el valor más probable que este hubiera respondido para esa variable (Van Buuren y Groothuis-Oudshoorn, 2011)

\subsubsection{Control Intencional}

Se realizaron análisis factoriales confirmatorios probando varios modelos: los cuatro factores originales correlacionados, los cuatro factores originales y un factor de segundo orden. Debido a que dos pares de los factores correlacionaban altamente entre sí y menos con el otro par, se probó un modelo bifactorial.

El modelo final con el mejor ajuste implicó la réplica de los 4 subfactores de la escala de control inhibitorio, propuestos en la versión original de la prueba (Putnam Rothbart, 2006). Se eliminó el ítem 86 (A veces se queda absorto mirando durante mucho tiempo un dibujo de un libro), debido a la poca carga en su factor. Además, se permitieron correlaciones entre los errores de los ítems 72 y 76 (Placer de baja intensidad - debido a que ambos están relacionados con disfrute por estímulos auditivos); 62 y 71 (Control atencional - debido a que ambos están relacionados con concentración para tareas de trabajo manual); 13 y 32 (Sensibilidad perceptual - debido a que ambos están relacionados a que el niño note cambios en la apariencia de los padres); y 39 y 86 (Placer de baja intensidad - debido a que ambos se relacionan con muestras de afecto y proximidad con el cuidador.

Los índices de ajuste comparativo del modelo $\left(X^{2}[265, N=322]=567.08, p<\right.$ $.001)$ fueron buenos $(\mathrm{CFI}=.957, \mathrm{CFIr}=.910$, TLI $=.951$, TLIr $=.898)$; y las medidas de residuales fueron adecuadas $(\mathrm{RMSEA}=.059, \mathrm{RMSEAr}=.058)$. Todos los ítems contaron con cargas estandarizadas superiores a .3. Aunque las correlaciones entre los factores fueron altas, los índices de ajuste fueron más apropiados para el modelo de cuatro factores. 

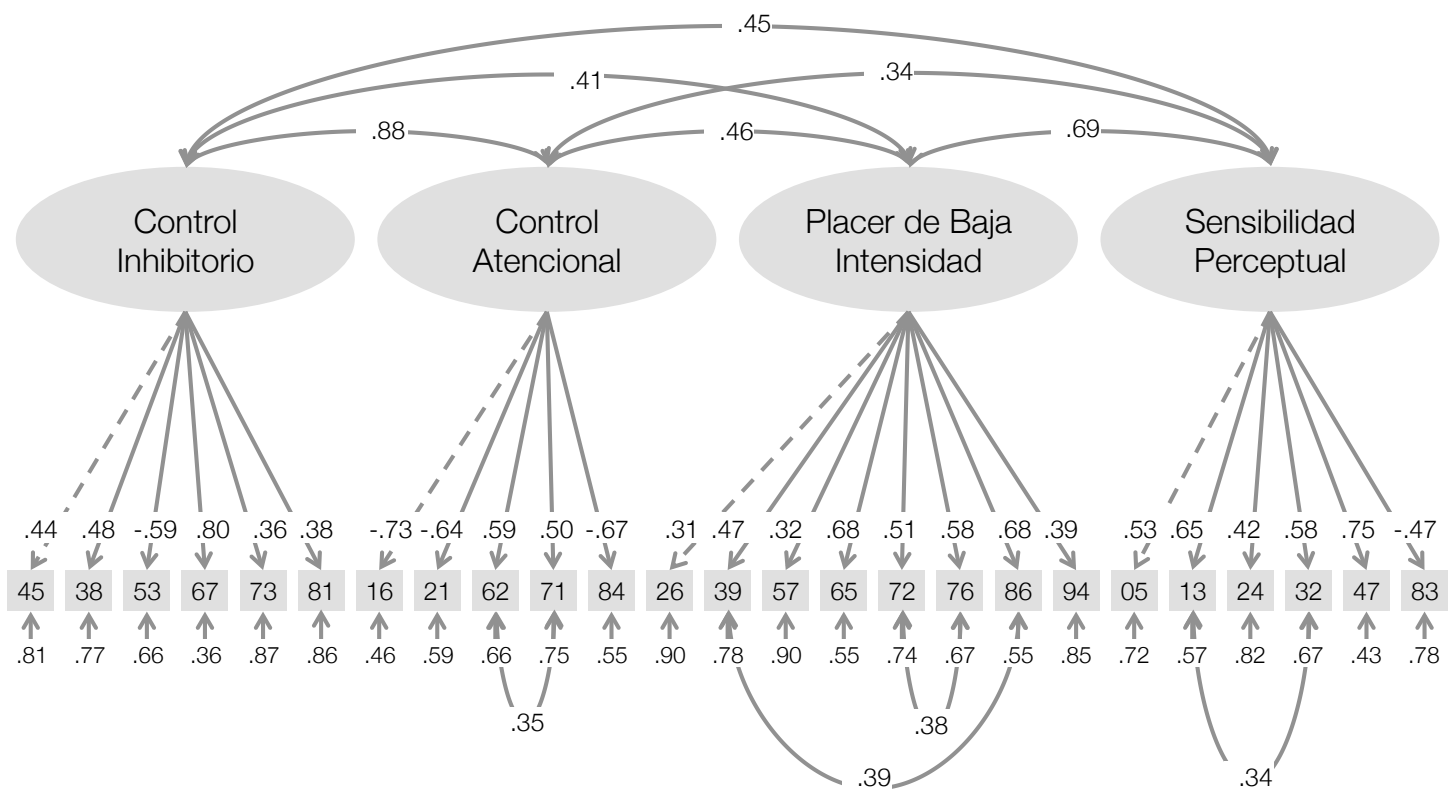

Figura 2. Análisis factorial confirmatorio de la prueba CBQ

Los alfas resultaron satisfactorios en todos los casos, y se presentan en la Tabla 1. Las correlaciones ítem-test corregidas fueron mayores a .3, en todos los casos, salvo en el ítem 57, perteneciente a la escala de placer de baja intensidad (ritc $=.26)$; en este caso, la eliminación del ítem no se justifica, debido a que el incremento en el coeficiente alfa sería de .01 .

Tabla 1

Confiablidad Ordinal de las subescalas de la prueba $C B Q$

\begin{tabular}{llll}
\hline Escala & Alfa Ordinal & Número de ítems & rITC Promedio \\
\hline Control Inhibitorio & .65 & 6 & .48 \\
Control Atencional & .77 & 5 & .63 \\
Placer de Baja Intensidad & .74 & 8 & .51 \\
Sensibilidad Perceptual & .74 & 6 & .56 \\
\hline
\end{tabular}

\subsubsection{Alexitimia}

Se realizaron varios análisis confirmatorios comparando el modelo original (Bagby, Parker, et al., 1994; Bagby, Taylor, et al., 1994), con un modelo unifactorial y con un modelo jerárquico. El modelo con mejor ajuste fue el modelo de tres factores propuesto originalmente (Ver figura 3) 
Se eliminaron 3 ítems de la escala de pensamiento dirigido al exterior. Al analizar el contenido de estos ítems se verificó que efectivamente no estaban adecuadamente redactados o no estaban suficientemente relacionados con el constructo (e.g. Prefiero ver espectáculos simples, pero entretenidos, que dramas psicológicos). Los indices de ajuste comparativo del modelo $\left(X^{2}[116, N=500]=705.80, p<.001\right)$ fueron buenos $(\mathrm{CFI}=.958, \mathrm{CFIr}=.881, \mathrm{TLI}=.951, \mathrm{TLI}=.86)$; y las medidas de residuales estuvieron cerca de los rangos aceptables $(\mathrm{RMSEA}=.09, \mathrm{RMSEAr}=.099)$. Todos los ítems contaron con cargas estandarizadas superiores a .3. Sin embargo, se observó una correlación muy elevada entre dos variables latentes, lo cual sugiere un solo factor.

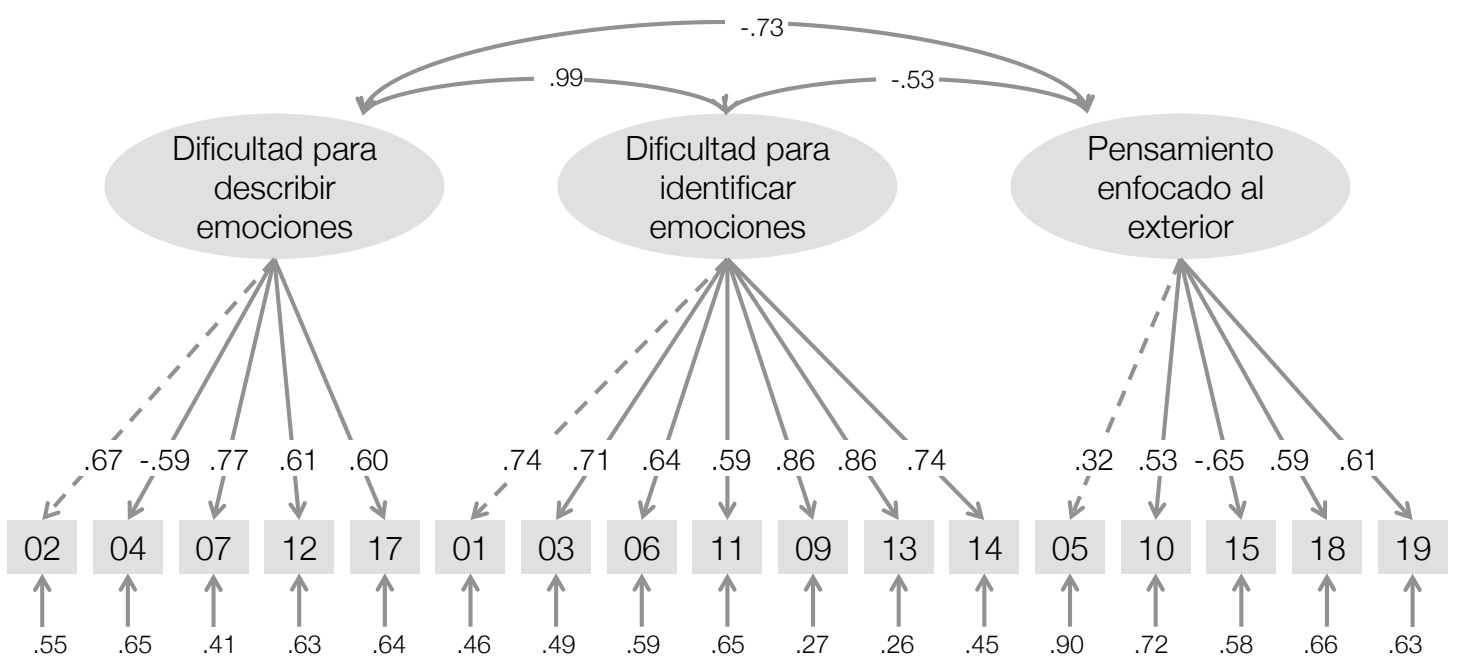

Figura 3. Análisis factorial confirmatorio inicial de la prueba TAS

Sin embargo, debido a la alta correlación entre dos variables latentes, se procedió a buscar una mejor solución exploratoria a este modelo. El índice de adecuación muestral de Kaiser-Meyer-Olkin fue de .85 para el conjunto de ítems, y a nivel individual todos los ítems tuvieron índices de adecuación superiores a .64, siendo superiores al punto de corte recomendado de .5 (Field et al., 2012). Adicionalmente, la prueba de Bartlett sugirió que la matriz de correlaciones no era una matriz de identidad $\left(X^{2}[190, N=500]\right.$ $=4673.88, p<.001)$, y el determinante de la matriz de correlaciones fue 0.00007 , lo cual es superior al criterio de .00001 planteado por Field et al. (2012). El gráfico de sedimentación (Figura 4) sugirió la extracción de un único factor. 


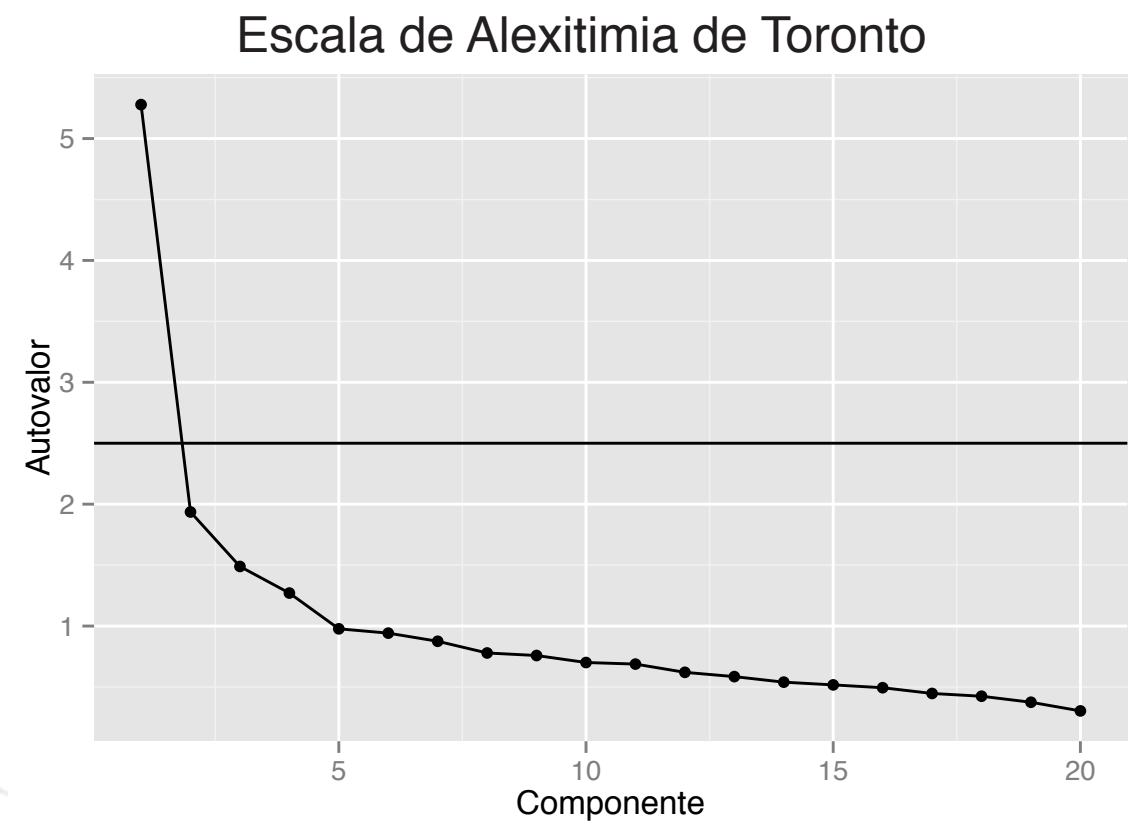

Figura 4. Gráfico de sedimentación para la prueba TAS

La Tabla 2 muestra las cargas factoriales resultantes de la extracción de un factor mediante la factorización de ejes principales. Dicho factor explica el 32\% de la varianza. Como se observa, hay cargas factoriales menores a .3, por lo que los ítems que las presentan se retiran de la prueba.

Tabla 2.

Cargas Factoriales de la Escala de Alexitimia de Toronto

\begin{tabular}{cccc}
\hline Variable & Carga Factorial & Variable & Carga Factorial \\
\hline TAS13 & .85 & TAS04 & -.55 \\
TAS09 & .83 & TAS11 & .54 \\
TAS07 & .76 & TAS15 & .46 \\
TAS14 & .76 & TAS18 & -.38 \\
TAS01 & .69 & TAS19 & -.36 \\
TAS02 & .67 & TAS10 & -.32 \\
TAS03 & .67 & TAS05 & -.26 \\
TAS06 & .61 & TAS08 & .22 \\
TAS12 & .58 & TAS16 & .18 \\
TAS17 & .57 & TAS20 & .17 \\
\hline
\end{tabular}

Se procedió a repetir el análisis con los 16 ítems restantes, y se obtuvo una solución que explica el $38 \%$ de la varianza. La tabla 3 presenta las cargas factoriales resultantes 
Tabla 3.

Cargas Factoriales de la Escala de Alexitimia de Toronto (16 items)

\begin{tabular}{cc}
\hline Variable & Carga Factorial \\
\hline TAS13 & .85 \\
TAS09 & .83 \\
TAS07 & .75 \\
TAS14 & .74 \\
TAS01 & .69 \\
TAS03 & .68 \\
TAS02 & .67 \\
TAS06 & .62 \\
TAS12 & .59 \\
TAS17 & .58 \\
TAS04 & -.55 \\
TAS11 & .55 \\
TAS15 & .46 \\
TAS18 & -.37 \\
TAS19 & -.35 \\
TAS10 & -.31 \\
\hline
\end{tabular}

A continuación, se pone a prueba este modelo en un análisis factorial confirmatorio. El modelo resultante $\left(X^{2}[104, N=500]=861.694, p<.001\right)$ no fue satisfactorio, en cuanto a sus índices de ajuste $(\mathrm{CFI}=.94, \mathrm{CFIr}=.83$, TLI $=.93, \mathrm{TLIr}=.81)$, ni en sus índices de residuales $($ RMSEA $=.11$, RMSEAr $=.12)$. Por lo tanto, se depuró el modelo, eliminando ítems con cargas factoriales bajas y aquellos ítems con altas correlaciones entre términos de error.

El modelo final $\left(X^{2}[51, N=500]=203.37, p<.001\right)$ contó con 12 ítems, $\mathrm{y}$ tuvo índices de ajuste adecuados $(\mathrm{CFI}=.99, \mathrm{CFIr}=.96, \mathrm{TLI}=.99, \mathrm{TLIr}=.95)$ e índices de residuales dentro de los valores deseables $(\mathrm{RMSEA}=.06, \mathrm{RMSEAr}=.08)$. El modelo resultante se presenta en la Figura 5. 


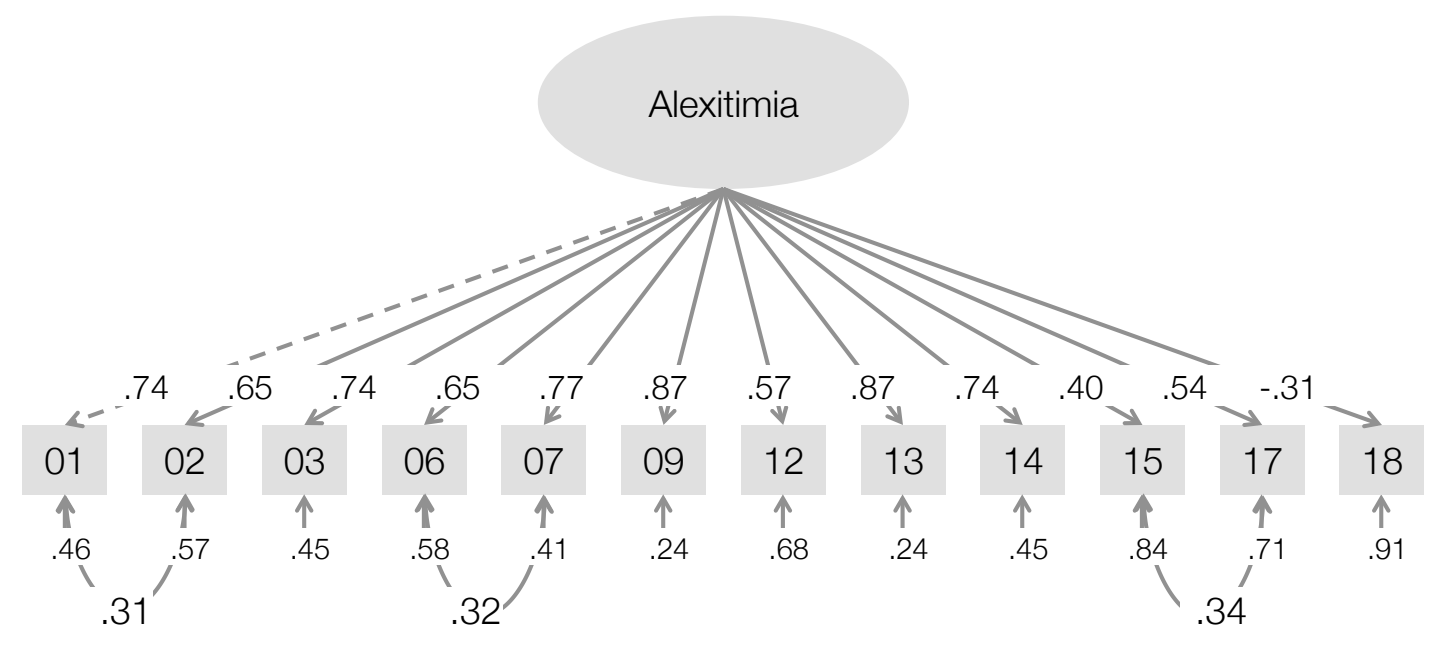

Figura 5. Análisis factorial confirmatorio de la prueba TAS

En cuanto a las evidencias de confiabilidad, el alfa ordinal de la escala de 12 ítems fue de .9 lo cual se considera muy bueno. Todas las correlaciones ítem test corregidas fueron superiores a .3 .

\subsubsection{Empatía}

En cuanto a la prueba IRI, se probó un modelo unifactorial, un modelo con las cuatro escalas originales que cargan a un factor de segundo orden, según lo propuesto por Cliffordson (2002), y el modelo original de 4 factores oblicuos (Davis, 1983), el cual fue el modelo mejor ajustado. Si bien, el ajuste del primer modelo no fue el óptimo, se tuvieron que eliminar los ítems 11 y 19 debido a problemas de validez discriminante (los índices de modificación sugerían permitir a los ítems cargar a todos los otros factores), y se eliminó el ítem 1 debido a que no cargaba adecuadamente en su factor. Además, se permitió la correlación de los términos de error de los ítems 3 y 4, y 12 y 7 , dado que en ambos casos eran parejas de ítems fraseados en negativo.

Los índices de ajuste comparativo del modelo $\left(X^{2}[267, N=500]=838.45, p<\right.$ $.001)$ fueron buenos $(\mathrm{CFI}=.923, \mathrm{CFIr}=.877$, TLI $=.913$, TLIr $=.862)$; y las medidas de residuales sugieren un poco de precaución ( $\mathrm{RMSEA}=.073, \mathrm{RMSEAr}=.065)$. Todos los ítems contaron con cargas estandarizadas superiores a .3. 


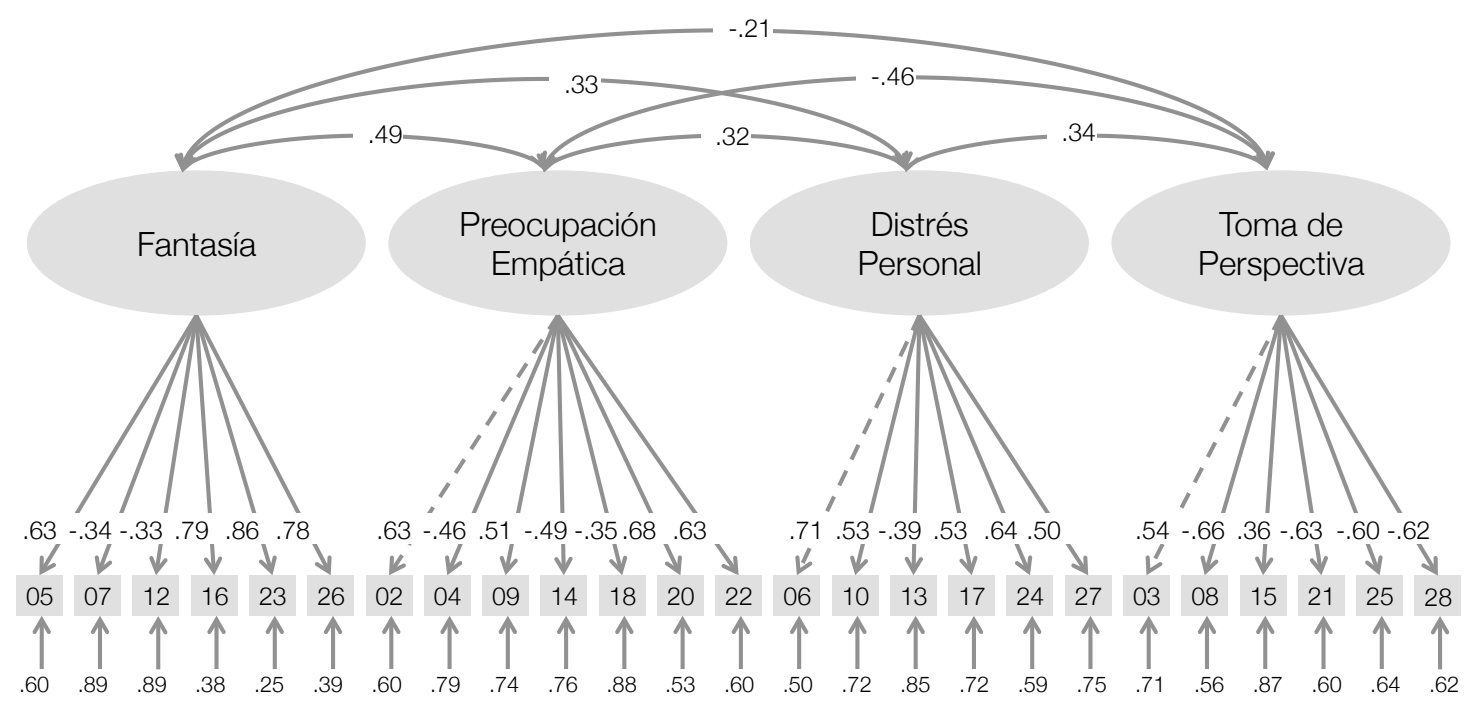

Figura 6. Análisis factorial confirmatorio de la prueba IRI

En cuanto a las evidencias de confiabilidad, los alfas ordinales fueron apropiados y se presentan en la Tabla 4. En todos los casos las correlaciones ítem-test corregidas fueron mayores a .3 .

Tabla 4

Confiabilidad Ordinal de las subescalas de la prueba IRI

\begin{tabular}{llll}
\hline Escala & Alfa Ordinal & \multirow{2}{*}{ Número de ítems } & $\begin{array}{l}\text { rITC } \\
\text { Promedio }\end{array}$ \\
\hline Fantasía & .81 & 6 & .64 \\
Preocupación Empática & .73 & 7 & .53 \\
Distrés Personal & .71 & 6 & .53 \\
Toma de Perspectiva & .72 & 6 & .55 \\
\hline
\end{tabular}

\subsubsection{Autorregulación Emocional}

Si bien anteriormente se había replicado su estructura factorial en Perú (Gargurevich y Matos, 2010), no existen evidencias de su validez o confiabilidad en Chile. Se realizó un análisis factorial confirmatorio de los diez ítems, y se compararon dos modelos: uno jerárquico en el que ambas estrategias de regulación emocional cargan a un factor de segundo orden de regulación emocional, y uno de dos factores oblicuos de primer orden como en la estructura original de la prueba (Gross y John, 2003). Finalmente, el modelo original fue el que presentó el mejor ajuste a los datos. 
Así, los estadísticos de ajuste del modelo $\left(X^{2}[34, N=500]=290.65, p<.001\right)$ son buenos $(\mathrm{CFI}=.966, \mathrm{CFIr}=.927, \mathrm{TLI}=.955, \mathrm{TLIr}=.904)$, mientras que los estadísticos de residuales sugieren precaución $($ RMSEA $=.110, \operatorname{RMSEAr}=0.122)$

Si bien permitir que correlacionen algunos de los errores mejora marginalmente los índices de ajuste y de residuales, se decidió mantener el modelo más parsimonioso dado que hacerlo no mejoraba significativamente el ajuste del modelo, $X^{2}[45, N=500]$ $=198.28, p<.001(\mathrm{CFI}=0.978, \mathrm{CFIr}=0.952, \mathrm{TLI}=0.968, \mathrm{TLI}=0.931, \mathrm{RMSEA}=$ 0.092, RMSEAr $=0.103$ )

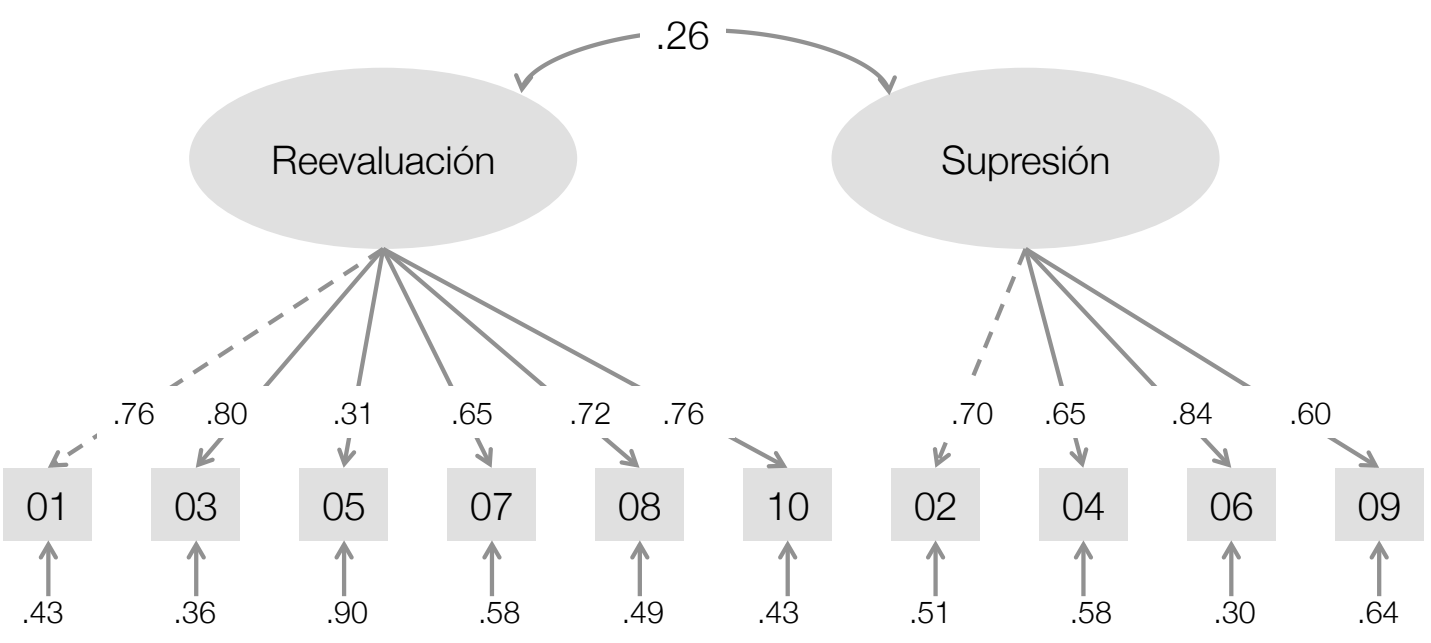

Figura 7. Análisis factorial confirmatorio de la prueba ERQ

En ambos casos los alfas ordinales fueron satisfactorios. En la escala de reevaluación (6 ítems) se obtuvo un alfa de .82 (rITC promedio $=.66$ ); y en la escala de supresión (4 ítems) se obtuvo un alfa de .78 (rITC promedio $=.67$ ). En todos los casos las correlaciones ítem-test corregidas fueron superiores a .3.

\subsection{Análisis Exploratorio de Datos}

Con la intención de eliminar valores extremos en los puntajes totales que pudieran distorsionar los resultados, se llevó a cabo un análisis exploratorio de datos. Siguiendo las recomendaciones de Field (2009) y Field et al. (2012), se eliminaron las puntuaciones con valores a 3.29 desviaciones estándar por encima o por debajo de la media. 


\subsection{Análisis Descriptivos}

Una vez culminada la etapa psicométrica de los análisis, se procedió a calcular los puntajes totales mediante el cálculo de promedios según factor. Se prefirió esto en lugar de los puntajes factoriales para mantener la comparabilidad con otros estudios. Se prefirió el promedio a la suma simple, debido a que en algunos casos cambió el número de ítems. Si se desea volver a comparar con puntajes sumativos, se pueden dividir los puntajes sumativos entre el número de ítems.

La Tabla 5 muestra los estadísticos descriptivos y la normalidad Shapiro-Wilk de las variables del estudio. De acuerdo a este criterio, la única variable que se distribuye normalmente es la preocupación empática del padre. Sin embargo, es importante acotar que cuando las muestras son grandes, las pruebas de normalidad son más sensibles a pequeñas desviaciones con respecto a la distribución normal. Por otro lado, el supuesto de normalidad no se refiere a la distribución de la muestra, sino a la distribución de muestreo, que tiende a la normalidad en muestras grandes debido al teorema del límite central (Field et al., 2012).

Tabla 5

Estadísticos descriptivos y análisis de normalidad de las variables del estudio

\begin{tabular}{|c|c|c|c|c|c|c|c|c|c|}
\hline & Variable & $\mathrm{n}$ & $M$ & $D E$ & $M e$ & $A s$ & $\mathrm{Cu}$ & $W$ & Sig. \\
\hline \multirow{5}{*}{ Niño } & Edad & 317 & 77.90 & 13.71 & 79.00 & -0.28 & -1.01 & 0.96 & $<.001$ \\
\hline & Control Inhibitorio & 325 & 5.05 & 0.92 & 5.17 & -0.33 & -0.35 & 0.98 & .001 \\
\hline & Control Atencional & 326 & 5.16 & 1.12 & 2.80 & -0.46 & -0.40 & 0.97 & $<.001$ \\
\hline & Placer de Baja intensidad & 323 & 5.33 & 0.58 & 5.38 & -0.40 & 0.11 & 0.98 & $<.001$ \\
\hline & lidad Percep & 324 & 5.64 & 0.83 & 5.67 & -0.55 & -0.11 & 0.97 & $<.001$ \\
\hline \multirow{8}{*}{ Padre } & Edad & 199 & 40.65 & 6.56 & 40.00 & 0.90 & 1.85 & 0.92 & $<.001$ \\
\hline & Fantasi & 203 & 2.71 & 0.76 & 2.67 & 0.01 & -0.72 & 0.99 & .03 \\
\hline & Preocupació & 203 & 3.60 & 0.58 & 3.57 & -0.07 & -0.33 & 0.99 & .10 \\
\hline & Distrés I & 203 & 2.25 & 0.66 & 2.17 & 0.13 & -0.61 & 0.98 & .01 \\
\hline & Toma de $\mathrm{P}$ & 202 & 3.58 & 0.61 & 3.67 & -0.32 & 0.19 & 0.98 & .01 \\
\hline & Reevaluació & 203 & 4.24 & 1.22 & 4.33 & -0.50 & 0.07 & 0.97 & $<.001$ \\
\hline & Sup & 203 & 3.3 & 1.26 & 3.25 & 0.07 & -0.69 & 0.98 & .01 \\
\hline & Alexi & 201 & 1.94 & 0.61 & 1.83 & 0.68 & -0.14 & 0.95 & $<.001$ \\
\hline \multirow{8}{*}{ Madre } & Edad & 287 & 37.94 & 5.11 & 38.00 & -0.17 & 0.54 & 0.99 & .01 \\
\hline & Fants & 291 & 3.06 & 0.91 & 3.00 & -0.07 & -0.38 & 0.99 & .02 \\
\hline & eocupaciór & 290 & 4.07 & 0.56 & 4.14 & -0.37 & -0.35 & 0.97 & $<.001$ \\
\hline & Distrés Per & 291 & 2.62 & 0.77 & 2.67 & 0.16 & -0.19 & 0.99 & .02 \\
\hline & Toma de Perspectiva & 290 & 3.62 & 0.70 & 3.67 & -0.23 & -0.05 & 0.99 & .01 \\
\hline & Reevaluación Cognitiva & 291 & 4.51 & 1.33 & 4.67 & -0.47 & -0.11 & 0.97 & $<.001$ \\
\hline & Supresión Emocional & 290 & 2.72 & 1.18 & 2.50 & 0.48 & -0.37 & 0.96 & $<.001$ \\
\hline & Alexitimia & 286 & 1.66 & 0.54 & 1.50 & 1.10 & 0.81 & 0.90 & $<.001$ \\
\hline
\end{tabular}




\subsection{Análisis de Regresión}

\subsubsection{Análisis correlacional}

Para identificar que variables ingresar al modelo, se realizó una correlación lineal simple entre los predictores (todas las variables de los padres) y los criterios (las cuatro subescalas del control intencional). La matriz de correlaciones presentada en la Tabla 6 evidencia pocas correlaciones significativas, y todas con efectos pequeños (Ferguson, 2009) o pequeños-medianos (Cohen, 1992). Como predictores del control inhibitorio destacan el distrés personal de la madre, su toma de perspectiva, y la alexitimia. Como predictores del control atencional destaca el distrés personal de la madre, su toma de perspectiva y su alexitimia. Como predictores del placer de baja intensidad destaca el distrés personal del padre y la toma de perspectiva de la madre. Para la sensibilidad perceptual destaca la preocupación empática del padre. Se emplearon correlaciones Pearson debido a que la regresión lineal asume una relación lineal entre predictores y criterios.

Tabla 6

Correlaciones entre el control intencional de los niños y ajuste emocional de los padres.

\begin{tabular}{|c|c|c|c|c|c|}
\hline & . & $\begin{array}{c}\text { Control } \\
\text { Inhibitorio }\end{array}$ & $\begin{array}{c}\text { Control } \\
\text { Atencional }\end{array}$ & $\begin{array}{l}\text { Placer de } \\
\text { Baja } \\
\text { Intensidad }\end{array}$ & $\begin{array}{c}\text { Sensibilidad } \\
\text { Perceptual }\end{array}$ \\
\hline \multirow{4}{*}{ Niño } & Control Inhibitorio & & & & \\
\hline & Control Atencional & $.56 * * *$ & & & \\
\hline & Placer de Baja Intensidad & $.14^{* *}$ & $.22 * * *$ & & \\
\hline & Sensibilidad Perceptual & $28 * * *$ & $.23 * * *$ & $.37 * * *$ & \\
\hline \multirow{7}{*}{ Padre } & Fantasía & -.11 & -.01 & .04 & -.06 \\
\hline & Preocupación Empática & -.05 & -.04 & .01 & $.18^{*}$ \\
\hline & Distrés Personal & -.02 & -.14 & $-.15 *$ & -.04 \\
\hline & Toma de Perspectiva & .06 & -.00 & .06 & .01 \\
\hline & Reevaluación Cognitiva & -.06 & -.01 & -.06 & .02 \\
\hline & Supresión Emocional & .13 & -.07 & -.08 & -.02 \\
\hline & Alexitimia & -.03 & -.12 & -.07 & -.06 \\
\hline \multirow{7}{*}{ Madre } & Fantasía & -.09 & .03 & .05 & .04 \\
\hline & Preocupación Empática & -.02 & .05 & .07 & .07 \\
\hline & Distrés Personal & $-.19 * *$ & $-.14^{*}$ & .02 & -.07 \\
\hline & Toma de Perspectiva & $.15 * *$ & $.16^{* *}$ & $.12 *$ & .07 \\
\hline & Reevaluación Cognitiva & .06 & .01 & .00 & .09 \\
\hline & Supresión Emocional & -.03 & -.08 & -.06 & .02 \\
\hline & Alexitimia & $-.13 *$ & $-.19 * *$ & -.05 & -.10 \\
\hline
\end{tabular}




\subsubsection{Regresión Lineal}

A continuación se presentan las regresiones múltiples para cada uno de los criterios en base a los predictores con los que tuvieron correlaciones significativas. En todos los casos se presenta el primer modelo, compuesto por todas las variables predictoras y el modelo final: aquel que maximiza el valor del $\mathrm{R}^{2}$ ajustado a la vez que cuenta con predictores significativos estadísticamente.

\section{Control inhibitorio}

La Tabla 7 muestra los resultados del primer y segundo modelo para la predicción del control inhibitorio. En ambos casos el poder predictivo del modelo ronda con lo insignificante prácticamente, aunque ambos modelos son significativamente mejores predictores que la media. Además, el modelo final cumple con el criterio de la independencia de los errores (Durbin Watson $=2.025$ ), y con los supuestos de no colinearidad $(\mathrm{FIV}=1.095 \mathrm{y}$ Tolerancia $=.913$ para ambos predictores $)$. Los gráficos de diagnóstico del modelo se muestran en la Figura 8.

\section{Tabla 7}

Modelos de regresión lineal para el control inhibitorio

\begin{tabular}{|c|c|c|c|c|c|c|c|c|c|}
\hline 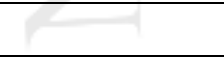 & $B$ & $E E$ & beta & $t$ & $p$ & $F$ & $g l$ & Sig & $\mathrm{R}^{2} \mathrm{Aj}$ \\
\hline Modelo 1 & & & & & & 5.347 & 3,275 & .001 & .045 \\
\hline Constante & 5.354 & 0.513 & & 10.437 & $<.001$ & & & & \\
\hline $\begin{array}{l}\text { Alexitimia } \\
\text { (M) }\end{array}$ & -0.262 & 0.103 & -0.157 & -2.556 & .011 & & & & \\
\hline $\begin{array}{l}\text { Toma de } \\
\text { Perspectiva } \\
\text { (M) }\end{array}$ & 0.194 & 0.084 & 0.147 & 2.305 & .022 & & & & \\
\hline $\begin{array}{c}\text { Preocupación } \\
\text { Empática } \\
(\mathrm{M})\end{array}$ & -0.14 & 0.101 & -0.086 & -1.389 & .166 & & & & \\
\hline Modelo 2 & & & & & & 6.826 & 2,277 & .001 & .04 \\
\hline Constante & 4.874 & 0.386 & & 12.632 & $<.001$ & & & & \\
\hline $\begin{array}{l}\text { Alexitimia } \\
\text { (M) }\end{array}$ & -0.244 & 0.102 & -0.146 & -2.382 & .018 & & & & \\
\hline $\begin{array}{l}\text { Toma de } \\
\text { Perspectiva } \\
\text { (M) }\end{array}$ & 0.162 & 0.081 & 0.123 & 1.998 & .047 & & & & \\
\hline
\end{tabular}



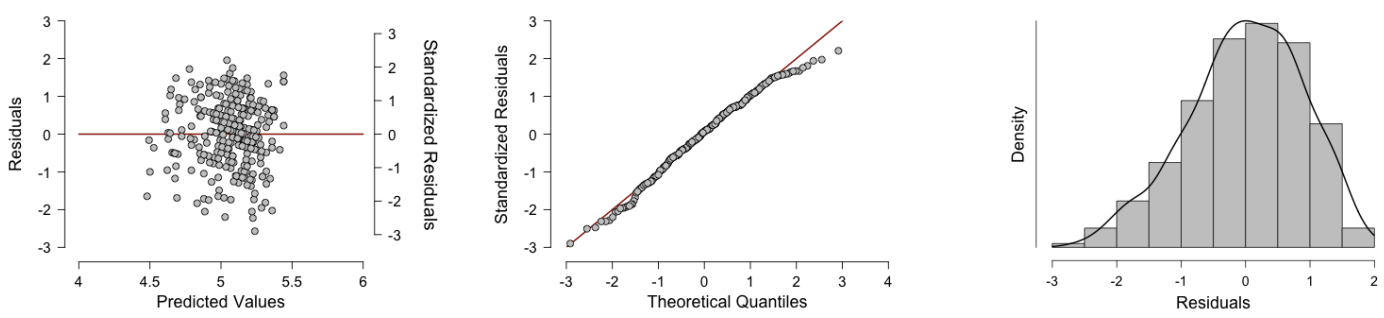

Figura 8. Diagnóstico del modelo de regresión para el control inhibitorio

\section{Control atencional}

La Tabla 8 muestra los resultados del primer modelo y el modelo final para la predicción del control atencional. En ambos casos el poder predictivo del modelo ronda con lo insignificante prácticamente, aunque ambos modelos son significativamente mejores predictores que la media. Además, el modelo final cumple con el criterio de la independencia de los errores (Durbin Watson $=1.92$ ). Los gráficos de diagnóstico del modelo se muestran en la Figura 9.

Tabla 8

Modelos de regresión lineal para el control atencional

\begin{tabular}{|c|c|c|c|c|c|c|c|c|c|}
\hline 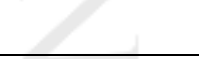 & $B$ & $E E$ & beta & $t$ & $p$ & $F$ & $g l$ & Sig & $\mathrm{R}^{2} \mathrm{Aj}$ \\
\hline Modelo 1 & & & & & & 4.68 & 3,277 & .003 & .038 \\
\hline Constante & 5.536 & 0.568 & & 9.752 & $<.001$ & & & & \\
\hline $\begin{array}{l}\text { Distrés } \\
\text { Personal } \\
\text { (M) }\end{array}$ & -0.092 & 0.094 & -0.062 & -0.97 & .333 & & & & \\
\hline $\begin{array}{l}\text { Toma de } \\
\text { Perspectiva } \\
\text { (M) }\end{array}$ & 0.114 & 0.105 & 0.069 & 1.084 & .279 & & & & \\
\hline $\begin{array}{l}\text { Alexitimia } \\
\text { (M) }\end{array}$ & -0.324 & 0.13 & -0.156 & -2.488 & .013 & & & & \\
\hline Modelo 2 & & & & & & 10.1 & 1,280 & .002 & .035 \\
\hline Constante & 5.817 & 0.212 & & 27.488 & $<.001$ & & & & \\
\hline $\begin{array}{l}\text { Alexitimia } \\
\text { (M) }\end{array}$ & -0.385 & 0.121 & -0.187 & -3.178 & .002 & & & & \\
\hline
\end{tabular}



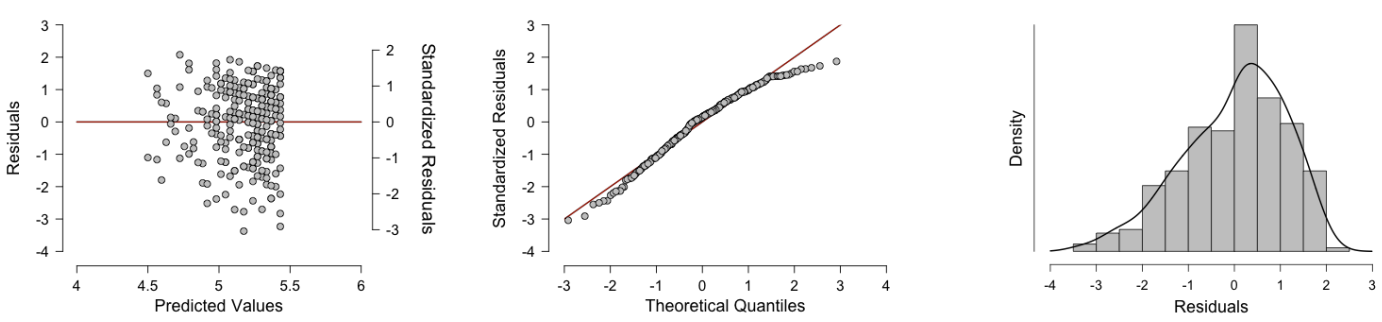

Figura 9. Diagnóstico del modelo de regresión para el control atencional

\section{Placer de Baja Intensidad}

La Tabla 9 muestra los modelos de predicción del placer de baja intensidad. El primer modelo no fue un modelo significativamente más predictivo que la media y ninguno de los dos predictores fue significativamente diferente de cero. Sin embargo, al tomar en cuenta únicamente al distrés personal del padre, este fue significativo, aunque con un tamaño de efecto irrelevante. Además, el modelo cumple con el criterio de independencia de errores (Durbin Watson $=2.09$ ). Los gráficos de diagnóstico del modelo se muestran en la Figura 10.

Tabla 9

Modelos de regresión lineal para el placer de baja intensidad.

\begin{tabular}{|c|c|c|c|c|c|c|c|c|c|}
\hline & B & $E E$ & beta & $t$ & $p$ & $F$ & $g l$ & Sig & $\mathrm{R}^{2} \mathrm{Aj}$ \\
\hline Modelo 1 & & 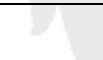 & & & & 1.47 & 2,167 & .230 & .017 \\
\hline Constante & 5.502 & 0.292 & & 18.831 & $<.001$ & & & & \\
\hline Distrés & & & & & & & & & \\
\hline $\begin{array}{l}\text { Personal } \\
\text { (P) }\end{array}$ & -0.113 & 0.07 & -0.124 & -1.608 & .110 & & & & \\
\hline $\begin{array}{l}\text { Toma de } \\
\text { Perspectiva } \\
\text { (M) }\end{array}$ & 0.029 & 0.063 & 0.035 & 0.461 & .645 & & & & \\
\hline Modelo 2 & & & & & & 4.064 & 1,198 & .045 & .015 \\
\hline Constante & 5.636 & 0.144 & & 39.206 & $<.001$ & & & & \\
\hline $\begin{array}{l}\text { Distrés } \\
\text { Personal } \\
\text { (P) }\end{array}$ & -0.124 & 0.061 & -0.142 & -2.016 & .045 & & & & \\
\hline
\end{tabular}



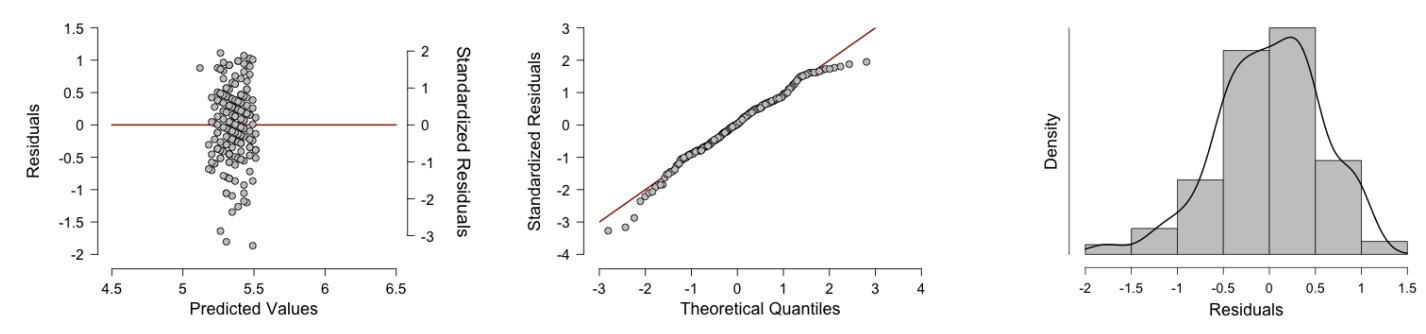

Figura 10. Diagnóstico del modelo de regresión para el placer de baja intensidad

\section{Sensibilidad Perceptual}

La Tabla 10 muestra el modelo para la predicción de la sensibilidad perceptual. Si bien el modelo resulta significativo, su relevancia práctica es nula. Si bien los residuales muestran un poco de asimetría negativa, los estadísticos de independencia de los errores se encuentran dentro de los límites aceptables (Durbin Watson $=2.17$ ). Los gráficos de diagnóstico del modelo se muestran en la Figura 11.

Tabla 10

Modelo de regresión lineal para la sensibilidad perceptual.

\begin{tabular}{lccccccccc}
\hline & $B$ & $E E$ & beta & $t$ & $p$ & $F$ & $g l$ & $\mathrm{Sig}$ & $\mathrm{R}^{2} \mathrm{Aj}$ \\
\hline $\begin{array}{l}\text { Modelo 1 } \\
\text { Constante }\end{array}$ & 4.907 & 0.361 & & 13.602 & $<.001$ & & & & \\
$\begin{array}{l}\text { Preocupación } \\
\text { Empática (P) }\end{array}$ & 0.203 & 0.099 & 0.145 & 2.056 & .041 & & & & \\
\hline
\end{tabular}
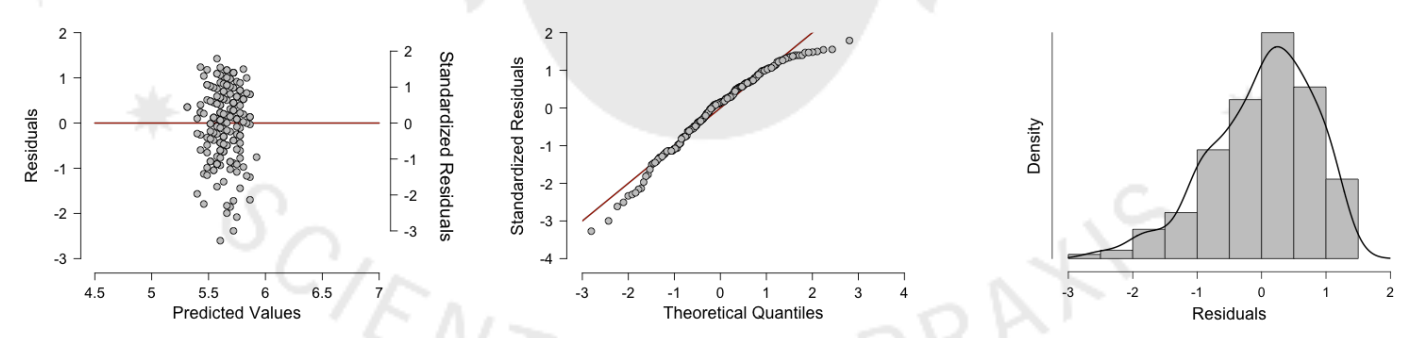

Figura 11. Diagnóstico del modelo de regresión para la sensibilidad perceptual

\subsubsection{Modelos Estructurales}

\section{Predicción del control intencional}

Se introdujeron las variables de los padres y madres que estuvieron significativamente correlacionadas al control intencional para evitar incluir muchas variables sin un impacto claro. Se usó el método de estimación MLM (Estimación de máxima verosimilitud con errores estándar robustos y la corrección Satorra-Bentler) 
para evitar el sesgo en los parámetros producto de las desviaciones con respecto a la curva normal. A continuación se presentan los resultados del primer modelo, y del último, después de depurar, una a una, las variables que no obtengan significancia estadística.

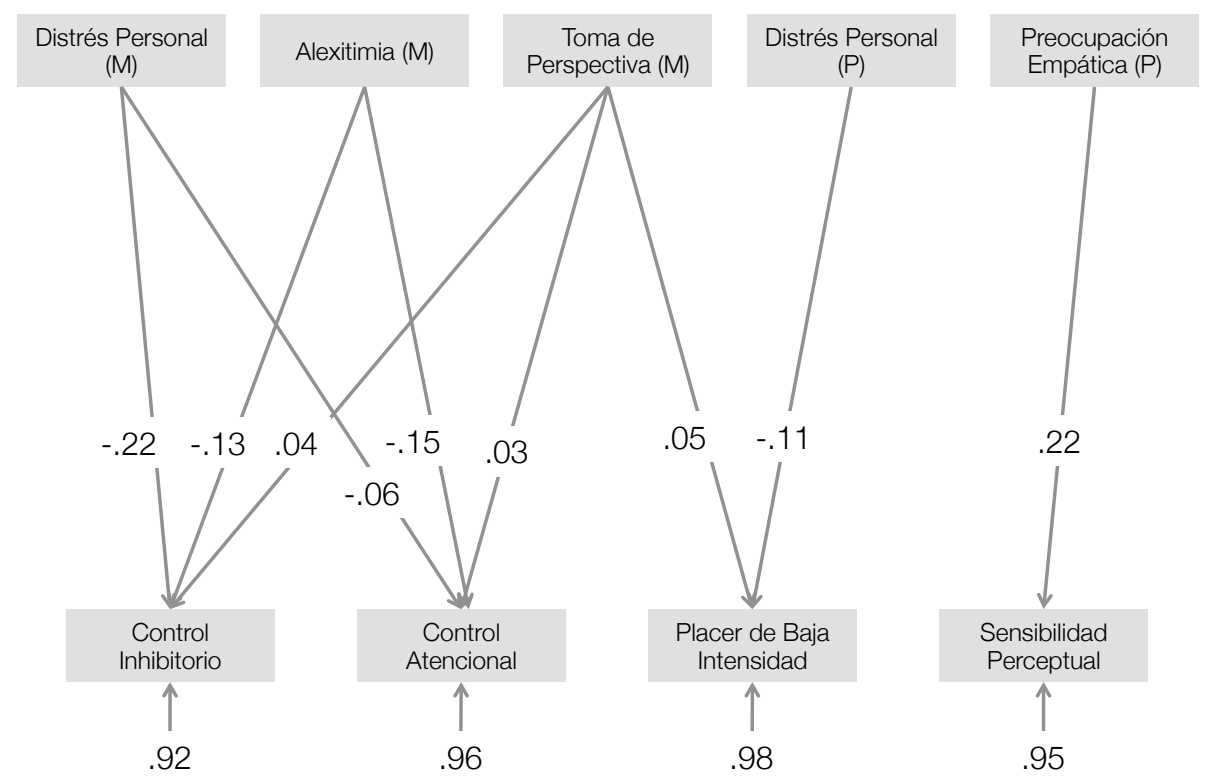

Figura 12. Modelo inicial para la predicción del control intencional a partir de las variables con correlaciones estadísticamente significativas

Tabla 11

Parámetros del modelo de senderos inicial para la predicción del control intencional

\begin{tabular}{|c|c|c|c|c|c|c|}
\hline$T$ & $B$ & $E E$ & $Z$ & $p$ & Beta & $\mathrm{R}^{2}$ \\
\hline Control Inhibitorio & & & & & & .084 \\
\hline Distrés Personal (M) & -0.265 & 0.091 & -2.917 & .004 & -0.219 & \\
\hline Toma de Perspectiva (M) & 0.047 & 0.105 & 0.445 & .656 & 0.038 & \\
\hline Alexitimia (M) & -0.202 & 0.128 & -1.574 & .115 & -0.125 & \\
\hline Control Atencional & $\sqrt{H}$ & & & & & .036 \\
\hline Distrés Personal (M) & -0.094 & 0.119 & -0.796 & .426 & -0.063 & \\
\hline Toma de Perspectiva (M) & 0.053 & 0.14 & 0.381 & .703 & 0.034 & \\
\hline Alexitimia (M) & -0.308 & 0.18 & -1.712 & .087 & -0.152 & \\
\hline Placer de Baja Intensidad & & & & & & .017 \\
\hline Distrés Personal $(\mathrm{P})$ & -0.102 & 0.074 & -1.369 & .171 & -0.113 & \\
\hline Toma de Perspectiva (M) & 0.045 & 0.056 & 0.82 & .412 & 0.055 & \\
\hline Sensibilidad Perceptual & & & & & & .047 \\
\hline Preocupación Empática (P) & 0.304 & 0.099 & 3.053 & .002 & 0.217 & \\
\hline
\end{tabular}


El modelo final acaba por tener solo dos variables con poder explicativo y con efectos muy pequeños.

Tabla 12

Parámetros del modelo de senderos final para la predicción del control intencional

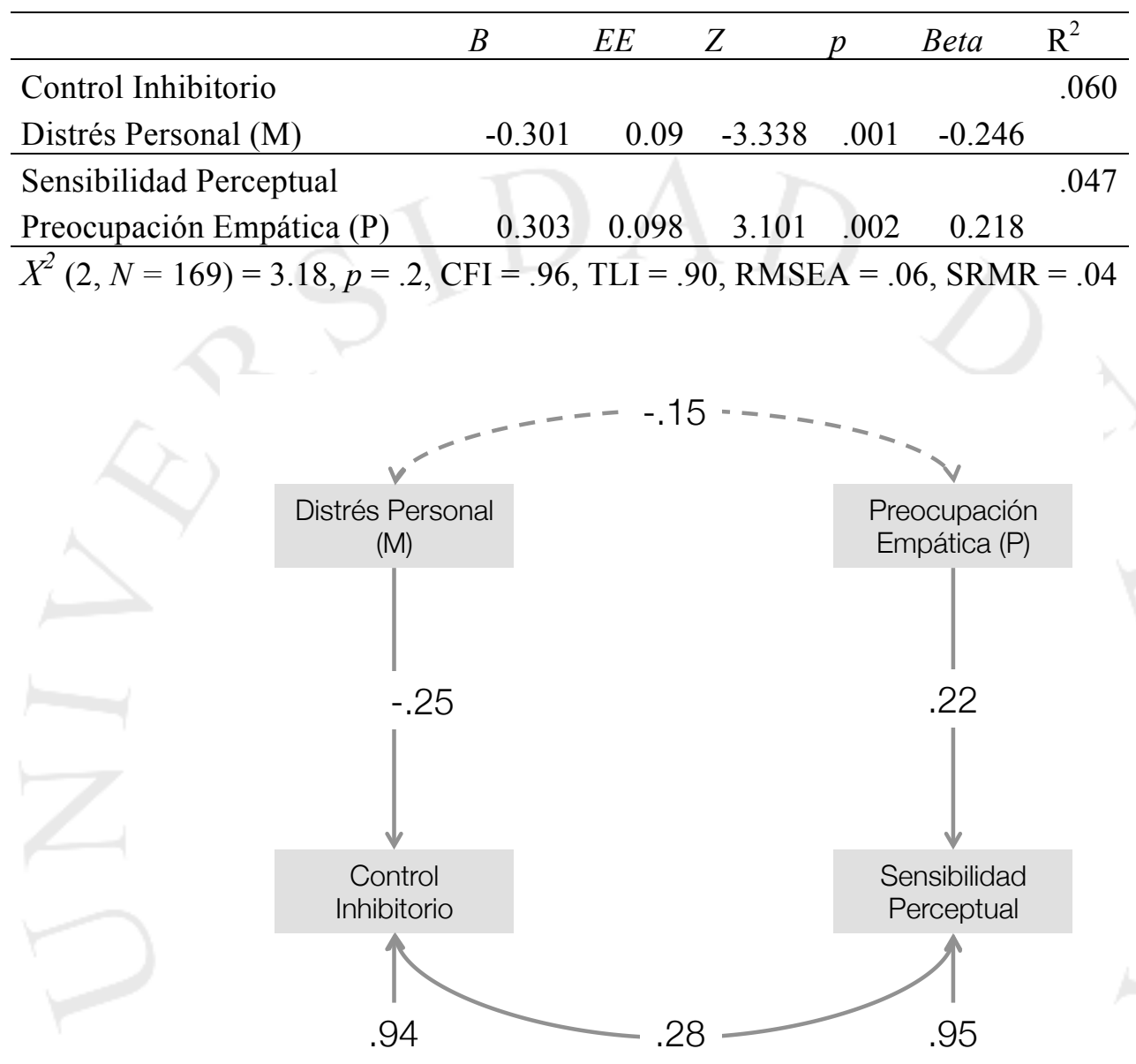

Figura 13. Modelo final de predicción del control intencional 


\section{Comparación del rol predictor del padre y la madre}

Como un análisis adicional, sin la intención de construir un modelo predictivo, sino comparar el poder predictivo de las variables de los padres y las madres se construyeron dos modelos incluyendo todas las variables de padres y madres con la intención de comparar la varianza explicada de estos modelos.

Tabla 13

Comparación entre el rol predictor de padres y madres sobre el control intencional.

\begin{tabular}{|c|c|c|c|c|c|c|c|c|c|c|c|c|}
\hline$X^{2}(34, N$ & $\begin{array}{r}\text { Madr } \\
=275)= \\
\end{array}$ & 1.32 & $\mathrm{p}<.0$ & & & & $X^{2}(34$, & $N=1$ & $\begin{array}{l}\text { Padre } \\
86)=1\end{array}$ & 13.60, & $\mathrm{p}<.00$ & \\
\hline & $B$ & $E E$ & $Z$ & $p$ & beta & $\mathrm{R}^{2}$ & $B$ & $E E$ & $Z$ & $p$ & beta & $\mathrm{R}^{2}$ \\
\hline Control Inhibitorio & & & & & & .08 & & & & & & .04 \\
\hline Fantasía & -0.06 & 0.07 & -0.96 & .337 & -.06 & & -0.14 & 0.08 & -1.65 & .098 & -.12 & \\
\hline Preocupación Empática & -0.10 & 0.12 & -0.83 & .407 & -.06 & & -0.13 & 0.13 & -0.94 & .348 & -.08 & \\
\hline Distrés Personal & -0.14 & 0.08 & -1.72 & .086 & -.12 & & -0.01 & 0.11 & -0.10 & .918 & -.01 & \\
\hline Toma de Perspectiva & 0.15 & 0.09 & 1.68 & .093 & .12 & & 0.16 & 0.11 & 1.52 & .130 & .11 & \\
\hline Reevaluación Cognitiva & 0.04 & 0.05 & 0.75 & .453 & .05 & & 0.02 & 0.06 & 0.27 & .786 & .02 & \\
\hline Supresión Emocional & 0.01 & 0.05 & 0.17 & .864 & .01 & & 0.07 & 0.06 & 1.20 & .230 & .10 & \\
\hline Alexitimia & -0.21 & 0.12 & -1.77 & .076 & -.13 & & -0.03 & 0.15 & -0.20 & .841 & -.02 & \\
\hline Control Atencional & & & & & & .06 & & & & & & .03 \\
\hline Fantasía & 0.06 & 0.08 & 0.74 & .459 & .05 & & -0.04 & 0.11 & -0.36 & .719 & -.03 & \\
\hline Preocupación Empática & -0.08 & 0.14 & -0.56 & .573 & -.04 & & 0.01 & 0.18 & 0.03 & .975 & .00 & \\
\hline Distrés Personal & -0.10 & 0.10 & -0.98 & .325 & -.07 & & -0.19 & 0.17 & -1.10 & .271 & -.11 & \\
\hline Toma de Perspectiva & 0.13 & 0.11 & 1.18 & .239 & .08 & & -0.11 & 0.16 & -0.68 & .500 & -.06 & \\
\hline Reevaluación Cognitiva & -0.04 & 0.06 & -0.69 & .488 & -.05 & & -0.06 & 0.07 & -0.82 & .410 & -.06 & \\
\hline Supresión Emocional & -0.03 & 0.07 & -0.39 & .695 & -.03 & & -0.02 & 0.08 & -0.28 & .782 & -.02 & \\
\hline Alexitimia & -0.31 & 0.16 & -1.95 & .051 & -.15 & & -0.12 & 0.18 & -0.65 & .516 & -.06 & \\
\hline Placer de Baja Intensidad & & & & & & .02 & & & & & & .04 \\
\hline Fantasía & 0.01 & 0.04 & 0.26 & .797 & .02 & & 0.04 & 0.06 & 0.64 & .520 & .05 & \\
\hline Preocupación Empática & 0.02 & 0.07 & 0.29 & .770 & .02 & & 0.02 & 0.09 & 0.25 & .802 & .02 & \\
\hline Distrés Personal & 0.04 & 0.05 & 0.72 & .471 & .05 & & -0.13 & 0.07 & -1.78 & .075 & -.15 & \\
\hline Toma de Perspectiva & 0.08 & 0.06 & 1.40 & .160 & .09 & & 0.02 & 0.08 & 0.28 & .777 & .02 & \\
\hline Reevaluación Cognitiva & -0.01 & 0.03 & -0.35 & .729 & -.02 & & -0.02 & 0.03 & -0.62 & .537 & -.04 & \\
\hline Supresión Emocional & -0.03 & 0.03 & -0.89 & .372 & -.06 & & -0.05 & 0.04 & -1.17 & .243 & -.10 & \\
\hline Alexitimia & 0.01 & 0.08 & 0.13 & .895 & .01 & & 0.04 & 0.08 & 0.52 & .604 & .05 & \\
\hline Sensibilidad Perceptual & & & & & & .03 & & & & & & .06 \\
\hline Fantasía & 0.07 & 0.06 & 1.09 & .277 & .07 & & -0.16 & 0.07 & -2.13 & .033 & -.15 & \\
\hline Preocupación Empática & 0.07 & 0.10 & 0.65 & .516 & .05 & & 0.37 & 0.12 & 2.98 & .003 & .26 & \\
\hline Distrés Personal & -0.03 & 0.08 & -0.41 & .681 & -.03 & & -0.10 & 0.10 & -0.92 & .360 & -.08 & \\
\hline Toma de Perspectiva & 0.00 & 0.10 & 0.01 & .991 & .00 & & -0.17 & 0.11 & -1.49 & .137 & -.13 & \\
\hline Reevaluación Cognitiva & 0.03 & 0.04 & 0.63 & .528 & .04 & & -0.03 & 0.04 & -0.72 & .471 & -.05 & \\
\hline Supresión Emocional & 0.06 & 0.05 & 1.26 & .208 & .09 & & 0.04 & 0.05 & 0.74 & .462 & .06 & \\
\hline Alexitimia & -0.18 & 0.12 & -1.52 & .128 & -.12 & & -0.06 & 0.12 & -0.48 & .629 & -.04 & \\
\hline
\end{tabular}




\subsection{Análisis Complementarios}

\subsubsection{Diferencias según sexo}

Se realizaron pruebas U de Mann-Whitney para comparar los niveles de las subescalas de control intencional según sexo. Los efectos de esta diferencia es prácticamente significativo (Ferguson, 2009) siendo de tamaño pequeño-mediano (Cohen, 1992). Los resultados se muestran en la Figura 14 y la Tabla 14

Tabla 14

Diferencias entre las subescalas de control intencional según sexo.

\begin{tabular}{lrrrrr}
\hline & \multicolumn{1}{c}{$W$} & \multicolumn{1}{c}{$p$} & Diferencia de Medias & Error estándar de la diferencia & $d$ \\
\hline Control Inhibitorio & 9160 & $<.001$ & -0.500 & 0.100 & 0.518 \\
Control Atencional & 15528 & .003 & 0.400 & 0.124 & 0.304 \\
Placer de Baja Intensidad & 10458 & .005 & -0.250 & 0.065 & 0.329 \\
Sensibilidad Perceptual & $9672<.001$ & -0.333 & 0.091 & 0.441 \\
\hline
\end{tabular}

Nota. *El puntaje más alto está en el grupo femenino. $\mathrm{N}=157$ (Masculino) y 166 (Femenino); 323 total.

\section{Masculino Femenino}

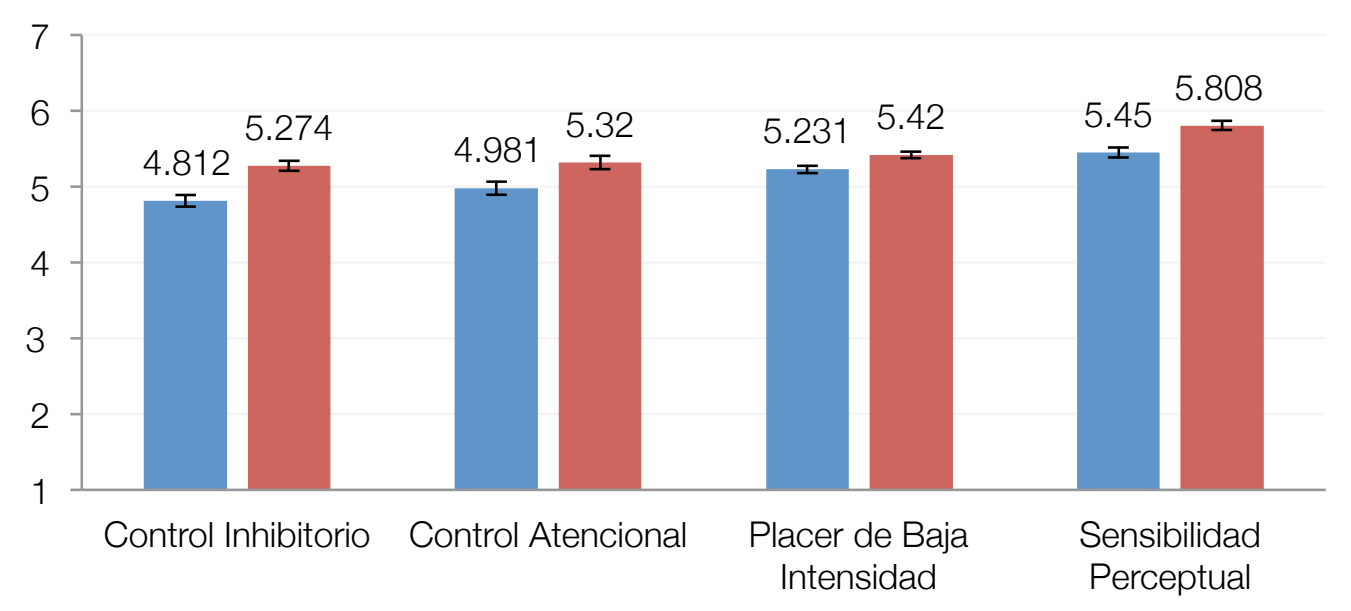

Subdimensiones

Figura 14. Diferencias de medias en las puntuaciones promedio (1-7) de las escalas de control intencional según sexo. 


\subsubsection{Relación entre la edad y el control intencional}

Se empleó un análisis correlacional para detectar una relación entre la edad de los niños (medida en meses) y su nivel de control intencional. Debido a la falta de normalidad de las variables, se usaron correlaciones no-paramétricas y se observaron correlaciones sin significación estadística ni práctica.

La Tabla 15 muestra las correlaciones de Pearson, Spearman y Kendall entre la edad y las subescalas del control intencional. Se observan efectos significativos para el control inhibitorio, sin embargo de tamaño pequeño, los efectos referidos para placer de baja intensidad son un poco más altos, sin embargo no llegan a superar el criterio de 2 para ser considerados prácticamente relevantes (Ferguson, 2009). La Figura 15 muestra las nubes de puntos pertinentes.

Tabla 15

Matriz de correlaciones entre la edad y las subescalas de control intencional

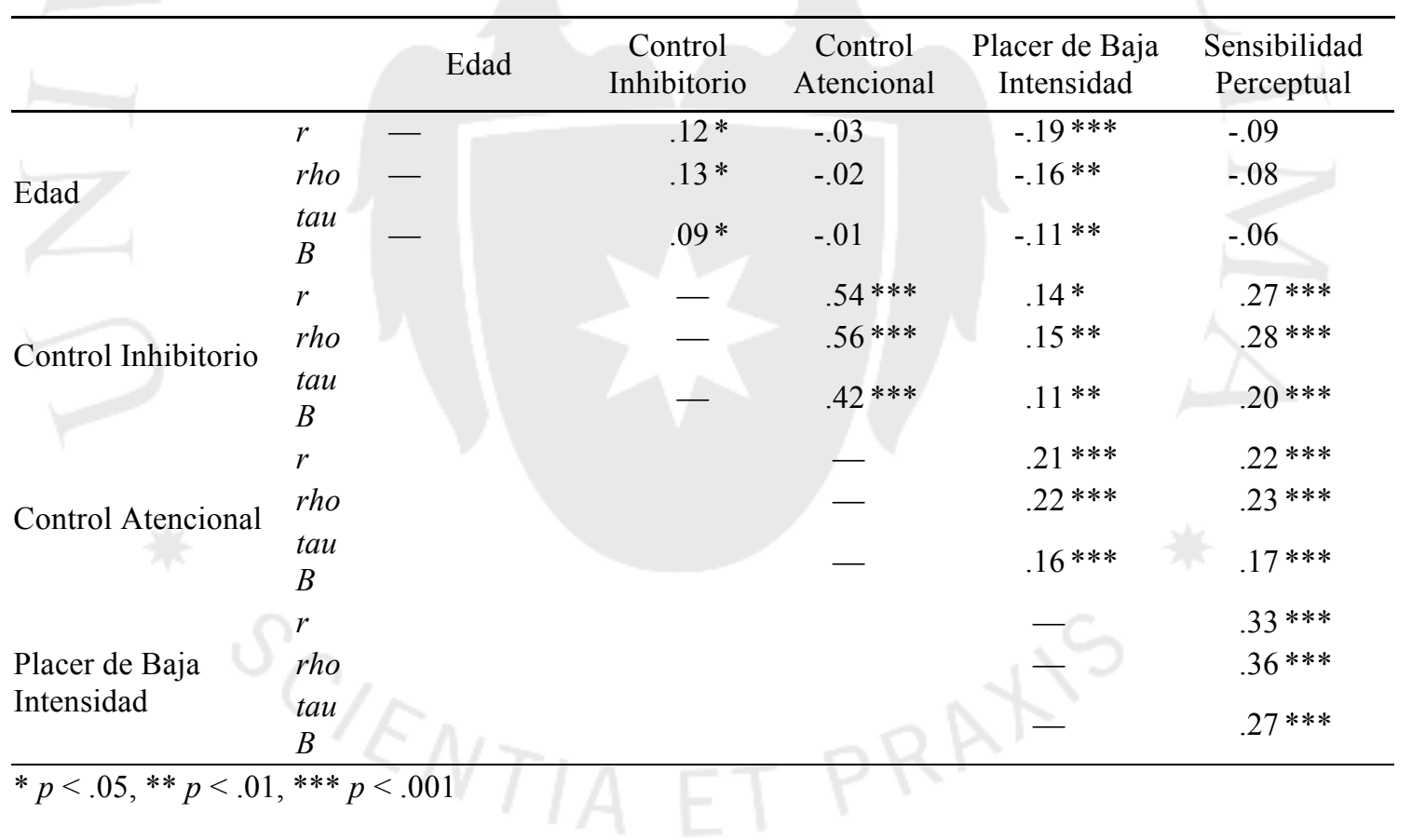



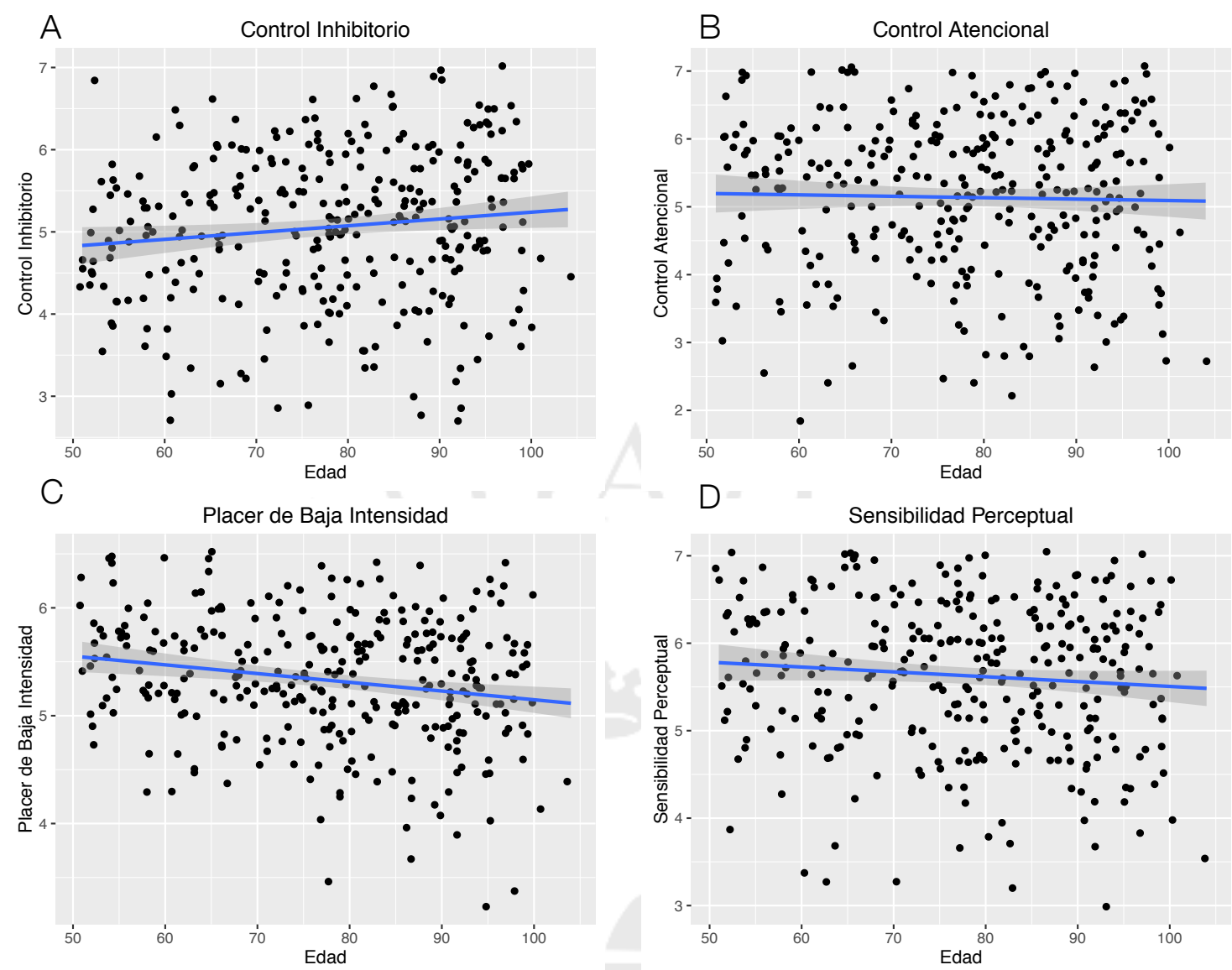

Figura 15. Relación entre la edad del niño y su nivel de control intencional. La línea muestra la tendencia de asociación lineal entre ambas variables

\subsubsection{Diferencias en control intencional según grado}

La intención detrás de este análisis era comprobar si existía alguna asociación entre grado y los niveles de control intencional. Para esto se llevaron a cabo ANOVAS univariados para cada una de las subescalas de control intencional. En todos los casos no se obtuvo significancia estadística $(p>.05)$; salvo por el caso del placer de baja intensidad $\left(F(3,320)=3.8, p=.011, \eta^{2}=.034\right)$. El efecto es de tamaño pequeño-mediano (Lakens, 2013). Debido a que las varianzas entre los grupos son iguales, $(F(3,320)=$ $1.087 ; p=.355)$ se empleó un análisis post-hoc de Tukey y fue significativo únicamente para la diferencia entre pre-kínder y segundo grado de primaria $(t=3.046, p=.013)$.

\subsubsection{Diferencias en control intencional según salud psicológica de los padres}

En todos los casos las cantidades de padres que reportaron haber recibido o estar recibiendo tratamiento terapéutico o farmacológico para la ansiedad fueron muy pocos como para ser analizados (en todos los casos $n \leq 10$ ). En el caso de las madres, fueron pocas las que reportaron estar tomando pastillas para dormir $(n=7)$, o llevando 
tratamiento farmacológico $(n=14)$ o terapéutico para la ansiedad $(n=2)$, por lo que estos datos, no serán analizados por que los resultados tendrán muy baja potencia estadística. Un número relativamente más alto de madres reportan haber seguido un tratamiento farmacológico para la ansiedad $(n=33)$, aunque pocas reportan haber llevado terapia por la misma razón $(n=3)$.

Así, usó la prueba U de Mann-Whitney para evaluar la existencia de diferencias entre madres que han recibido tratamiento farmacológico para la ansiedad en el pasado y madres que no. Los resultados solo fueron significativos para el caso del control inhibitorio a favor de los niños cuyas madres no han recibido tratamiento en el pasado. Es importante recordar que estos resultados deben ser tomados con cautela debido a que las muestras son muy pequeñas. Los resultados se presentan en la Tabla 16.

Tabla 16

Diferencias en el control intencional de niños cuyas madres han o no recibido tratamiento farmacológico para la ansiedad en el pasado.

\begin{tabular}{lccccc}
\hline \multicolumn{1}{c}{ Variables } & $W$ & $p$ & $\begin{array}{c}\text { Diferencia de } \\
\text { Medias }\end{array}$ & $\begin{array}{c}\text { Error estándar } \\
\text { de la diferencia }\end{array}$ & $d$ \\
\hline Control Inhibitorio & 4890 & .012 & 0.500 & 0.175 & 0.436 \\
Control Atencional & 3056 & .062 & 0.600 & 0.271 & 0.443 \\
Placer de Baja Intensidad & 3222 & .159 & -0.125 & 0.100 & 0.312 \\
Sensibilidad Perceptual & 3053 & .066 & -0.333 & 0.159 & 0.313 \\
\hline
\end{tabular}

Nota. En el control atencional e inhibitorio las diferencias implicaron mayores niveles de control en niños cuyas madres no recibieron tratamiento. Lo contrario se cumple para el placer de baja intensidad y la sensibilidad perceptual.

\subsubsection{Relaciones entre la alexitimia, la empatía y la regulación emocional}

Se analizó en conjunto los datos de madres y padres, para buscar relaciones entre los constructos de ajuste emocional. Las correlaciones entre estos son muy bajas, y solo en algunos casos son suficientemente elevadas como para sugerir una relación de relevancia práctica (Ferguson, 2009). Existieron correlaciones relevantes entre las escalas de empatía, especialmente entre fantasía y preocupación empática; y entre preocupación empática y toma de perspectiva. La alexitimia correlaciona negativamente con las medidas de preocupación empática y toma de perspectiva y positivamente con supresión emocional. Interesantemente, se observa además una correlación entre distrés personal con la dificultad para identificar emociones. Finalmente se observan correlaciones moderadas entre las escalas de dificultades para 
expresar e identificar emociones, y pequeñas-moderadas entre estas dos escalas y la supresión emocional.

La Tabla 17 muestra estas relaciones. Se usó el coeficiente rho de Spearman, debido a que todas las variables mostraron distribuciones distintas a la normal.

Tabla 17

Matriz de correlaciones entre las variables de ajuste emocional recogidas de los padres y madres.

\begin{tabular}{|c|c|c|c|c|c|c|}
\hline & Fantasía & $\begin{array}{l}\text { Preocupación } \\
\text { Empática }\end{array}$ & $\begin{array}{l}\text { Distrés } \\
\text { Personal } \\
\end{array}$ & $\begin{array}{l}\text { Toma de } \\
\text { Perspectiva }\end{array}$ & $\begin{array}{l}\text { Reevaluación } \\
\text { Cognitiva }\end{array}$ & $\begin{array}{l}\text { Supresión } \\
\text { Emocional }\end{array}$ \\
\hline Fantasía & & & & & & \\
\hline Preocupación & & & & & & \\
\hline Empática & $.34 * * *$ & & & & & \\
\hline Distrés Personal & $.17 * * *$ & $.18^{* * *}$ & & & & \\
\hline Toma de Perspectiva & $.13^{* *}$ & $.34 * * *$ & $-.26 * * *$ & & & \\
\hline Reevaluación & & & & & & \\
\hline Cognitiva & $.15^{* * *}$ & $.16^{* * *}$ & .03 & $.14^{* *}$ & & \\
\hline Supresión Emocional & $-.10^{*}$ & $-.26 * * *$ & .07 & $-.16^{* * *}$ & $.16^{* * *}$ & \\
\hline Alexitimia & -.06 & $-.21 * * *$ & $.27 * * *$ & $-.32 * * *$ & .03 & $46^{* * *}$ \\
\hline
\end{tabular}

Una manera de facilitar la identificación de patrones en las correlaciones es mediante el uso de gráficos de redes para matrices de correlaciones. En estos, las variables se representan como puntos que se separan en una distancia proporcional al valor absoluto de las correlaciones entre ellas. Adicionalmente, estas se unen por arcos de grosor y transparencia proporcional a la magnitud de las correlaciones. Finalmente, se colorean las correlaciones positivas de azul, y las negativas de rojo. Este se muestra en la Figura 16. 


\section{Distrés Personal}

\section{Fantasía}

\section{Toma de Perspectiva}

\section{Preocupación Empática}

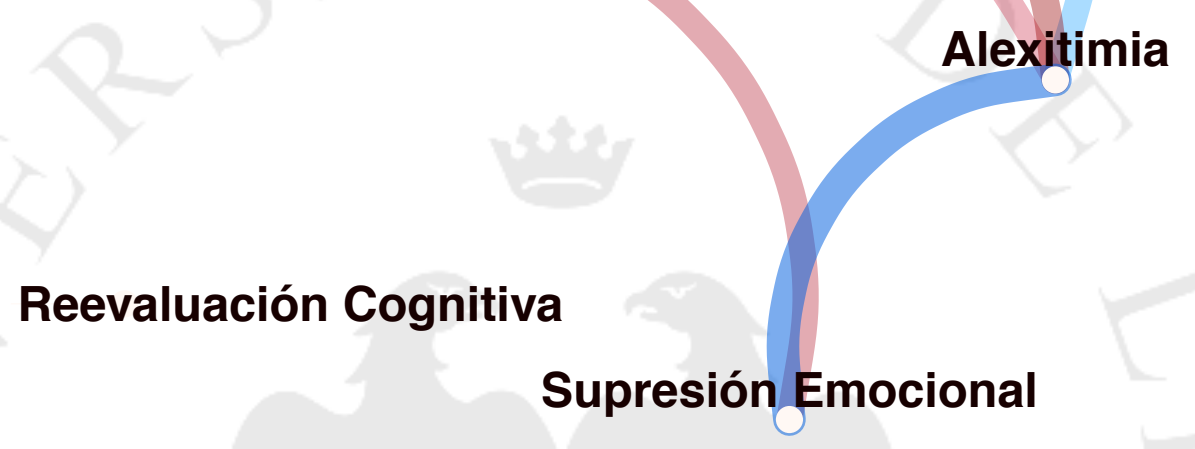

Figura 16. Gráfico de red de correlaciones entre los predictores parentales. Se omiten las correlaciones menores a .20 debido a que este valor es menor al mínimo recomendado. 


\section{CAPÍTULO VI. DISCUSIÓN}

Tradicionalmente, el temperamento ha sido comprendido como un componente innato de la personalidad, transmitido por vías exclusivamente genéticas, y que es imposible de ser afectado por vías sociales. Sin embargo, las definiciones más modernas del temperamento (e.g. Rothbart y Bates, 2007) admiten que la carga genética no es más importante que en otras variables psicológicas, y que son influenciadas por el ambiente temprano de desarrollo (Eisenberg et al., 2011). Más aún, estudios recientes han empezado a clarificar el rol que pueden tener determinadas variables, adicionales a los genes, como el apego (Viddal et al., 2015), la sensibilidad e intrusión maternas (Li et al., 2016), crianza ineficaz (Elizur, Somech, y Vinokur, 2016), así como la extraversión materna y estrés parental (Gartstein et al., 2013) en el desarrollo del control intencional.

Este estudio tuvo como objetivo principal la construcción de un modelo predictivo del control intencional infantil en base al ajuste emocional de sus padres, definido como sus tendencias de empatía, regulación emocional y alexitimia. Adicionalmente, el estudio tuvo seis objetivos secundarios adicionales: comparar el poder predictivo de padres y madres en el control intencional de sus hijos; explorar la calidad psicométrica de las pruebas utilizadas, diferenciar los niveles de control intencional según sexo; evaluar la relación entre el control intencional y la edad y el grado; evaluar las diferencias del control intencional entre niños cuyos padres y madres hayan recibido tratamiento para la ansiedad; y evaluar las relaciones entre las variables de ajuste emocional de los padres.

En general, los resultados indicaron una consonancia relativamente adecuada entre las estructuras factoriales de las pruebas propuestas teóricamente y las respuestas de los individuos. Sin embargo, en todas las pruebas, salvo por la escala ERQ, fue necesario realizar pequeños ajustes (eliminar algunos ítems o permitir correlaciones entre los términos de error) para alcanzar los índices de ajuste aceptables. En algunos casos esto fue debido a la existencia de ítems que no discriminaban adecuadamente entre las subescalas de las pruebas. Por ejemplo, el fraseo poco específico de algunos ítems hizo que estos carguen a todos los factores, o que no carguen suficientemente a ninguno.

En cuanto a la prueba CBQ, este estudio evaluó únicamente las propiedades psicométricas de la escala de control intencional, y el ajuste a un modelo oblicuo fue 
apropiado tras la eliminación de un ítem y la correlación entre algunos términos de error justificados teóricamente. Sin embargo, el análisis correlacional entre las subescalas y la falta de soporte para un modelo de segundo orden fue contrario a lo planteado por la estructura de segundo orden original de la prueba (Putnam y Rothbart, 2006; Rothbart et al., 2001). Si bien la estructura original plantea que el control intencional se compone por el control inhibitorio, control atencional, placer de baja intensidad (PBI) y sensibilidad perceptual (SP); en los datos, solo las dos primeras escalas presentaron elevadas correlaciones entre si, y las otras dos también están relacionadas entre si, pero en menor medida. Esto sugeriría que en la prueba, el control intencional sería medido mejor por las subescalas de control atencional e inhibitorio; y que no sería aconsejable incluir SP y PBI. Esto es precisamente lo que hicieron Sulik et al. (2010), al plantear una estructura unifactorial del control intencional: combinando tareas de laboratorio con las subescalas de control inhibitorio y atencional, debido a que estaban correlacionadas entre si (con magnitudes del efecto muy similares a las de este estudio).

Esto es consistente con los resultados de un análisis de componentes principales y un análisis factorial exploratorio, en los que los ítems de SP y PBI cargaron poco o no cargaron (respectivamente) junto con los ítems de control atencional e inhibitorio, pero si lo hicieron ítems relacionados al miedo y la impulsividad. El caso de la impulsividad es especialmente relevante dado que no existe acuerdo en la literatura sobre su conceptualización. Mientras que algunos prefieren definirla como una característica en sí, otros la definen como la falta de control inhibitorio acompañada de emocionalidad positiva (Rothbart y Bates, 2007). Los resultados apoyarían la idea de que la impulsividad no es una característica temperamental aislada, sino que puede ser entendida como un déficit en el control inhibitorio (Zentner y Bates, 2008). El caso del miedo podría explicarse porque la prueba reporta que conductas los padres observan en el niño. Por tanto, sentir el miedo y no expresarlo puede ser una manifestación del control inhibitorio, al presentarse un estímulo que genera una respuesta automática (la expresión conductual del miedo) que es suprimida voluntariamente para regular esa emoción, inhibir su expresión o afrontarla de alguna otra manera.

Finalmente, es importante notar que aunque la escala CBQ es ampliamente utilizada en la literatura sobre temperamento (Rothbart y Bates, 2007); recientemente se publicó el primer artículo en poner a prueba la estructura de la prueba CBQ a nivel de ítems. Kotelnikova, Olino, Klein, Kryski, y Hayden (2016) realizaron análisis factorial 
exploratorio de la versión larga de la prueba (185 ítems) e identificaron 88 ítems adecuados (i.e. con cargas factoriales $>$.4) para la construcción de factores. A nivel de análisis factorial de segundo orden, recomendaron la extracción de 4 y no 3 factores.

En el caso de la alexitimia, tras la eliminación de tres ítems que podían ser comprendidos ambiguamente, no se logró replicar adecuadamente el modelo original de la prueba (Bagby, Parker, et al., 1994; Bagby, Taylor, et al., 1994) debido a una correlación casi perfecta entre las escalas de describir e identificar emociones. Esto implicó que se realice un nuevo modelo unifactorial de la alexitimia. A nivel teórico, resulta esperable que para poder identificar una emoción, se debe ser capaz de describirla, por lo que estos dos procesos son prácticamente equivalentes. Asimismo, resulta notoria la asimetría tanto en los ítems como en los puntajes totales, lo cual sesga los modelos factoriales que dependen de la normalidad de las variables. Este modelo unifactorial fue inconsistente con el único estudio de evaluó la estructura factorial de esta prueba en Chile (Sáez Vilches y Tiznado Cerda, 2012); quienes extrajeron 7 componentes. Esto, probablemente porque aplicaron la regla de autovalores mayores a uno, que ha sido criticada (Field et al., 2012).

En cuanto a la empatía, el ajuste de los datos a la estructura original de la prueba (Davis, 1983) fue apropiado, consistente con lo que estudios previos habían mostrado en Chile (Fernández et al., 2011). Al igual que en el estudio mencionado, hubo más soporte para un modelo oblicuo, que para uno jerárquico. En este caso, las diferencias entre los ajustes de ambos modelos fueron aún más pronunciadas, contrario a lo propuesto por Cliffordson (2002).

En el caso de la prueba ERQ, los resultados refuerzan estudios que han encontrado la adecuación de la prueba al contexto latinoamericano (Gargurevich y Matos, 2010), encontrándose, al igual que en dicho estudio, la carga más baja para el ítem 5 (Cuando hago frente a una situación estresante, me obligo a pensar en ella de una manera que me ayude a mantener la calma). Es posible que este sea causado porque es este el único ítem que introduce el concepto de estrés. Todos los otros ítems están fraseados en términos de emociones positivas o negativas, sin incluir el componente de estrés. Curiosamente, otros estudios, realizados con muestras comunitarias en Australia y el Reino Unido han sugerido la eliminación del ítem 3, sin observar dificultades con el ítem 5 (Spaapen, Brummer, Stopa, Waters, y Bucks, 2014). 
En todos los casos, los alfas fueron satisfactorios (.66 - .88), lo cual evidencia la adecuación de los modelos de medición y la unidimensionalidad de las escalas. La mayor precaución en términos de consistencia interna debe tomarse con respecto a la escala de control inhibitorio (control intencional). Finalmente, es importante recordar que una práctica equivocada muy común es usar coeficientes de correlación inadecuados (Pearson) para el calculo del alfa, en lugar de las correlaciones policóricas.

Contrario a las hipótesis del estudio, las correlaciones entre el control intencional de los niños y las variables de ajuste emocional de los padres fueron débiles y pocas alcanzaron la significancia estadística. Las únicas dignas de ser mencionadas son el distrés personal, la toma de perspectiva y la alexitimia de la madre para la predicción del control inhibitorio y atencional. Para el placer de baja intensidad el distrés personal del padre. Para la sensibilidad perceptual, la preocupación empática del padre.

Aún menos variables mantuvieron su poder predictivo al ser ingresadas a los modelos de regresión. Esto implica que es muy poca la varianza adicional que explican las segundas y terceras variables una vez ingresada la primera. Así, para la predicción del control intencional, ninguna variable explica varianza adicional a la ya explicada por el distrés materno. En cuanto al control atencional, la única variable que tiene poder explicativo es la alexitimia de la madre; pero este efecto solo se ve en una regresión lineal, no en modelos de senderos, en los que esto deja de ser significativo, probablemente por las relaciones entre control inhibitorio y atencional.

El papel explicativo del distrés personal en el control inhibitorio es consistente con lo propuesto por Li et al. (2016), así como con el rol del apego propuesto por Viddal et al. (2015): el distrés personal se relaciona con la incapacidad de responder ante emergencias, y por tanto estaría vinculado al apego debido al hecho de que este distrés pueda ser percibido como una incapacidad de ser una base segura para el desarrollo del niño (e.g. Si la madre se desborda emocionalmente ante situaciones cargadas, no será percibida como una fuente de seguridad para el niño). Adicionalmente, el distrés personal puede ser explicado como la incapacidad de realizar una respuesta subdominante (ayudar al otro manteniendo la calma) en lugar de una respuesta dominante (una experiencia emocional intensa) (Eisenberg et al., 2011). Así, no es de sorprender que se transmita, sea por vías genéticas (i.e. es posible que déficits en el control intencional y el distrés personal compartan bases genéticas) o por vías sociales (i.e. La madre posee un déficit que le impide modelar adecuadamente el control 
intencional. En ambos casos, esto redundaría en un menor desarrollo del control intencional en el niño.

Por otro lado, la alexitimia en la madre es un predictor, aunque leve del control atencional. Esto es consistente con la idea de que el control intencional necesita como precursor un clima emocional positivo, en el que las emociones son discutidas y tratadas abiertamente (Li et al., 2016).

Sin embargo, es inesperado que las otras variables no hayan tenido un poder predictivo. El estudio de predictores de características temperamentales es reciente, y no hay estudios previos que ofrezcan justificación para el hecho de que solo algunos factores sean predictivos y otros no.

Es posible que estos aspectos de ajuste emocional de los padres estén capturando un aspecto específico de la dinámica familiar, y que sea por esto que no se explica varianza a la ya explicada por la variable con mayor poder explicativo; sin embargo, las bajas correlaciones bivariadas sugieren precaución en esta línea de argumentación.

Por otro lado, es importante recordar que estos resultados deben ser tomados con cautela, debido a la falta de normalidad en las variables, lo cual puede sesgar los resultados. Podría sugerirse que con muestras más grandes más predictores hubieran resultado significativos; lo cual es cierto, con la salvedad de que no necesariamente hubieran aumentado los tamaños de los efectos, que en todos los casos bordean los mínimos valores de significancia práctica planteados por Ferguson (2009).

Otras posible familia de explicaciones se sustenta en las dificultades en la medición. Es posible que los efectos estén ocultos debido a que los informantes son los padres, y las puntuaciones, tanto para el control intencional de los niños como para sus variables emocionales provienen de un mismo informante. Este sesgo de respuesta subjetiva, aunada al hecho de que es posible que hayan ciertas características personales que expliquen la variabilidad en las respuestas podría estar subestimando las relaciones entre las variables.

Otro factor a considerar es el sesgo de publicación. El estudio de predictores del control intencional es muy reciente, y son pocos los estudios que abordan esta problemática. Es posible que estudios que no presenten efectos significativos no sean publicados, debido a la tendencia de sobrevalorar los resultados positivos y desestimar la ausencia de efectos. 
Finalmente, y la explicación más probable, es que simplemente, las variables escogidas (tal vez especialmente si son medidas mediante autorreportes) no tienen tanto poder explicativo. De hecho, en la literatura, los efectos presentados no son directos, sino de mediación o moderación (Elizur et al., 2016), no tienen tamaños del efecto altos, o son validos solo para un grupo. Por ejemplo: Viddal et al. (2015) destacan la importancia del apego para el desarrollo del control intencional, pero este efecto es únicamente significativo en niños, no en niñas.

Consistente con las hipótesis del estudio y con la selección de variables en la literatura, para las dos subescalas más vinculadas al control intencional, se mostró un mayor poder explicativo de las variables de las madres que de los padres. Esto es consistente con la importancia del apego para el control intencional (Viddal et al., 2015); y con el hecho de que frecuentemente la figura de apego más importante para un niño es la madre. Esto es probablemente más marcado en Latinoamérica donde aspectos culturales hacen que tradicionalmente se comprenda el rol de la mujer vinculado al trabajo en el hogar y a la crianza de los hijos y a los padres en el mundo laboral.

Asimismo, esta diferencia podría estar relacionada con la ausencia de información sobre la influencia de los padres en la literatura: sea porque no son incluidos en los diseños de las investigaciones, o porque lo son, pero no son presentados al no presentar efectos significativos.

Curiosamente, en el caso de sensibilidad perceptual y placer de baja intensidad son los padres quienes tienen mayor influencia, aunque en estas dos variables los efectos son más pequeños. Este es un hallazgo inesperado que sugiere mayor investigación para esclarecer este hecho. Es posible que, debido a que los efectos son muy pequeños, que sea producto del azar. Sería interesante ver si estos resultados o resultados similares se replican en próximos estudios.

Al analizar las diferencias entre control intencional y sexo, se encontraron diferencias significativas en todas las subescalas a favor de las mujeres, estas fueron de tamaño pequeño-mediano. Las diferencias más importantes estuvieron en el control inhibitorio y la sensibilidad perceptual. Estudios previos comprueban la invarianza del control intencional según sexos (Sulik et al., 2010) y un metaanálisis de 741 tamaños de efecto en 277 estudios encontró efectos negligibles en favor a las mujeres $(d=0.08)$ (Cross, Copping, y Campbell, 2011). Así, en contraposición a estos estudios, los resultados parecen alinearse con (Else-Quest et al., 2006) que reporta, también en meta- 
análisis tamaños del efecto más similares a los obtenidos en el presente estudio. Una posible explicación sobre porqué ocurren estas diferencias puede estar dada por que son los mismos padres quienes evalúan a los niños en cuanto a su control intencional, y un prejuicio común que los padres suelen tener es que las "niñas maduran más rápidamente". Así, si los padres creen en esto es posible que esto se demuestre en los datos; si es que este fuera el caso, estas diferencias de sexo no deberían observarse si se mide el control inhibitorio de una manera más objetiva.

Interesantemente, y contrario a lo generalmente observado en la literatura (Eisenberg et al., 2011; Rothbart y Bates, 2007; Zentner y Bates, 2008) no se observó la correlación esperada entre edad y control intencional. Son pocas las investigaciones que reportan la ausencia de un efecto de la edad sobre el control intencional (Simonds, Kieras, Rueda, y Rothbart, 2007). Estos resultados son posiblemente evidencia de las diferencias entre la medición directa del control intencional (i.e. mediante tareas conductuales de laboratorio) y la medición mediante cuestionarios a los padres. Es probable que los padres ajusten sus respuestas a las creencias que ellos tienen acerca de qué niveles de control intencional debe tener un niño de la edad de su hijo. Así, no responden a las encuestas en términos objetivos de conductas observables, sino en términos relativos (e.g. que tanto control intencional ejerce mi hijo en comparación a otros niños de su edad). Esta substitución de la pregunta trae problemas dado que la medición no se basa en "cantidades" objetivas de control intencional sino en la comparación subjetiva del padre con un grupo de referencia que puede ser variable. Esto podría explicar la falta del efecto esperado de la edad, y subraya entonces la importancia de mejorar las instrucciones de la prueba, o de combinar los cuestionarios con observación conductual para obtener datos mas confiables. Sin embargo, Putnam (comunicación personal, 6 de agosto, 2015) plantea que no es sorprendente que no se encuentre un efecto de la edad, dado que en varias muestras este efecto no se ha encontrado, solo que no se reporta. Esto levanta la importancia de discutir el sesgo positivo en las publicaciones. Los resultados en cuanto a diferencias de grado fueron también principalmente insignificantes, por las mismas razones.

Finalmente, se compararon los niveles de las escalas de control intencional según grupos definidos por si la madre o el padre, alguna vez o actualmente recibieron tratamiento para la ansiedad farmacológico o psicológico y si tomaron pastillas de dormir. Debido a los baja cantidad de personas que reportó esto y ante la amenaza de falsos positivos por falta de potencia estadística, se analizó únicamente las diferencias 
entre niños cuyas madres habían o no recibido tratamiento farmacológico para la ansiedad en el pasado. La diferencia solo resultó ser significativa para el control inhibitorio y atencional, a favor de niños cuyas madres no habían recibido tratamiento, pero con un tamaño del efecto pequeño-moderado. Si bien las muestras pequeñas sugieren cautela al interpretar los resultados, este es un primer acercamiento al rol que puede tener la ansiedad de la madre en el desarrollo del control intencional. A nivel teórico, la relación tiene sentido, considerando los vínculos entre la ansiedad y la capacidad de brindar apego seguro (Viddal et al., 2015) y un clima emocional positivo en el hogar (Li et al., 2016). De la misma manera, estos resultados son consistentes con lo reportado por Gartstein et al. (2013) que demuestra el rol predictor del estrés materno en el control intencional infantil.

El último de los objetivos de la tesis fue analizar las correlaciones entre las variables de ajuste emocional de los padres. En este sentido se observan varios aspectos. En primer lugar, la supresión emocional se vincula cercanamente a la alexitimia. Esto es consonante con la idea de que para llevar a cabo estrategias de regulación emocional que sean adaptativas, es necesario cierto nivel de conciencia emocional (Gross, 2014); y sencillamente con la similitud conceptual entre los dos conceptos. Mientras que la alexitimia se refiere a una inconsciencia e inexpresión emocional en la vida cotidiana; la supresión emocional implica usar la inexpresión emocional como estrategia regulatoria. Adicionalmente, se observan vínculos entre la empatía y la alexitimia. Esto es consiste con estudios previos que señalan vínculos entre la falta de empatía y la alexitimia (Bernhardt y Singer, 2012). A nivel general, todas las correlaciones tienen las direcciones esperables teóricamente.

A continuación se presentan cinco limitaciones del estudio, acompañadas de recomendaciones para estudios futuros. En primer lugar, la medición del temperamento resulta ser un tema complejo. Por un lado, los reportes parentales son de fácil aplicación, bajo costo y tienen un amplio muestreo de posibles conductas, sin embargo pueden tener problemas de objetividad como los discutidos: principalmente si hay un vínculo entre el informante y niño, que pueda llevar a problemas de deseabilidad social; o si los informantes comparan a los niños contra un estándar de lo "esperable para la edad" y no se cuantifica el control intencional de manera directa u objetiva. Sin embargo, otras opciones, como la observación natural o las tareas de laboratorio pueden ser muy costosas y tener un muestreo insuficiente de conductas -en el caso de la observación natural- o problemas de validez ecológica o ser cuestionables éticamente - 
en el caso de las observaciones de laboratorio (Rothbart y Bates, 2007). Así, cualquier investigador debe decidir si conceder objetividad a favor de una muestra más grande; o si sacrificar la validez ecológica o un muestreo completo del constructo a favor de mayores niveles de objetividad. Más aún, no se termina de establecer una estructura del temperamento que no tenga ambigüedades (Zentner y Bates, 2008), lo cual se demuestra en las críticas a instrumentos de medición ampliamente utilizados (Kotelnikova et al., 2016).

En segundo lugar, al ser una investigación con datos secundarios, fue imposible participar del proceso de selección de instrumentos y técnicas de muestreo. Tras realizar análisis descriptivos preliminares, se observa que la distribución de la escala de alexitimia es asimétrica, probablemente por el sesgo clínico de la prueba. Así, estudios posteriores podrían emplear instrumentos de medición más dirigidos a población normal. Adicionalmente, medir niveles de ansiedad normal o estrés podría ser un siguiente paso para avanzar este aspecto, de acuerdo con los resultados de esta investigación y con lo planteado en la literatura (Gartstein et al., 2013).

En tercer lugar, es importante notar que es muy difícil desambiguar causalidades en un estudio de tipo correlacional. Las relaciones entre control intencional de los niños y ajuste emocional de la madre podrían ser explicadas por influencia del ambiente temprano de socialización en el temperamento de los niños; o de manera inversa, se podría hipotetizar que niños con temperamentos difíciles (Rothbart y Bates, 2007), generen síntomas de desajuste emocional en las madres. Dicho de otra manera: los padres tienen altos niveles de alexitimia por la frustración causada por lidiar con un niño con bajo control intencional, o si padres con niveles más elevados de alexitimia tienen dificultades para desarrollar el control intencional de un niño. Más aún, es incluso posible que existan terceras variables (e.g. genética) que expliquen ambas partes de la relación. Para poder solucionar esto, se hace necesario diseñar estudios de tipo longitudinal, en los que se puedan medir el ajuste emocional antes de la llegada del hijo; o estudios de tipo experimental en los cuales, por ejemplo, se haga interactuar a mujeres con niños pequeños, sin que estos sean sus hijos para observar como determinadas diferencias en el temperamento pueden sesgar los estilos de interacción de las madres.

En cuarto lugar, el estudio no puede determinar si estas relaciones son genéticas o ambientales, o cuál es la contribución de cada una de estas. Cada vez se otorga mayor importancia a la genética y epigenética para la explicación del comportamiento, por lo 
que es probable que esta tenga un impacto en esta pregunta de investigación. Tan es así, que contrario a la definición tradicional del temperamento, la heredabilidad no ha sido considerada como un factor definitorio del temperamento; no porque no sea importante, sino porque los niveles de heredabilidad del temperamento son tan elevados como las de otras variables psicológicas. Así, estudios futuros, deben seguir la línea iniciada por Li et al. (2016) en la identificación de factores genéticos y epigenéticos que expliquen los orígenes del control intencional.

Finalmente, sería iluso pensar que en el caso del control intencional, y en las variables psicológicas en general, las definiciones son mutuamente excluyentes. En el caso del control intencional, son muchos los esfuerzos que buscan desambiguar el concepto de las funciones ejecutivas (especialmente el control inhibitorio), de la autorregulación y el autocontrol, así como de la red atencional ejecutiva planteada por Petersen y Posner (1990, 2012); y en definitiva hay aspectos en los que los bordes siguen difusos (Diamond, 2013). Estas diferencias en los constructos probablemente se deben más a los diferentes orígenes de los investigadores (investigadores del temperamento enfocados en control intencional e investigadores cognitivos enfocados en funciones ejecutivas) más que por diferencias intrínsecas a los conceptos en sí (Liew, 2012). Aún así, la evidencia no logra desambiguar claramente los conceptos. Un ejemplo de esto es el hecho de que el control intencional medido mediante reporte parental correlaciona fuertemente con pruebas de reporte parental de funciones ejecutivas; pero las correlaciones son débiles o insignificantes estadísticamente si se correlacionan con pruebas de laboratorio de las funciones ejecutivas (Gonzáles-Salinas et al., 2014). Esto mismo fue observado por Samyn, Roeyers, Bijttebier, Rosseel, y Wiersema (2015) quienes enfatizan las diferencias entre los cuestionarios de control intencional y las tareas de función ejecutiva. Debido a que estos no capturan la misma variable latente, no es aconsejable usarlos de manera intercambiable. Así, es importante que estudios futuros se encarguen de desambiguar estos conceptos y reorganizar el exceso de constructos para poder ofrecer explicaciones más parsimoniosas de los hechos de la realidad.

En conclusión, esta investigación representa una aproximación exploratoria al campo emergente de buscar los correlatos o antecedentes del control intencional en las características de los cuidadores principales. Conociendo estos correlatos, es posible comprender la importancia del papel que juega el ajuste emocional y la salud mental de los padres, lo cual puede permitir trabajar con un enfoque preventivo para el desarrollo 
del control intencional en niños pequeños, especialmente en las comunidades más vulnerables. Esto debido al importante rol predictor que tiene el control intencional en el ajuste a la escuela tanto académico como socioemocional (e.g. Blair y Razza, 2007), a los vínculos entre control intencional y problemas de conducta (Rothbart y Bates, 2007), la psicopatología (Elizur et al., 2016; Muris, 2006) y el desarrollo moral (Eisenberg et al., 2011; Luengo Kanacri et al., 2013). 


\section{CONCLUSIONES}

- En cuanto a las evidencias de validez provenientes de la estructura interna de las pruebas, los instrumentos empleados mostraron estructuras factoriales similares a las originales, y las diferencias fueron explicables teóricamente

- La estimación de la confiabilidad de las puntuaciones derivadas de los ítems de las pruebas empleadas, mediante el coeficiente alfa de Cronbach ordinal, fue satisfactoria.

- Solo se relacionó con el control inhibitorio con el distrés personal, la toma de perspectiva y la alexitimia de la madre. De estas solo el distrés personal mantuvo significancia estadística en los modelos predictivos. El control atencional estuvo relacionado con las tres variables de la madre anteriormente mencionadas pero adicionalmente con la dificultad para expresar emociones; de estas ninguna mantuvo significancia estadística en los modelos de senderos. Finalmente, la sensibilidad perceptual estuvo relacionada con la preocupación empática del padre y la reevaluación cognitiva de la madre, solo la preocupación empática del padre mantuvo significancia.

- Las variables de ajuste emocional de las madres tuvieron mayor poder predictivo que las de los padres sobre el control inhibitorio y el control atencional de los niños, a pesar de que el tamaño el efecto fue pequeño. Aunque el tamaño del efecto fue aún menor, las variables de ajuste emocional de los padres fueron predictivas para la sensibilidad perceptual y el placer de baja intensidad. Para estos criterios, las variables predictoras de las madres no resultaron significativas.

- Se observaron diferencias de género de tamaño mediano en el control inhibitorio según sexo a favor de las niñas.

- Contrario a lo esperado, no se observó una relación entre el control intencional y la edad o el grado. Parece ser que los padres respondieron a la prueba de manera relativa, comparando a su hijo con un grupo de referencia y no de forma objetiva comparando con características observables de conducta. 
- Existen diferencias de tamaño mediano en el control inhibitorio a favor de niños cuyas madres no han recibido tratamiento farmacológico para la ansiedad comparados con niños que sí.

- Se observaron correlaciones esperables teóricamente entre las medidas de ajuste emocional en los adultos 


\section{RECOMENDACIONES}

- Usar modelos de regresión más robustos que no se vean afectados por la falta de normalidad y la presencia de datos atípicos en los datos.

- Revisar las instrucciones o el formato de respuesta del cuestionario de temperamento infantil para evitar los problemas de subjetivización o relativización de la respuesta.

- Replicar la investigación incluyendo mediciones de ansiedad materna, que parece ser un predictor relevante del control intencional.

- Desarrollar estrategias para el diagnóstico de problemas en los perfiles emocionales de padres y madres; especialmente en lo referente a la empatía y la alexitimia; con la intención de generar programas para mejorar estas variables.

- Se recomienda el uso de los instrumentos de investigación empleados en la presente investigación, tomando en cuenta la evidencias de validez y confiabilidad halladas. De acuerdo con Kotelinikova et al. (2016), se recomienda especial cautela para el uso de la prueba CBQ. 


\section{REFERENCIAS}

Bagby, R. M., Parker, J. D., \& Taylor, G. J. (1994). The twenty-item Toronto Alexithymia Scale--I. Item selection and cross-validation of the factor structure. Journal of Psychosomatic Research, 38(1), 23-32. http://doi.org/10.1016/00223999(94)90005-1

Bagby, R. M., Taylor, G. J., \& Parker, J. D. (1994). The Twenty-item Toronto Alexithymia Scale--II. Convergent, discriminant, and concurrent validity. Journal of Psychosomatic Research, 38(1), 33-40. http://doi.org/10.1016/00223999(94)90006-X

Barata, M. C. (2011). Executive Function Skills in Chilean Preschool Children. Harvard University. Retrieved from http://search.proquest.com/docview/908960000

Barra, G. (2009). Oral narrative skills of chilean preschool children. University of Massachusetts Lowell. Retrieved from http://gateway.proquest.com/openurl?url_ver=Z39.882004\&res_dat $=$ xri:pqdiss\&rft_val_fmt=info:ofi/fmt:kev:mtx:dissertation\&rft_dat $=$ xri:pqdiss:3351368

Bernhardt, B. C., \& Singer, T. (2012). The Neural Basis of Empathy. Annual Review of Neuroscience, 35(1), 1-23. http://doi.org/10.1146/annurev-neuro-062111-150536

Blair, C., \& Razza, R. P. (2007). Relating effortful control, executive function, and false belief understanding to emerging math and literacy ability in kindergarten. Child Development, 78(2), 647-663. http://doi.org/10.1111/j.14678624.2007.01019.x

Brown, T. A. (2015). Confirmatory Factor Analysis for Applied Research. Methodology in the Social Sciences.

Carranza, J. A., González, C., \& Hidalgo, M. D. (2000). Spanish adaptation of the Children Behavior Assessment Questionnaire. In Poster presented at the XII Conference of Infantile Psychiatry and Psychology. Stockholm, Sweden.

Cliffordson, C. (2002). The hierarchical structure of empathy: Dimensional organization and relations to social functioning. Scandinavian Journal of Psychology, 43(1), 49-59. http://doi.org/10.1111/1467-9450.00268 
Cohen, J. (1992). Quantitaive methods in psychology: A power primer. Psychological Bulletin, 112(1), 155-159. http://doi.org/10.1038/141613a0

Coplan, R. J., Barber, A. M., \& Lagacé-Séguin, D. G. (1999). The role of child temperament as a predictor of early literacy and numeracy skills in preschoolers.

Early Childhood Research Quarterly, 14(4), 537-553. http://doi.org/10.1016/S0885-2006(99)00025-3

Cross, C. P., Copping, L. T., \& Campbell, A. (2011). Sex differences in impulsivity: a meta-analysis. Psychological Bulletin, 137(1), 97-130. http://doi.org/10.1037/a0021591

Cueto, S. (2007). Las evaluaciones nacionales e internaciones de rendimiento escolar en el Perú: balance y perspectivas. In Investigación, políticas y desarrollo en el Perú (pp. 405-455). Lima: GRADE.

Damasio, A. (2005). Descartes' Error: Emotion, Reason, and the Human Brain. New York: Penguin Publishing Group.

Davidson, M. C., Amso, D., Cruess Anderson, L., \& Diamond, A. (2006). Development of cognitive control and executive functions from 4 to 13 years: Evidence from manipulations of memory, inhibition, and task switching. Neuropsychologia, 44(11), 2037-2078. http://doi.org/10.1016/j.neuropsychologia.2006.02.006

Davis, M. H. (1983). Measuring individual differences in empathy: Evidence for a multidimensional approach. Journal of Personality and Social Psychology, 44(1), 113-126. http://doi.org/10.1037/0022-3514.44.1.113

Deyoung, C. G. (2011). Impulsivity as a personality trait. In K. D. Vohs \& R. F. Baumeister (Eds.), Handbook of Self-Regulation: Research, Theory and Applications (pp. 485-502). New York: The Guilford Press.

Diamond, A. (2013). Executive Functions. Annual Review of Psychology, 64, 135-158. http://doi.org/10.1146/annurev-psych-113011-143750

Digman, J. M. (1990). Personality Structure: Emergence of the Five-Factor Model. Annual Review of Psychology, 41(1), 417-440. http://doi.org/10.1146/annurev.ps.41.020190.002221

Eisenberg, N., Smith, C. L., \& Spinrad, T. L. (2011). Effortful Control. In K. D. Vohs \& R. F. Baumeister (Eds.), Handbook of Self-Regulation: Research, Theory and 
Applications (pp. 263-283). New York: The Guilford Press.

Elizur, Y., Somech, L. Y., \& Vinokur, A. D. (2016). Effects of Parent Training on Callous-Unemotional Traits, Effortful Control, and Conduct Problems: Mediation by Parenting. Journal of Abnormal Child Psychology. http://doi.org/10.1007/s10802-016-0163-7

Else-Quest, N. M., Hyde, J. S., Goldsmith, H. H., \& Van Hulle, C. A. (2006). Gender differences in temperament: a meta-analysis. Psychological Bulletin, 132(1), 3372. http://doi.org/10.1037/0033-2909.132.1.33

Eysenck, H. J. (1950). Dimensions of Personality. New Jersey: Routledge \& Kegan Paul.

Faul, F., Erdfelder, E., Buchner, A., \& Lang, A.-G. (2009). Statistical power analyses using $G^{*}$ Power 3.1: tests for correlation and regression analyses. Behavior Research Methods, 41(4), 1149-1160. http://doi.org/10.3758/BRM.41.4.1149

Ferguson, C. J. (2009). An effect size primer: A guide for clinicians and researchers. Professional Psychology: Research and Practice, 40(5), 532-538. http://doi.org/10.1037/a0015808

Fernández-Vilar, M. A., \& Carranza, J. A. (2013). Temperament in the school context: A historical review. European Journal of Psychology of Education, 28(3), 923944. http://doi.org/10.1007/s10212-012-0147-0

Fernández, A. M., Dufey, M., \& Kramp, U. (2011). Testing the psychometric properties of the Interpersonal Reactivity Index (IRI) in Chile: Empathy in a different cultural context. European Journal of Psychological Assessment, 27(3), 179-185. http://doi.org/10.1027/1015-5759/a000065

Field, A. (2009). Discovering Statistics Using SPSS Statistics (Third). London: Sage Publications.

Field, A., Miles, J., \& Field, Z. (2012). Discovering Statistics Using R. London: Sage Publications.

Gadermann, A. M., Guhn, M., \& Zumbo, B. D. (2012). Estimating Ordinal Reliability for Likert-Type and Ordinal Item Response Data: A Conceptual, Empirical, and Practical Guide. Practical Assessment, Research \& Evaluation, 17(3), 1-13. http://doi.org/http://pareonline.net/getvn.asp?v=17\&n=3 
Gargurevich, R., \& Matos, L. (2010). Propiedades psicométicas del cuestionario de autorregulación emocional adaptado para el Perú (ERQP). Revista de Psicología, $12,192-215$.

Gartstein, M. A., Bridgett, D. J., Young, B. N., Panksepp, J., \& Power, T. (2013). Origins of Effortful Control: Infant and Parent Contributions. Infancy, 18(2), 149183. http://doi.org/10.1111/j.1532-7078.2012.00119.x

Gavidia-Payne, S., Denny, B., Davis, K., Francis, A., \& Jackson, M. (2015). Parental resilience: A neglected construct in resilience research. Clinical Psychologist, 111. http://doi.org/10.1111/cp.12053

Gonzáles-Salinas, C., Sánchez-Pérez, N., Martella, D., Santos, F. H., Castillo, A., \& Fuentes, L. J. (2014). Relations Between Effortful Control and Executive Functions in Childhood. In 20th Occasional Temperament Conference. Temperament: Biology, Behavior and Adjustment.

Grabe, H. J., Spitzer, C., \& Freyberger, H. J. (2001). Alexithymia and the temperament and character model of personality. Psychotherapy and Psychosomatics, 70(5), 261-267. http://doi.org/10.1159/000056264

Gross, J. J. (2014). Emotion Regulation: Conceptual and Empirical Foundations. In J. J. Gross (Ed.), Handbook of Emotion Regulation (pp. 3-20). New York: The Guilford Press. http://doi.org/10.1080/00140130600971135

Gross, J. J., \& John, O. P. (2003). Individual differences in two emotion regulation processes: implications for affect, relationships, and well-being. Journal of Personality and Social Psychology, 85(2), 348-362. http://doi.org/10.1037/00223514.85.2.348

Guerin, D. W., Gottfried, A. W., Oliver, P. H., \& Thomas, C. W. (1994). Temperament and School Functioning During Early Adolescence. Journal of Early Adolescence, 14(2), 200-225.

Hernández, R., Fernández, C., \& Baptista, P. (2014). Metodología de la investigación (Sexta Ed.). México D.F.: McGraw-Hill.

Hu, L., \& Bentler, P. M. (1999). Cutoff criteria for fit indexes in covariance structure analysis: Conventional criteria versus new alternatives. Structural Equation Modeling: $\quad$ A Multidisciplinary Journal, 6(1), 1-55. 
http://doi.org/10.1080/10705519909540118

Kochanska, G., Aksan, N., \& Joy, M. E. (2007). Children's fearfulness as a moderator of parenting in early socialization: Two longitudinal studies. Developmental Psychology, 43(1), 222-237. http://doi.org/10.1037/0012-1649.43.1.222

Kochanska, G., \& Knaack, A. (2003). Effortful Control as a Personality Characteristic of Young Children: Antecedents, Correlates, and Consequences. Journal of Personality, 71(6), 1087-1112. http://doi.org/10.1111/1467-6494.7106008

Kotelnikova, Y., Olino, T. M., Klein, D. N., Kryski, K. R., \& Hayden, E. P. (2016). Higher- and Lower-Order Factor Analyses of the Children's Behavior Questionnaire in Early and Middle Childhood, 28(1), 92-108.

Lakens, D. (2013). Calculating and reporting effect sizes to facilitate cumulative science: A practical primer for t-tests and ANOVAs. Frontiers in Psychology, 4(NOV), 1-12. http://doi.org/10.3389/fpsyg.2013.00863

Li, Y., Sulik, M. J., Eisenberg, N., Spinrad, T. L., Lemery-Chalfant, K., Stover, D. A., \& Verrelli, B. C. (2016). Predicting childhood effortful control from interactions between early parenting quality and children's dopamine transporter gene haplotypes. Development and Psychopathology, 28(1), 1-14. http://doi.org/10.1017/S0954579415000383

Liew, J. (2012). Effortful Control, Executive Functions, and Education: Bringing SelfRegulatory and Social-Emotional Competencies to the Table. Child Development Perspectives, 6(2), 105-111. http://doi.org/10.1111/j.1750-8606.2011.00196.x

Luengo Kanacri, B. P., Pastorelli, C., Eisenberg, N., Zuffianò, A., \& Caprara, G. V. (2013). The development of prosociality from adolescence to early adulthood: The role of effortful control. Journal of Personality, 81(3), 302-312. http://doi.org/10.1111/jopy.12001

McCrae, R. R., \& Costa, P. T. (1987). Validation of the five-factor model of personality across instruments and observers. Journal of Personality and Social Psychology, 52(1), 81-90. http://doi.org/10.1037/0022-3514.52.1.81

Miyake, A., Friedman, N. P., Emerson, M. J., Witzki, A. H., Howerter, A., \& Wager, T. D. (2000). The unity and diversity of executive functions and their contributions to complex "Frontal Lobe" tasks: a latent variable analysis. Cognitive Psychology, 
41(1), 49-100. http://doi.org/10.1006/cogp.1999.0734

Moffitt, T. E., Arseneault, L., Belsky, D., Dickson, N., Hancox, R. J., Harrington, H., ... Caspi, A. (2011). A gradient of childhood self-control predicts health, wealth, and public safety. Proceedings of the National Academy of Sciences of the United States of America, 108(7), 2693-8. http://doi.org/10.1073/pnas.1010076108

Muris, P. (2006). Unique and interactive effects of neuroticism and effortful control on psychopathological symptoms in non-clinical adolescents. Personality and Individual Differences, $\quad 40(7), \quad 1409-1419$. http://doi.org/10.1016/j.paid.2005.12.001

Ochsner, K. N., \& Gross, J. J. (2011). The Reason in Passion. In K. D. Vohs \& R. F. Baumeister (Eds.), Handbook of Self-Regulation: Research, Theory and Applications (pp. 144-148). New York: The Guilford Press.

Organización para la Cooperación y el Desarrollo Económico. (2014). Resultados de PISA 2012 en foco. Lo que los alumnos saben a los 15 años de edad y lo que pueden hacer con lo que saben. Retrieved from http://www.oecd.org/pisa/keyfindings/PISA2012_Overview_ESP-FINAL.pdf

Petersen, S. E., \& Posner, M. I. (1990). The Attention System Of The Human Brain. Annual Review of Neuroscience, 13, 25-42.

Petersen, S. E., \& Posner, M. I. (2012). The Attention System of the Human Brain: 20 Years After. Annual Review of Neuroscience, 35, 73-89. http://doi.org/10.1146/annurev-neuro-062111-150525.

Posner, M. I., \& Rothbart, M. K. (2007). Research on attention networks as a model for the integration of psychological science. Annual Review of Psychology, 58, 1-23. http://doi.org/10.1146/annurev.psych.58.110405.085516

Posner, M. I., Rothbart, M. K., \& Tang, Y. (2013). Developing self-regulation in early childhood. Trends in Neuroscience and Education, 2(3-4), 107-110. http://doi.org/10.1016/j.tine.2013.09.001

Putnam, S. P., \& Rothbart, M. K. (2006). Development of short and very short forms of the Children's Behavior Questionnaire. Journal of Personality Assessment, 87(1), 102-112. http://doi.org/10.1207/s15327752jpa8701_09

Rosseel, Y. (2014). Structural Equation Modeling with lavaan. In Using $R$ for 
personality research (pp. 1-127). Bertinoro: Ghent University.

Rothbart, M. K. (1981). Measurement of Temperament in Infancy. Child Development, $52,569-578$.

Rothbart, M. K. (2007). Temperament, Development, and Personality. Current Directions in Psychological Science, 16(4), 207-213.

Rothbart, M. K., Ahadi, S. A., Hershey, K. L., \& Fisher, P. (2001). Investigations of Temperament at Three to Seven Years: The Children's Behavior Questionnaire. Child Development, 72(5), 1394-1408.

Rothbart, M. K., \& Bates, J. E. (2007). Temperament. In N. Eisenberg (Ed.), Handbook of Child Psychology (pp. 115-141). John Wiley \& Sons, Inc. http://doi.org/10.1002/9780470147658.chpsy0303

Rothbart, M. K., Ellis, L. K., \& Posner, M. I. (2011). Temperament and SelfRegulation. In K. D. Vohs \& R. F. Baumeister (Eds.), Handbook of SelfRegulation: Research, Theory and Applications (pp. 441-460). New York: The Guilford Press.

Rothbart, M. K., \& Rueda, M. R. (2005). The development of effortful control. In U. Mayr, E. Awh, \& S. Keele (Eds.), Developing individuality in the human brain: A tribute to Michael I. Posner (pp. 167-188). Washington, D.C.: American Psychological Association. http://doi.org/10.1037/11108-009

Rothbart, M. K., Sheese, B. E., \& Posner, M. I. (2007). Executive Attention and Effortful Control: Linking Temperament, Brain Networks, and Genes. Child Development Perspectives, $\quad 1(1), \quad 2-7 . \quad$ http://doi.org/10.1111/j.17508606.2007.00002.x

Rothbart, M. K., Sheese, B. E., \& Posner, M. I. (2014). Temperament and Emotion Regulation. In J. J. Gross (Ed.), Handbook of Emotion Regulation (Second, pp. 305-320). New York: The Guilford http://doi.org/10.1001/jama.298.15.1808

Rothbart, M. K., Sheese, B. E., Rueda, M. R., \& Posner, M. I. (2011). Developing Mechanisms of Self-Regulation in Early Life. Emotional Review, 3(2), 207-213. http://doi.org/10.1177/1754073910387943.Developing

Sáez Vilches, C. A., \& Tiznado Cerda, G. D. (2012). Validación de la Escala de 
Alexitímia de Toronto. Universidad del Bío-Bío.

Samyn, V., Roeyers, H., Bijttebier, P., Rosseel, Y., \& Wiersema, J. R. (2015). Assessing effortful control in typical and atypical development: Are questionnaires and neuropsychological measures interchangeable? A latent-variable analysis. Research in Developmental Disabilities, 36, 587-599. http://doi.org/10.1016/j.ridd.2014.10.018

Simonds, J., Kieras, J. E., Rueda, M. R., \& Rothbart, M. K. (2007). Effortful control, executive attention, and emotional regulation in 7-10-year-old children. Cognitive Development, 22(4), 474-488. http://doi.org/10.1016/j.cogdev.2007.08.009

Sinay, V., Manes, F., \& Gleichgerrcht, E. (2012). Alexythimia and Moral Judgment in Patients with Multiple Sclerosis. Neurology, 78.

Singer, T. (2006). The neuronal basis and ontogeny of empathy and mind reading: Review of literature and implications for future research. Neuroscience and Biobehavioral Reviews, $30(6)$, $855-863$. http://doi.org/10.1016/j.neubiorev.2006.06.011

Spaapen, D. L., Brummer, L., Stopa, L., Waters, F., \& Bucks, R. S. (2014). The Emotion Regulation Questionnaire: Validation of the ERQ-9 in Two Community Samples. Psychological Assessment, $26(1)$ $46-54$. http://doi.org/10.1037/a0034474

Sulik, M. J., Huerta, S., Zerr, A. A., Eisenberg, N., Spinrad, T. L., Valiente, C., ... Wilson, S. B. (2010). The factor structure of effortful control and measurement invariance across ethnicity and sex in a high-risk sample. Journal of Psychopathological Behavior Assessment, 32(1), 8-22. http://doi.org/10.1007/s10862-009-9164-y.

Timoney, L. R., \& Holder, M. D. (2013). Emotional Processing Deficits and Happiness: Assessing the Measurement, Correlates, and Well-Being of People with Alexithymia. Berlin: Springer.

Van Buuren, S., \& Groothuis-Oudshoorn, K. (2011). Multivariate imputation by chained equations. Journal of Statistical Software, 45(3), 1-67. http://doi.org/10.1177/0962280206074463

Viddal, K. R., Berg-Nielsen, T. S., Wan, M. W., Green, J., Hygen, B. W., \& 
Wichstrøm, L. (2015). Secure attachment promotes the development of effortful control in boys. Attachment \& Human Development, 17(3), 319-335. http://doi.org/10.1080/14616734.2014.999098

Yan, N. (2016). Children's resilience in the presence of mothers' depressive symptoms: Examining regulatory processes related to active agency. Children and Youth Services Review, 61, 90-100. http://doi.org/10.1016/j.childyouth.2015.12.008

Zentner, M., \& Bates, J. E. (2008). Child temperament: An integrative review of concepts, research programs, and measures. European Journal of Developmental Science, 2(1), 7-37. http://doi.org/10.3233/DEV-2008-21203 


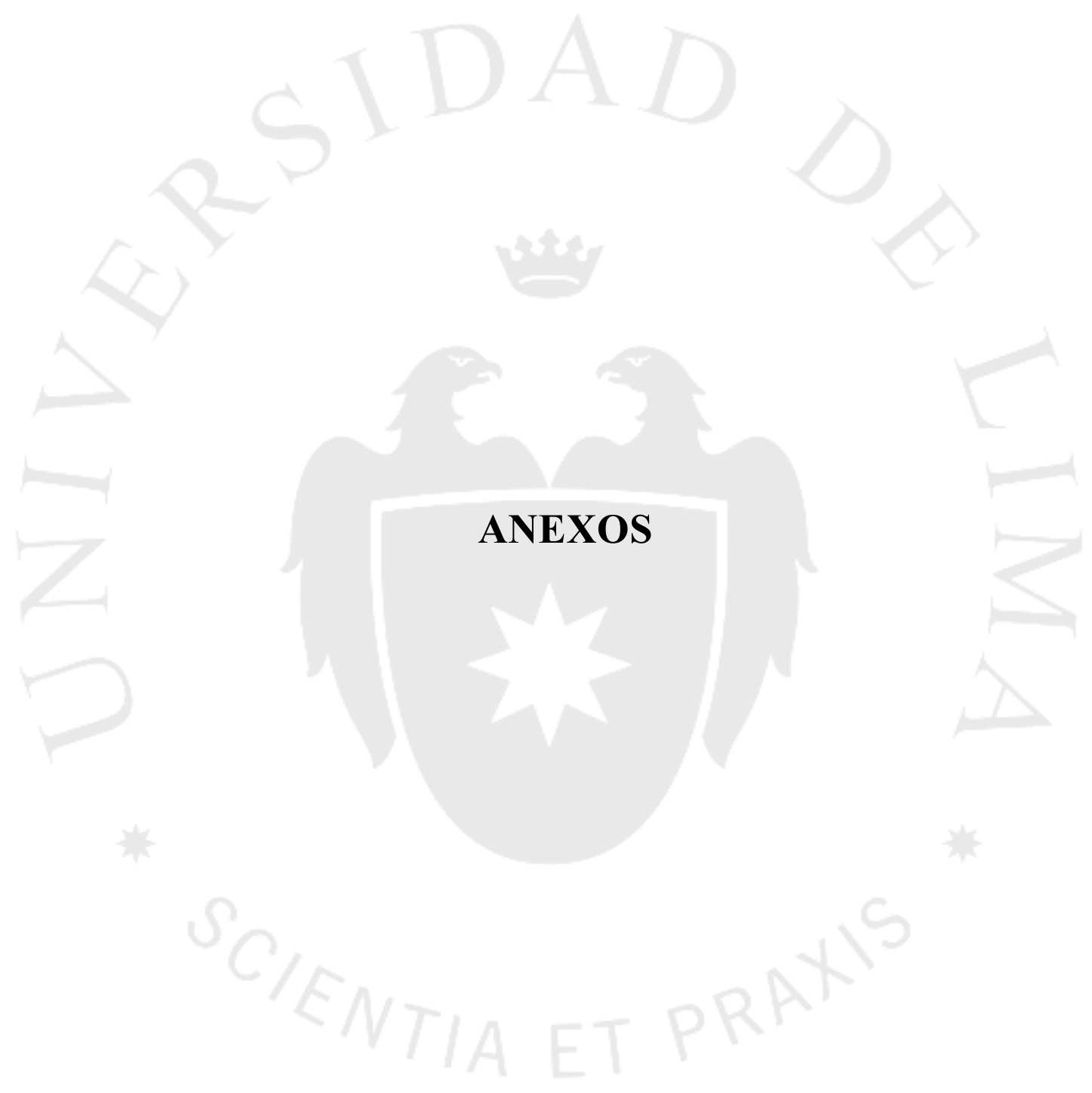




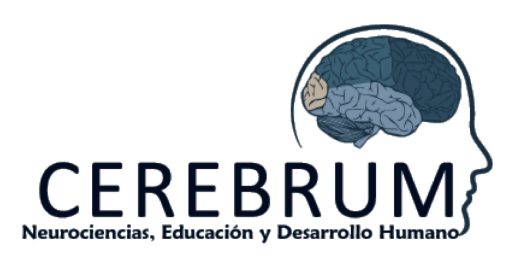

DiRECCIÓN DE INVESTIGACIÓN

\section{CONSENTIMIENTO INFORMADO}

El Centro Iberoamericano de Neurociencias, Educación y Desarrollo Humano - CEREBRUM, es una institución privada que tiene como objetivo contribuir al mejoramiento de la calidad de la educación y al desarrollo humano, en diferentes países y contextos de Latinoamérica, a través de los aportes de la neurociencia educacional al campo educativo. Para ello, CEREBRUM interviene en cuatro ámbitos de acción: Difusión, Formación, Investigación y Aplicación, con la finalidad de fomentar la ciencia emergente de la Mente, el Cerebro y la Educación, permitiendo que la transformación de la práctica pedagógica esté construida sobre fundamentos científicos. En este sentido, lo invitamos a responder algunas preguntas organizadas en cuestionarios y a la vez solicitamos su autorización para utilizar los datos recaudados e incluirlos en nuestros estudios.

A través de su consentimiento, usted acepta que:

- Su participación es totalmente voluntaria.

- El uso de los datos será para fines científicos, lo que no le significará ningún tipo de retribución económica.

- Su identidad será resguardada y todos los datos personales serán confidenciales.

- Todos los datos alcanzados serán analizados estadísticamente, los mismos que conformarán información científica importante a ser compartida de forma escrita u oral, bajo el carácter de confidencialidad de los datos.

FIRMA DEL PARTICIPANTE

Ciudad: , Fecha: País: 


\section{DATOS GENERALES}

1. Edad:

2. Sexo: ( ) Masculino ( ) Femenino

3. Lugar de nacimiento:

4. Ciudad donde vive:

5. Número de hijos:

6. Formación académica:

( ) Universidad nacional

( ) Universidad privada

( ) Instituto

( ) Otros (especifique):

7. Especialidad:

8. Conocimiento previos sobre neurociencia educacional ( ) sí ( ) no

9. Recibe en la actualidad tratamiento para la ansiedad? ( ) No ( ) Sí, farmacológico ( ) Sí, terapeútico

10. Recibió en el pasado tratamiento para la ansiedad? ( ) No （）Sí, farmacológico （）Sí, terapeútico

11. Toma alguna medicación para dormir? ( ) No ( ) Sí, indique:

Nombre de su hijo(a):

Edad: años, meses.

Sexo del niño/a:

Fecha de hoy: 


\section{ERQ ${ }^{1}$}

Nos gustaría que respondieras a algunas preguntas relacionadas con tu vida emocional, en particular cómo controlas o cómo manejas y regulas tus emociones. En este sentido, estamos interesados en dos aspectos principales: por un lado tu experiencia emocional, o cómo sientes las emociones; y por otro la expresión emocional o como muestras las emociones en tu forma de hablar o de comportarte. Aunque algunas de las siguientes preguntas pudieran parecer similares, difieren en aspectos bastante importantes.

Por favor, responde cuan de acuerdo o en desacuerdo estas con cada una de las preguntas que se hacen a continuación usando la siguiente escala de respuestas:

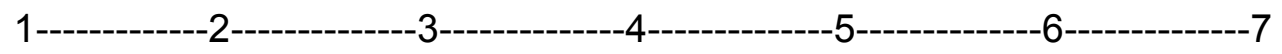

Totalmente en desacuerdo

Neutral

Totalmente de acuerdo

1. Cuando quiero sentir una emoción positiva con mayor intensidad (por ejemplo, más alegría), modifico lo que pienso para hacerlo.

2.___ Mantengo ocultas mis emociones (las guardo sólo para mí).

3._Cuando quiero sentir una emoción negativa con menor intensidad (por ejemplo, menos tristeza), modifico lo que pienso para hacerlo.

4.__ Cuando estoy sintiendo emociones positivas, tengo cuidado de no expresarlas.

5. Cuando hago frente a una situación estresante, me obligo a pensar en ella de una manera que me ayude a mantener la calma.

6.___ Controlo mis emociones no expresándolas.

7. Cuando quiero sentir una emoción positiva con mayor intensidad, cambio mi manera de pensar sobre la situación que generó la emoción.

8.___ Controlo mis emociones cambiando la manera de pensar sobre la situación en la que me encuentro.

9.___ Cuando estoy sintiendo emociones negativas, me aseguro de no expresarlas.

10. Cuando quiero sentir una emoción negativa en menor intensidad, cambio la manera de pensar sobre la situación que situación que generó la emoción

\footnotetext{
1 Traducción y adaptación de Rafael Gargurevich, autorizada por James Gross, versión original de Gross J.J. \& John O.P. (2003) Estudio PP-M1 indiv- 06-2014- CEREBRUM
} 


\section{TAS-20 - A}

Para cada una de las siguientes sentencias, elija qué opción representa mejor su personalidad

1 = Totalmente en desacuerdo // 2 = Moderadamente en desacuerdo // $3=$ No sé, ni en acuerdo ni en desacuerdo 4 = Moderadamente de acuerdo $/ / 5=$ Totalmente de acuerd

\begin{tabular}{|c|c|c|c|c|c|}
\hline \multirow{2}{*}{ A menudo estoy confundido con las emociones que estoy sintiendo } & 1 & 2 & 3 & 4 & 5 \\
\hline & & & & & \\
\hline \multicolumn{5}{|l|}{ Me es difícil encontrar las palabras correctas para mis sentimientos } & \\
\hline \multicolumn{5}{|l|}{ Tengo sensaciones físicas que incluso ni los doctores entienden } & \\
\hline \multicolumn{5}{|l|}{ Soy capaz de expresar mis sentimientos fácilmente } & \\
\hline \multicolumn{5}{|l|}{ Prefiero pensar bien acerca de un problema en lugar de solo mencionarlo } & \\
\hline \multicolumn{5}{|l|}{ Cuando estoy mal no sé si estoy triste, asustado o enfadado } & \\
\hline \multicolumn{5}{|l|}{ A menudo estoy confundido con las sensaciones de mi cuerpo } & \\
\hline \multicolumn{6}{|l|}{$\begin{array}{l}\text { Prefiero dejar que las cosas sucedan solas, mejor que preguntarme por qué } \\
\text { suceden de ese modo }\end{array}$} \\
\hline \multicolumn{5}{|l|}{ Tengo sentimientos que casi no puedo identificar } & \\
\hline \multicolumn{5}{|l|}{ Estar en contacto con las emociones es muy importante } & \\
\hline \multicolumn{5}{|l|}{ Me es difícil expresar lo que siento acerca de las personas } & \\
\hline \multicolumn{5}{|l|}{ La gente me dice que exprese más mis sentimientos } & \\
\hline \multicolumn{5}{|l|}{ No sé qué pasa dentro de mí } & \\
\hline \multicolumn{2}{|l|}{ A menudo no sé por qué estoy enfadado } & & & & \\
\hline \multicolumn{6}{|l|}{$\begin{array}{l}\text { Prefiero hablar con la gente de sus actividades diarias mejor que de sus } \\
\text { sentimientos }\end{array}$} \\
\hline \multicolumn{6}{|l|}{$\begin{array}{l}\text { Prefiero ver espectáculos simples, pero entretenidos, que dramas } \\
\text { psicológicos }\end{array}$} \\
\hline \multicolumn{6}{|l|}{$\begin{array}{l}\text { Me es difícil revelar mis sentimientos más profundos incluso a mis amigos } \\
\text { más íntimos }\end{array}$} \\
\hline \multicolumn{6}{|l|}{ Puedo sentirme cercano a alguien, incluso en momentos de silencio. } \\
\hline \multicolumn{6}{|l|}{$\begin{array}{l}\text { Encuentro útil examinar mis sentimientos para resolver problemas } \\
\text { personales }\end{array}$} \\
\hline $\begin{array}{l}\text { Buscar significados ocultos a películas o juegos disminuye el placer de } \\
\text { disfrutarlos }\end{array}$ & & & & & \\
\hline
\end{tabular}

Estudio PP-M1 indiv- 06-2014- CEREBRUM 


\section{IRI}

Los siguientes enunciados indagan acerca de sus pensamientos y sentimientos ante una variedad de situaciones. Para cada ítem, indique qué tan bien lo describe a usted seleccionando la letra adecuada acorde a la escala que está al comienzo de la página: $A, B, C, D$ o E. Cuando haya decidido su respuesta, rellene dentro de un círculo la letra próxima al número del ítem. LEA CADA ITEM DETENIDAMENTE ANTES DE CONTESTAR. Responda de la manera más honesta que pueda. Gracias.

ESCALA DE RESPUESTA:

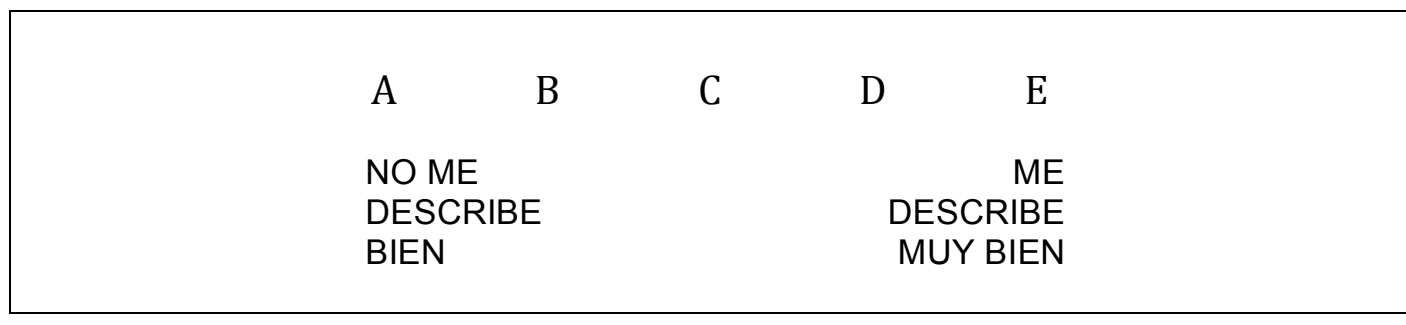

1. Suelo soñar despierto $y$ fantasear con cierta regularidad acerca de las cosas que me puedan suceder.

2. A menudo tengo sentimientos de ternura y preocupación por la gente menos afortunada que yo.

3. A veces se me hace difícil mirar

A $\quad$ B $\quad$ C $\quad$ D $\quad$ E
las cosas desde el punto de vista de las otras personas.

4. No siempre me apeno de las otras personas cuando tienen problemas.

5. Me siento realmente involucrado con los sentimientos de los personajes de una novela.

6. En situaciones de emergencia,

A $B \quad$ C $\quad$ D $\quad$ E
me siento aprehensivo e incómodo.

7. Normalmente soy objetivo cuando observo una película o

A B C D
una obra de teatro y a menudo no me siento totalmente involucrado en ella.

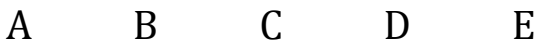

A $\quad$ B $\quad$ C $\quad$ D $\quad$ E

A $\quad$ B $\quad$ C $\quad$ D $\quad$ E 
8. Trato de considerar las perspectivas de todas las partes en un desacuerdo, antes de tomar una decisión.

9. Cuando veo que se están aprovechando de alguien, tiendo a sentirme protector ante él.

10. A veces me siento desamparado cuando estoy en medio de una situación muy emocional.

11. A veces trato de comprender mejor a mis amistades imaginando cómo se ven las cosas desde su perspectiva.

12. Rara vez me veo extremadamente involucrado en un buen libro o película.

13. Cuando veo que alguien se hiere, tiendo a permanecer calmado.

14. No tiendo a perturbarme demasiado con las desgracias de otras personas.

15. Cuando estoy seguro de tener razón en algo, no gasto mucho tiempo escuchando los argumentos de otros.

16. Después de ver una película u obra de teatro, me he sentido como si fuera uno de sus personajes.

17. Me asusta estar en una situación emocional tensa.

18. Cuando veo que alguien está siendo tratado injustamente, a veces no siento lástima de él. (EC) $(-)$
A $\quad$ B $\quad$ C $\quad$ D $\quad$ E

A $\quad$ B $\quad$ C $\quad$ D $\quad$ E

A $\quad$ B $\quad$ C $\quad$ D $\quad$ E

A $\quad$ B $\quad$ C $\quad$ D $\quad$ E

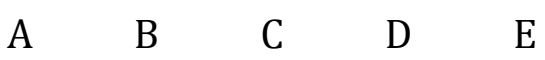

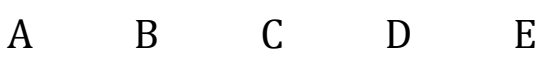

A $\quad$ B $\quad$ C $\quad$ D $\quad$ E

A $\quad$ B $\quad$ C $\quad$ D $\quad$ E

A $\quad$ B $\quad$ C $\quad$ D $\quad$ E

A $\quad$ B $\quad$ C $\quad$ D $\quad$ E

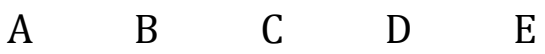


19. Soy usualmente eficiente en lidiar con emergencias.

20. A menudo me siento tocado por las cosas que veo que suceden.

21. Creo que cada cuestión tiene dos perspectivas y trato de mirar a ambas.

22. Me describiría más bien como una persona de corazón blando.

23. Cuando veo una buena película, puedo fácilmente ponerme en el lugar del protagonista.

24. Tiendo a perder el control durante las emergencias.

25. Cuando estoy molesto con alguien, trato de "ponerme en sus zapatos" por un momento.

26. Cuando estoy leyendo una novela o cuento interesante, imagino cómo me sentiría si los sucesos de la historia me estuviesen ocurriendo a mí.

27. Me derrumbo cuando veo que alguien necesita urgentemente ayuda en una emergencia.

28. Antes de criticar a alguien, trato de imaginar cómo me sentiría si estuviese en su lugar.
A $\quad$ B $\quad$ C $\quad$ D $\quad$ E

A $\quad$ B $\quad$ C $\quad$ D $\quad$ E

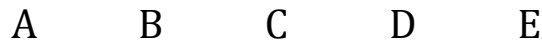

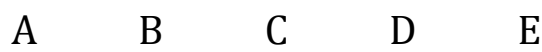

A $\quad$ B $\quad$ C $\quad$ D $\quad$ E

A $\quad$ B $\quad$ C $\quad$ D $\quad$ E

A $\quad$ B $\quad$ C $\quad$ D $\quad$ E

$\begin{array}{lllll}\text { A } & \text { B } & \text { C } & \text { D } & \text { E }\end{array}$

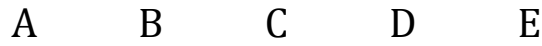

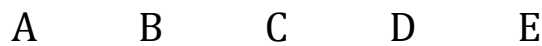




\section{V.ATQ}

\section{INSTRUCCIONES}

En las siguientes páginas encontrará una serie de afirmaciones que las personas pueden utilizar para describirse a sí mismas. No hay respuestas buenas o malas. Cada persona es única y diferente de las otras, y estas diferencias son las que tratamos de comprender. Por favor, lea cuidadosamente cada enunciado y evalúe hasta qué punto este lo describe bien. Marque el número apropiado teniendo en cuenta los siguientes criterios:

1. Extremadamente en desacuerdo

2. Muy en desacuerdo

3. Más o menos en desacuerdo

4. Ni en desacuerdo ni de acuerdo

5. Más o menos de acuerdo

6. Muy de acuerdo

7. Completamente de acuerdo

Si alguno de los enunciados no se aplica a su caso (por ejemplo, si este implica conducir un coche y usted no conduce), marque la "X" (no aplicable). Por favor, verifique que ha contestado todas las preguntas del cuestionario. 
$\begin{array}{ccccccc}\text { Extremada- } & \text { Muy } & \text { Más } & \text { Ni en } & \text { Más } & & \text { Completa- No se } \\ \text { mente } & \text { en } & o & \text { desacuerdo } & 0 & \text { Muy } & \begin{array}{c}\text { Comte aplica } \\ \text { mente }\end{array}\end{array}$ menos desacuerdo menos de aplica desacuerdo desacuerdo desacuerdo acuerdo co de acuerdo acuerdo caso

\begin{tabular}{|c|c|c|c|c|c|c|c|c|c|}
\hline 1. & Me asusto fácilmente & 1 & 2 & 3 & 4 & 5 & 6 & 7 & $\mathrm{X}$ \\
\hline 2. & A menudo llego tarde a mis citas & 1 & 2 & 3 & 4 & 5 & 6 & 7 & $\mathrm{X}$ \\
\hline 3. & $\begin{array}{l}\text { Algunas veces, cosas muy pequeñas me } \\
\text { hacen sentir una intensa alegría }\end{array}$ & 1 & 2 & 3 & 4 & 5 & 6 & 7 & $X$ \\
\hline 4. & $\begin{array}{l}\text { Me doy cuenta de que los ruidos fuertes me } \\
\text { irritan mucho }\end{array}$ & 1 & 2 & 3 & 4 & 5 & 6 & 7 & $X$ \\
\hline 5. & $\begin{array}{l}\text { Generalmente me cuesta trabajo alternar } \\
\text { entre dos tareas diferentes }\end{array}$ & 1 & 2 & 3 & 4 & 5 & 6 & 7 & $x$ \\
\hline 6. & $\begin{array}{l}\text { Raramente me enojo cuando tengo que } \\
\text { esperar en una fila que avanza lentamente }\end{array}$ & 1 & 2 & 3 & 4 & 5 & 6 & 7 & $X$ \\
\hline 7. & $\begin{array}{l}\text { No disfrutaría escuchando música fuerte con } \\
\text { efectos visuales de rayos láser }\end{array}$ & 1 & 2 & 3 & 4 & 5 & 6 & 7 & $X$ \\
\hline 8. & $\begin{array}{l}\text { Hago proyectos que con frecuencia no } \\
\text { finalizo }\end{array}$ & 1 & 2 & 3 & 4 & 5 & 6 & 7 & $X$ \\
\hline 9. & $\begin{array}{l}\text { Casi nunca me siento triste después de } \\
\text { despedirme de mis amigos o de mis } \\
\text { familiares }\end{array}$ & 1 & 2 & 3 & 4 & 5 & 6 & 7 & $X$ \\
\hline 10. & $\begin{array}{l}\text { Los detalles visuales poco perceptibles } \\
\text { raramente captan mi atención }\end{array}$ & 1 & 2 & 3 & 4 & 5 & 6 & 7 & X \\
\hline 11. & $\begin{array}{l}\text { Aun cuando me siento con mucha energía, } \\
\text { por lo general no tengo problemas para } \\
\text { quedarme quieto si es necesario }\end{array}$ & 1 & 2 & 3 & 4 & 5 & 6 & 7 & $\mathrm{X}$ \\
\hline 12. & $\begin{array}{l}\text { Mirar hacia abajo desde un edificio muy alto } \\
\text { me haría sentir inquieto }\end{array}$ & 1 & 2 & 3 & 4 & 5 & 6 & 7 & $X$ \\
\hline 13. & $\begin{array}{l}\text { Cuando escucho música, generalmente soy } \\
\text { consciente de los tonos emocionales sutiles }\end{array}$ & 1 & 2 & 3 & 4 & 5 & 6 & 7 & $X$ \\
\hline 14. & $\begin{array}{l}\text { No disfrutaría con un trabajo que requiriera } \\
\text { relacionarse con la gente }\end{array}$ & 1 & 2 & 3 & 4 & 5 & 6 & 7 & $X$ \\
\hline 15. & $\begin{array}{l}\text { Puedo continuar realizando una tarea aun } \\
\text { cuando preferiría no estar llevándola a cabo }\end{array}$ & 1 & 2 & 3 & 4 & 5 & 6 & 7 & $X$ \\
\hline 16. & $\begin{array}{l}\text { Algunas veces soy incapaz de sentir placer } \\
\text { con algunos eventos o actividades aunque } \\
\text { me gusten }\end{array}$ & 1 & 2 & 3 & 4 & 5 & 6 & 7 & $X$ \\
\hline 17. & $\begin{array}{l}\text { Me molesta mucho que una tienda no tenga } \\
\text { un producto que me gustaría comprar }\end{array}$ & 1 & 2 & 3 & 4 & 5 & 6 & 7 & X \\
\hline 18. & $\begin{array}{l}\text { Soy sensible a los aspectos emocionales } \\
\text { presentes en las pinturas y fotografías }\end{array}$ & 1 & 2 & 3 & 4 & 5 & 6 & 7 & $X$ \\
\hline 19. & Normalmente me gusta hablar bastante & 1 & 2 & 3 & 4 & 5 & 6 & 7 & $\mathrm{X}$ \\
\hline 20. & $\begin{array}{l}\text { Casi nunca me entristezco cuando veo una } \\
\text { película triste }\end{array}$ & 1 & 2 & 3 & 4 & 5 & 6 & 7 & $\mathrm{X}$ \\
\hline 21. & $\begin{array}{l}\text { A menudo me doy cuenta del canto de los } \\
\text { pájaros a mi alrededor }\end{array}$ & 1 & 2 & 3 & 4 & 5 & 6 & 7 & $\mathrm{X}$ \\
\hline 22. & $\begin{array}{l}\text { Me siento intranquilo cuando estoy } \\
\text { encerrado en lugares pequeños tales como } \\
\text { un ascensor }\end{array}$ & 1 & 2 & 3 & 4 & 5 & 6 & 7 & $\mathrm{X}$ \\
\hline 23. & $\begin{array}{l}\text { Generalmente me gusta escuchar la música } \\
\text { más fuerte que a otras personas }\end{array}$ & 1 & 2 & 3 & 4 & 5 & 6 & 7 & $X$ \\
\hline 24. & $\begin{array}{l}\text { Algunas veces siento que puedo } \\
\text { comprender las cosas de manera intuitiva }\end{array}$ & 1 & 2 & 3 & 4 & 5 & 6 & 7 & $X$ \\
\hline 25. & $\begin{array}{l}\text { A veces, pequeñas cosas me hacen sentir } \\
\text { una intensa tristeza }\end{array}$ & 1 & 2 & 3 & 4 & 5 & 6 & 7 & $X$ \\
\hline 26. & $\begin{array}{l}\text { Me resulta fácil contener la risa en } \\
\text { situaciones en las que no es apropiado } \\
\text { reírse }\end{array}$ & 1 & 2 & 3 & 4 & 5 & 6 & 7 & $X$ \\
\hline 27. & $\begin{array}{l}\text { Soy capaz de hacer una tarea difícil, aunque } \\
\text { no tenga ganas de hacerlo }\end{array}$ & 1 & 2 & 3 & 4 & 5 & 6 & 7 & $x$ \\
\hline 28. & $\begin{array}{l}\text { Es muy raro que no haya días en los que } \\
\text { experimente algunos breves momentos de } \\
\text { intensa felicidad }\end{array}$ & 1 & 2 & 3 & 4 & 5 & 6 & 7 & $X$ \\
\hline 29. & $\begin{array}{l}\text { Me distraigo fácilmente cuando trato de } \\
\text { concentrarme }\end{array}$ & 1 & 2 & 3 & 4 & 5 & 6 & 7 & $x$ \\
\hline 30. & $\begin{array}{l}\text { Probablemente disfrutaría jugando un video } \\
\text { juego difícil y rápido, que fuera ruidoso, y } \\
\text { que además tuviera muchas luces brillantes } \\
\text { y parpadeantes }\end{array}$ & 1 & 2 & 3 & 4 & 5 & 6 & 7 & $x$ \\
\hline 31. & $\begin{array}{l}\text { Me pongo nervioso cuando tengo que estar } \\
\text { sentado esperando para algo (por ejemplo., } \\
\text { en una sala de espera) }\end{array}$ & 1 & 2 & 3 & 4 & 5 & 6 & 7 & $x$ \\
\hline 32. & $\begin{array}{l}\text { Frecuentemente me molestan las luces que } \\
\text { son demasiado intensas }\end{array}$ & 1 & 2 & 3 & 4 & 5 & 6 & 7 & $X$ \\
\hline 33. & $\begin{array}{l}\text { Raramente me doy cuenta del color de los } \\
\text { ojos de la gente }\end{array}$ & 1 & 2 & 3 & 4 & 5 & 6 & 7 & $X$ \\
\hline
\end{tabular}




\begin{tabular}{|c|c|c|c|c|c|c|c|c|c|}
\hline & & $\begin{array}{r}\text { Extremada- } \\
\text { mente } \\
\text { en } \\
\text { desacuerdo }\end{array}$ & $\begin{array}{c}\text { Muy } \\
\text { en } \\
\text { desacuerdo }\end{array}$ & $\begin{array}{l}\text { Más } \\
\text { o } \\
\text { menos } \\
\text { en } \\
\text { desacuerdo }\end{array}$ & $\begin{array}{l}\text { Ni en } \\
\text { desacuerdo } \\
\text { ni en } \\
\text { acuerdo }\end{array}$ & $\begin{array}{l}\text { Más } \\
\text { o } \\
\text { menos } \\
\text { de } \\
\text { acuerdo }\end{array}$ & $\begin{array}{l}\text { Muy } \\
\text { de } \\
\text { acuerdo }\end{array}$ & $\begin{array}{l}\text { Completa- } \\
\text { mente } \\
\text { de } \\
\text { acuerdo }\end{array}$ & $\begin{array}{l}\text { No se } \\
\text { aplica } \\
\text { en } \\
\text { su } \\
\text { caso }\end{array}$ \\
\hline 34. & $\begin{array}{l}\text { Casi nunca me entristezco cuando escucho } \\
\text { hablar de un acontecimiento triste o } \\
\text { desafortunado }\end{array}$ & 1 & 2 & 3 & 4 & 5 & 6 & 7 & $\mathrm{x}$ \\
\hline 35. & $\begin{array}{l}\text { Cuando me interrumpen o me distraen, } \\
\text { usualmente puedo volver a centrar mi } \\
\text { atención con facilidad en lo que estaba } \\
\text { haciendo }\end{array}$ & 1 & 2 & 3 & 4 & 5 & 6 & 7 & $\mathrm{x}$ \\
\hline 36. & $\begin{array}{l}\text { Algunos sonidos estridentes me parecen } \\
\text { muy irritantes }\end{array}$ & 1 & 2 & 3 & 4 & 5 & 6 & 7 & $\mathrm{X}$ \\
\hline 37. & $\begin{array}{l}\text { Me gustan las conversaciones en las que } \\
\text { participan varias personas }\end{array}$ & 1 & 2 & 3 & 4 & 5 & 6 & 7 & $\mathrm{X}$ \\
\hline 38. & Normalmente soy una persona paciente & 1 & 2 & 3 & 4 & 5 & 6 & 7 & $x$ \\
\hline 39. & $\begin{array}{l}\text { Cuando estoy descansando con los ojos } \\
\text { cerrados, a veces veo imágenes }\end{array}$ & 1 & 2 & 3 & 4 & 5 & 6 & 7 & $x$ \\
\hline 40. & $\begin{array}{l}\text { Es muy difícil para mí concentrarme cuando } \\
\text { estoy perturbado }\end{array}$ & 1 & 2 & 3 & 4 & 5 & 6 & 7 & $x$ \\
\hline 41. & $\begin{array}{l}\text { A veces mi mente está llena de } \\
\text { pensamientos e imágenes vagamente } \\
\text { relacionados los unos con los otros }\end{array}$ & 1 & 2 & 3 & 4 & 5 & 6 & 7 & $x$ \\
\hline 42. & $\begin{array}{l}\text { Los colores muy brillantes en ocasiones me } \\
\text { molestan }\end{array}$ & 1 & 2 & 3 & 4 & 5 & 6 & 7 & $x$ \\
\hline 43. & $\begin{array}{l}\text { Puedo resistir con facilidad esperar mi turno } \\
\text { para hablar, incluso cuando estoy } \\
\text { emocionado y quiero expresar una idea }\end{array}$ & 1 & 2 & 3 & 4 & 5 & 6 & 7 & $x$ \\
\hline 44. & $\begin{array}{l}\text { Probablemente no me gustaría dar vueltas } \\
\text { rápidas y alocadas en el carrusel de una } \\
\text { feria }\end{array}$ & 1 & 2 & 3 & 4 & 5 & 6 & 7 & $x$ \\
\hline 45. & $\begin{array}{l}\text { Algunas veces me siento triste por más de } \\
\text { una hora }\end{array}$ & 1 & 2 & 3 & 4 & 5 & 6 & 7 & $X$ \\
\hline 46. & $\begin{array}{l}\text { Casi nunca disfruto relacionándome con un } \\
\text { grupo grande de personas }\end{array}$ & 1 & 2 & 3 & 4 & 5 & 6 & 7 & $x$ \\
\hline 47. & $\begin{array}{l}\text { Si pienso que algo debe hacerse, por lo } \\
\text { general, me pongo a trabajar en ello } \\
\text { inmediatamente }\end{array}$ & 1 & 2 & 3 & 4 & 5 & 6 & 7 & $x$ \\
\hline 48. & $\begin{array}{l}\text { No se necesita mucho para que me sienta } \\
\text { frustrado o irritado }\end{array}$ & 1 & 2 & 3 & 4 & 5 & 6 & 7 & $x$ \\
\hline 49. & $\begin{array}{l}\text { No se necesita de mucho para suscitar en } \\
\text { mí una reacción de felicidad }\end{array}$ & 1 & 2 & 3 & 4 & 5 & 6 & 7 & $X$ \\
\hline 50. & $\begin{array}{l}\text { Cuando estoy contento y entusiasmado por } \\
\text { un evento que va a ocurrir, me es difícil } \\
\text { concentrarme en actividades que requieren } \\
\text { mi atención }\end{array}$ & 1 & 2 & 3 & 4 & 5 & 6 & 7 & $x$ \\
\hline 51. & $\begin{array}{l}\text { A veces tengo sensaciones de pánico o de } \\
\text { terror sin razón aparente }\end{array}$ & 1 & 2 & 3 & 4 & 5 & 6 & 7 & $x$ \\
\hline 52. & $\begin{array}{l}\text { Con frecuencia percibo los olores y } \\
\text { fragancias }\end{array}$ & 1 & 2 & 3 & 4 & 5 & 6 & 7 & $x$ \\
\hline 53. & $\begin{array}{l}\text { A menudo tengo problemas para resistirme a } \\
\text { mis antojos de comida, bebidas, etc. }\end{array}$ & 1 & 2 & 3 & 4 & 5 & 6 & 7 & $x$ \\
\hline 54. & $\begin{array}{l}\text { Los destellos de las luces de colores me } \\
\text { molestan }\end{array}$ & 1 & 2 & 3 & 4 & 5 & 6 & 7 & $x$ \\
\hline 55. & $\begin{array}{l}\text { Suelo acabar de hacer las cosas antes de lo } \\
\text { debido (por ejemplo., pagar facturas, acabar } \\
\text { tareas en casa, etc.) }\end{array}$ & 1 & 2 & 3 & 4 & 5 & 6 & 7 & $x$ \\
\hline 56. & Me siento triste muy a menudo & 1 & 2 & 3 & 4 & 5 & 6 & 7 & $\mathrm{x}$ \\
\hline 57. & $\begin{array}{l}\text { Con frecuencia me doy cuenta de cómo el } \\
\text { color y la iluminación de una habitación } \\
\text { afectan mi estado de animo }\end{array}$ & 1 & 2 & 3 & 4 & 5 & 6 & 7 & $\mathrm{x}$ \\
\hline 58. & $\begin{array}{l}\text { Suelo mantener la calma sin sentirme } \\
\text { frustrado, cuando las cosas no marchan } \\
\text { bien para mi }\end{array}$ & 1 & 2 & 3 & 4 & 5 & 6 & 7 & $x$ \\
\hline 59. & Me desagrada la música a todo volumen & 1 & 2 & 3 & 4 & 5 & 6 & 7 & $x$ \\
\hline 60. & \begin{tabular}{|l|} 
Cuando estoy entusiasmado con algo, por \\
lo general, me resulta difícil aguantarme y no \\
hacerlo, antes de considerar las \\
consecuencias
\end{tabular} & 1 & 2 & 3 & 4 & 5 & 6 & 7 & $x$ \\
\hline
\end{tabular}




\begin{tabular}{|c|c|c|c|c|c|c|c|c|c|}
\hline 61. & $\begin{array}{l}\text { Los ruidos fuertes algunas veces me } \\
\text { asustan }\end{array}$ & 1 & 2 & 3 & 4 & 5 & 6 & 7 & $x$ \\
\hline 62. & $\begin{array}{l}\text { A veces sueño con escenas intensas, muy } \\
\text { detalladas y que no se parecen a nada de lo } \\
\text { que he experimentado estando despierto }\end{array}$ & 1 & 2 & 3 & 4 & 5 & 6 & 7 & $x$ \\
\hline
\end{tabular}

\begin{tabular}{|c|c|c|c|c|c|c|c|c|c|}
\hline & & $\begin{array}{l}\text { Extremada- } \\
\text { mente } \\
\quad \text { en } \\
\text { desacuerdo }\end{array}$ & $\begin{array}{l}\text { Muy } \\
\text { en } \\
\text { desacuerdo }\end{array}$ & $\begin{array}{c}\text { Más } \\
\text { o } \\
\text { menos } \\
\text { en } \\
\text { desacuerdo }\end{array}$ & $\begin{array}{l}\mathrm{Ni} \text { en } \\
\text { desacuerdo } \\
\text { ni en } \\
\text { acuerdo }\end{array}$ & $\begin{array}{l}\text { Más } \\
\text { o } \\
\text { menos } \\
\text { de } \\
\text { acuerdo }\end{array}$ & $\begin{array}{l}\text { Muy } \\
\text { de } \\
\text { acuerdo }\end{array}$ & $\begin{array}{l}\text { Completa- } \\
\text { mente } \\
\text { de } \\
\text { acuerdo }\end{array}$ & $\begin{array}{l}\text { No se } \\
\text { aplica } \\
\text { en su } \\
\text { caso }\end{array}$ \\
\hline 63. & $\begin{array}{l}\text { Cuando veo algo que me gusta en una } \\
\text { tienda me resulta muy difícil no comprarlo }\end{array}$ & 1 & 2 & 3 & 4 & 5 & 6 & 7 & $x$ \\
\hline 64. & $\begin{array}{l}\text { Disfruto viendo un espectáculo de laser con } \\
\text { muchas luces de colores brillantes e } \\
\text { intermitentes }\end{array}$ & 1 & 2 & 3 & 4 & 5 & 6 & 7 & $X$ \\
\hline 65. & $\begin{array}{l}\text { Cuando escucho hablar de un evento } \\
\text { desafortunado, me pongo triste } \\
\text { inmediatamente }\end{array}$ & 1 & 2 & 3 & 4 & 5 & 6 & 7 & $X$ \\
\hline 66. & $\begin{array}{l}\text { Cuando veo una película, por lo general no } \\
\text { me doy cuenta de cómo se utiliza el } \\
\text { escenario para transmitir el estado de ánimo } \\
\text { de los personajes }\end{array}$ & 1 & 2 & 3 & 4 & 5 & 6 & 7 & $X$ \\
\hline 67. & $\begin{array}{l}\text { Normalmente prefiero pasar mi tiempo libre } \\
\text { con otras personas }\end{array}$ & 1 & 2 & 3 & 4 & 5 & 6 & 7 & $x$ \\
\hline 68. & $\begin{array}{l}\text { No me asusto si pienso que estoy solo y de } \\
\text { repente descubro que alguien está cerca de } \\
\text { mi }\end{array}$ & 1 & 2 & 3 & 4 & 5 & 6 & 7 & $x$ \\
\hline 69. & $\begin{array}{l}\text { Frecuentemente me doy cuenta de cómo el } \\
\text { clima parece afectar mi estado de animo }\end{array}$ & 1 & 2 & 3 & 4 & 5 & 6 & 7 & $x$ \\
\hline 70. & $\begin{array}{l}\text { Necesito bastante para sentirme realmente } \\
\text { feliz }\end{array}$ & 1 & 2 & 3 & 4 & 5 & 6 & 7 & $X$ \\
\hline 71. & $\begin{array}{l}\text { Pocas veces me doy cuenta de la textura de } \\
\text { las cosas que tomo entre mis manos }\end{array}$ & 1 & 2 & 3 & 4 & 5 & 6 & 7 & $X$ \\
\hline 72. & $\begin{array}{l}\text { Cuando me da miedo de como una situación } \\
\text { puede acabar, generalmente evito hacerle } \\
\text { frente }\end{array}$ & 1 & 2 & 3 & 4 & 5 & 6 & 7 & $x$ \\
\hline 73. & $\begin{array}{l}\text { Me gustan particularmente las } \\
\text { conversaciones donde puedo expresar las } \\
\text { cosas sin haberlas pensado antes }\end{array}$ & 1 & 2 & 3 & 4 & 5 & 6 & 7 & $x$ \\
\hline 74. & $\begin{array}{l}\text { Frecuentemente se me ocurren ideas } \\
\text { creativas sin mucho esfuerzo }\end{array}$ & 1 & 2 & 3 & 4 & 5 & 6 & 7 & $x$ \\
\hline 75. & $\begin{array}{l}\text { Cuando ensayo algo nuevo, muy pocas } \\
\text { veces me preocupa la posibilidad de } \\
\text { fracasar }\end{array}$ & 1 & 2 & 3 & 4 & 5 & 6 & 7 & $x$ \\
\hline 76. & $\begin{array}{l}\text { Me resulta fácil controlar los } \\
\text { comportamientos divertidos que pueden ser } \\
\text { inapropiados }\end{array}$ & 1 & 2 & 3 & 4 & 5 & 6 & 7 & $x$ \\
\hline 77. & $\begin{array}{l}\text { No disfruto de las sensaciones que tengo } \\
\text { después de gritar tan fuerte como puedo }\end{array}$ & 1 & 2 & 3 & 4 & 5 & 6 & 7 & $x$ \\
\hline
\end{tabular}




\section{CBQ}

Nombre del niño:

Edad: años, meses.

Sexo del niño/a:

Fecha de hoy:

INSTRUCCIONES: Rogamos que lea detenidamente las siguientes indicaciones antes de comenzar el presente cuestionario.

En las páginas siguientes le presentaremos la descripción de diversas reacciones de los niños ante determinadas situaciones. Solicitamos que nos indique qué reacción es la más probable de su hijo/a exhiba en cada una de estas situaciones. Sabemos que no existe una forma "correcta" de reaccionar; los niños se diferencian mucho en sus reacciones; son precisamente estas diferencias las que pretendemos captar. Por favor, lea cada descripción y decida si es verdadera o falsa en relación con la reacción de su hijo/a durante los últimos seis meses.

Utilice la escala siguiente para indicar el grado en que cada una de las afirmaciones se adecúa al comportamiento de su hijo/a:

Haga un círculo alrededor del número correspondiente si la descripción es:

$\begin{array}{ll}1 & \text { Extremadamente falsa } \\ 2 & \text { Bastante falsa } \\ 3 & \text { Ligeramente falsa } \\ 4 & \text { Ni falsa ni cierta } \\ 5 & \text { Ligeramente cierta } \\ 6 & \text { Bastante cierta } \\ 7 & \text { Extremadamente cierta. }\end{array}$

Si usted no puede contestar una de estas preguntas porque nunca ha visto a su hijo/a en una situación determinada, marque con un círculo la opción NA (No Aplicable). Así, por ejemplo, si le preguntan por la reacción de su hijo cuando usted canta, y usted no le ha cantado, entonces debe marcar NA.

\section{Por favor, asegúrese de responder a TODAS las preguntas para que sus datos sean válidos.}




$\begin{array}{llllllll}1 & 2 & 3 & 4 & 5 & 6 & 7 & \text { NA } \\ \text { Falso en } & \text { Bastante } & \text { Ligeramente } & \text { Ni falso ni } & \text { Ligeramente } & \text { Bastante } & \text { Cierto en } & \text { No } \\ \text { extremo } & \text { falso } & \text { falso } & \text { cierto } & \text { Cierto } & \text { Cierto } & \text { Extremo } & \text { aplicable }\end{array}$

\section{HIJO/A:}

1. Da la impresión de que siempre tiene prisa cuando se mueve de un sitio a otro.

$\begin{array}{llllllll}\mathrm{I} & 2 & 3 & 4 & 5 & 6 & 7 & \mathrm{NA}\end{array}$

2. Se enfada cuando se le dice que es la hora de acostarse.

$\begin{array}{llllllll}\mathrm{I} & 2 & 3 & 4 & 5 & 6 & 7 & \mathrm{NA}\end{array}$

3. No le molesta el dolor.

$\begin{array}{llllllll}\mathrm{I} & 2 & 3 & 4 & 5 & 6 & 7 & \text { NA }\end{array}$

4. Le gusta deslizarse por lugares altos o realizar otras actividades arriesgadas.

$\begin{array}{llllllll}\mathrm{I} & 2 & 3 & 4 & 5 & 6 & 7 & \mathrm{NA}\end{array}$

5. Cuando toca los objetos, percibe la suavidad o aspereza de los mismos.

$\begin{array}{llllllll}\mathrm{I} & 2 & 3 & 4 & 5 & 6 & 7 & \mathrm{NA}\end{array}$

6. Antes de un acontecimiento emocionante, es tanta su excitación, que tiene problemas para estarse quieto.

$\begin{array}{llllllll}\mathrm{I} & 2 & 3 & 4 & 5 & 6 & 7 & \mathrm{NA}\end{array}$

7. Normalmente se lanza a una actividad sin "pensarlo."

$\begin{array}{llllllll}\mathrm{I} & 2 & 3 & 4 & 5 & 6 & 7 & \mathrm{NA}\end{array}$

8. Llora desconsoladamente cuando uno de sus juguetes favoritos se pierde o se rompe.

$\begin{array}{llllllll}\mathrm{I} & 2 & 3 & 4 & 5 & 6 & 7 & \mathrm{NA}\end{array}$

9. Se siente bastante incómodo cuando se moja o tiene frío.

$\begin{array}{llllllll}\mathrm{I} & 2 & 3 & 4 & 5 & 6 & 7 & \mathrm{NA}\end{array}$




$\begin{array}{llllllll}1 & 2 & 3 & 4 & 5 & 6 & 7 & \text { NA } \\ \text { Falso en } & \text { Bastante } & \text { Ligeramente } & \text { Ni falso ni } & \text { Ligeramente } & \text { Bastante } & \text { Cierto en } & \text { No } \\ \text { extremo } & \text { falso } & \text { falso } & \text { cierto } & \text { Cierto } & \text { Cierto } & \text { Extremo } & \text { aplicable }\end{array}$

\section{HIJO/A:}

10. Le gusta jugar de forma tan salvaje y arriesgada que podría hacerse daño.

$\begin{array}{llllllll}\mathrm{I} & 2 & 3 & 4 & 5 & 6 & 7 & \text { NA }\end{array}$

11. Parece encontrarse cómodo/a con casi todo el mundo.

$\begin{array}{llllllll}\mathrm{I} & 2 & 3 & 4 & 5 & 6 & 7 & \text { NA }\end{array}$

12. Tiende a correr en vez de caminar para ir de una habitación a otra.

$\begin{array}{llllllll}\mathrm{I} & 2 & 3 & 4 & 5 & 6 & 7 & \text { NA }\end{array}$

13. Se da cuenta cuando los padres usan ropa nueva.

$\begin{array}{llllllll}\mathrm{I} & 2 & 3 & 4 & 5 & 6 & 7 & \text { NA }\end{array}$

14. Hace rabietas cuando no consigue lo que quiere.

$\begin{array}{llllllll}\mathrm{I} & 2 & 3 & 4 & 5 & 6 & 7 & \text { NA }\end{array}$

15. Se entusiasma con las cosas que hace.

$\begin{array}{llllllll}\mathrm{I} & 2 & 3 & 4 & 5 & 6 & 7 & \text { NA }\end{array}$

16. Cuando realiza una actividad, le cuesta mantener la atención sobre ella.

$\begin{array}{llllllll}\mathrm{I} & 2 & 3 & 4 & 5 & 6 & 7 & \mathrm{NA}\end{array}$

17. Tiene miedo de los ladrones y del "coco".

$\begin{array}{llllllll}\mathrm{I} & 2 & 3 & 4 & 5 & 6 & 7 & \text { NA }\end{array}$

18. Cuando está fuera de casa, a menudo se queda sentado tranquilo/a.
I 2
3
4
56
$7 \quad N A$ 


$\begin{array}{llllllll}1 & 2 & 3 & 4 & 5 & 6 & 7 & \text { NA } \\ \text { Falso en } & \text { Bastante } & \text { Ligeramente } & \text { Ni falso ni } & \text { Ligeramente } & \text { Bastante } & \text { Cierto en } & \text { No } \\ \text { extremo } & \text { falso } & \text { falso } & \text { cierto } & \text { Cierto } & \text { Cierto } & \text { Extremo } & \text { aplicable }\end{array}$

\section{HIJO/A:}

19. Le gustan las historias divertidas, pero normalmente no se ríe con ellas.

$\begin{array}{llllllll}\mathrm{I} & 2 & 3 & 4 & 5 & 6 & 7 & \text { NA }\end{array}$

20. Tiende a ponerse triste si los planes familiares no se realizan.

$\begin{array}{llllllll}\text { I } & 2 & 3 & 4 & 5 & 6 & 7 & \text { NA }\end{array}$

21. Cambia de una tarea a otra sin terminar ninguna de ellas.

$\begin{array}{llllllll}\mathrm{I} & 2 & 3 & 4 & 5 & 6 & 7 & \text { NA }\end{array}$

22. Cuando juega en casa es muy activo (corre, salta, trepa...).

$\begin{array}{llllllll}\mathrm{I} & 2 & 3 & 4 & 5 & 6 & 7 & \mathrm{NA}\end{array}$

23. Le asustan los ruidos fuertes.

$\begin{array}{llllllll}\mathrm{I} & 2 & 3 & 4 & 5 & 6 & 7 & \text { NA }\end{array}$

24. Parece escuchar incluso los sonidos más bajos.

$\begin{array}{llllllll}\mathrm{I} & 2 & 3 & 4 & 5 & 6 & 7 & \text { NA }\end{array}$

25. Le cuesta calmarse después de una actividad excitante.

$\begin{array}{llllllll}\mathrm{I} & 2 & 3 & 4 & 5 & 6 & 7 & \mathrm{NA}\end{array}$

26. Disfruta bañándose en agua caliente.

$\begin{array}{llllllll}\mathrm{I} & 2 & 3 & 4 & 5 & 6 & 7 & \text { NA }\end{array}$

27. Parece sentirse triste cuando no puede finalizar alguna tarea.
12
3
4
56
$7 \quad N A$ 


$\begin{array}{llllllll}1 & 2 & 3 & 4 & 5 & 6 & 7 & \text { NA } \\ \text { Falso en } & \text { Bastante } & \text { Ligeramente } & \text { Ni falso ni } & \text { Ligeramente } & \text { Bastante } & \text { Cierto en } & \text { No } \\ \text { extremo } & \text { falso } & \text { falso } & \text { cierto } & \text { Cierto } & \text { Cierto } & \text { Extremo } & \text { aplicable }\end{array}$

\section{HIJO/A:}

28. Con frecuencia se lanza hacia nuevas situaciones.

$\begin{array}{llllllll}\mathrm{I} & 2 & 3 & 4 & 5 & 6 & 7 & \mathrm{NA}\end{array}$

29. Se suele mostrar muy molesto por un pequeño corte o golpe.

$\begin{array}{llllllll}\mathrm{I} & 2 & 3 & 4 & 5 & 6 & 7 & \mathrm{NA}\end{array}$

30. Se siente bastante frustrado cuando se le impide hacer algo que quiere hacer.

$\begin{array}{llllllll}\mathrm{I} & 2 & 3 & 4 & 5 & 6 & 7 & \mathrm{NA}\end{array}$

31. Se disgusta cuando familiares o amigos queridos se disponen a irse después de una visita.

$\begin{array}{llllllll}\mathrm{I} & 2 & 3 & 4 & 5 & 6 & 7 & \mathrm{NA}\end{array}$

32. Hace comentarios cuando uno de los padres cambia de aspecto o de apariencia.

$\begin{array}{llllllll}\mathrm{I} & 2 & 3 & 4 & 5 & 6 & 7 & \mathrm{NA}\end{array}$

33. Le divierten actividades como "jugar a perseguir" y/o "dar vueltas con los brazos extendidos".

$\begin{array}{llllllll}\mathrm{I} & 2 & 3 & 4 & 5 & 6 & 7 & \mathrm{NA}\end{array}$

34. Cuando se enoja por algo, suele estar molesto durante 10 minutos o más.

$\begin{array}{llllllll}\mathrm{I} & 2 & 3 & 4 & 5 & 6 & 7 & \mathrm{NA}\end{array}$

35. No tiene miedo a la oscuridad.

$\begin{array}{llllllll}\mathrm{I} & 2 & 3 & 4 & 5 & 6 & 7 & \mathrm{NA}\end{array}$

36. Le lleva mucho tiempo entrar en contacto con nuevas situaciones.
12
3
$4 \quad 5$
56
$7 \quad$ NA 


$\begin{array}{llllllll}1 & 2 & 3 & 4 & 5 & 6 & 7 & \text { NA } \\ \text { Falso en } & \text { Bastante } & \text { Ligeramente } & \text { Ni falso ni } & \text { Ligeramente } & \text { Bastante } & \text { Cierto en } & \text { No } \\ \text { extremo } & \text { falso } & \text { falso } & \text { cierto } & \text { Cierto } & \text { Cierto } & \text { Extremo } & \text { aplicable }\end{array}$

\section{HIJO/A:}

37. A veces es tímido/a, incluso con gente que conoce desde hace tiempo.

$\begin{array}{llllllll}\mathrm{I} & 2 & 3 & 4 & 5 & 6 & 7 & \mathrm{NA}\end{array}$

38. Puede esperar a emprender una nueva actividad si se le pide.

$\begin{array}{llllllll}\mathrm{I} & 2 & 3 & 4 & 5 & 6 & 7 & \mathrm{NA}\end{array}$

39. Le gusta acurrucarse junto a cualquiera de sus padres o a otro cuidador.

$\begin{array}{llllllll}\mathrm{I} & 2 & 3 & 4 & 5 & 6 & 7 & \mathrm{NA}\end{array}$

40. Se enfada cuando no encuentra algo con lo que quiere jugar.

$\begin{array}{llllllll}\mathrm{I} & 2 & 3 & 4 & 5 & 6 & 7 & \mathrm{NA}\end{array}$

41. Tiene miedo del fuego.

$\begin{array}{llllllll}\mathrm{I} & 2 & 3 & 4 & 5 & 6 & 7 & \mathrm{NA}\end{array}$

42. A veces se pone nervioso cuando habla con adultos a los que acaba de conocer.

$\begin{array}{llllllll}\mathrm{I} & 2 & 3 & 4 & 5 & 6 & 7 & \mathrm{NA}\end{array}$

43. Es lento y no tiene prisa para decidir lo que a continuación tiene que hacer.

$\begin{array}{llllllll}\mathrm{I} & 2 & 3 & 4 & 5 & 6 & 7 & \text { NA }\end{array}$

44. Cambia de estar molesto/preocupado a sentirse mucho mejor en pocos minutos.

$\begin{array}{llllllll}\mathrm{I} & 2 & 3 & 4 & 5 & 6 & 7 & \text { NA }\end{array}$

45. Prepara los viajes y excursiones planificando las cosas que necesitará.

$\begin{array}{llllllll}\mathrm{I} & 2 & 3 & 4 & 5 & 6 & 7 & \mathrm{NA}\end{array}$




$\begin{array}{llllllll}1 & 2 & 3 & 4 & 5 & 6 & 7 & \text { NA } \\ \text { Falso en } & \text { Bastante } & \text { Ligeramente } & \text { Ni falso ni } & \text { Ligeramente } & \text { Bastante } & \text { Cierto en } & \text { No } \\ \text { extremo } & \text { falso } & \text { falso } & \text { cierto } & \text { Cierto } & \text { Cierto } & \text { Extremo } & \text { aplicable }\end{array}$

\section{HIJO/A:}

46. Se entusiasma cuando se planean excursiones.

$\begin{array}{llllllll}\mathrm{I} & 2 & 3 & 4 & 5 & 6 & 7 & \text { NA }\end{array}$

47. Se da cuenta rápidamente de cualquier detalle nuevo en la sala.
I 2
23
4
5
6
$7 \quad$ NA

48. Raramente se ríe a carcajadas cuando juega con otros niños.

$\begin{array}{llllllll}\mathrm{I} & 2 & 3 & 4 & 5 & 6 & 7 & \text { NA }\end{array}$

49. No se molesta mucho por pequeños cortes o magulladuras.

$\begin{array}{llllllll}\mathrm{I} & 2 & 3 & 4 & 5 & 6 & 7 & \mathrm{NA}\end{array}$

50. Prefiere las actividades tranquilas antes que los juegos activos.

$\begin{array}{llllllll}\mathrm{I} & 2 & 3 & 4 & 5 & 6 & 7 & \mathrm{NA}\end{array}$

51. Tiende a decir lo primero que se le ocurre sin pararse a pensar sobre ello.
I
2
3
$4 \quad 5$
$5 \quad 6 \quad 7$
NA

52. Actúa de manera tímida con gente desconocida.

$\begin{array}{llllllll}\mathrm{I} & 2 & 3 & 4 & 5 & 6 & 7 & \mathrm{NA}\end{array}$

53. Le resulta difícil permanecer sentado y callado cuando se le pide (en la iglesia, en el cine, etc.).

$\begin{array}{llllllll}\mathrm{I} & 2 & 3 & 4 & 5 & 6 & 7 & \mathrm{NA}\end{array}$

54. Raramente llora cuando escucha una historia triste.
I 2

3
4
56
7
NA 


$\begin{array}{llllllll}1 & 2 & 3 & 4 & 5 & 6 & 7 & \text { NA } \\ \text { Falso en } & \text { Bastante } & \text { Ligeramente } & \text { Ni falso ni } & \text { Ligeramente } & \text { Bastante } & \text { Cierto en } & \text { No } \\ \text { extremo } & \text { falso } & \text { falso } & \text { cierto } & \text { Cierto } & \text { Cierto } & \text { Extremo } & \text { aplicable }\end{array}$

\section{HIJO/A:}

55. Algunas veces sonríe o ríe tontamente cuando juega solo.

$\begin{array}{llllllll}\mathrm{I} & 2 & 3 & 4 & 5 & 6 & 7 & \text { NA }\end{array}$

56. Raramente le afectan los sucesos tristes que aparecen en televisión.

$\begin{array}{llllllll}\mathrm{I} & 2 & 3 & 4 & 5 & 6 & 7 & \text { NA }\end{array}$

57. Disfruta sólo con que le hablen.

$\begin{array}{llllllll}\mathrm{I} & 2 & 3 & 4 & 5 & 6 & 7 & \text { NA }\end{array}$

58. Se ilusiona mucho antes de salir para una merienda, fiesta, etc.

$\begin{array}{llllllll}\mathrm{I} & 2 & 3 & 4 & 5 & 6 & 7 & \mathrm{NA}\end{array}$

59. Si está disgustado/a, se alegra rápidamente al pensar en otra cosa.

$\begin{array}{llllllll}\mathrm{I} & 2 & 3 & 4 & 5 & 6 & 7 & \text { NA }\end{array}$

60. Se siente a gusto cuando pide a otros niños que le dejen jugar con ellos.

$\begin{array}{llllllll}\mathrm{I} & 2 & 3 & 4 & 5 & 6 & 7 & \mathrm{NA}\end{array}$

61. Raramente se molesta cuando se le manda a la cama.

$\begin{array}{llllllll}\mathrm{I} & 2 & 3 & 4 & 5 & 6 & 7 & \mathrm{NA}\end{array}$

62. Muestra una gran concentración cuando dibuja o pinta (en un libro).

$\begin{array}{llllllll}\mathrm{I} & 2 & 3 & 4 & 5 & 6 & 7 & \mathrm{NA}\end{array}$

63. Tiene miedo a la oscuridad.

$\begin{array}{llllllll}\mathrm{I} & 2 & 3 & 4 & 5 & 6 & 7 & \text { NA }\end{array}$




$\begin{array}{llllllll}1 & 2 & 3 & 4 & 5 & 6 & 7 & \text { NA } \\ \text { Falso en } & \text { Bastante } & \text { Ligeramente } & \text { Ni falso ni } & \text { Ligeramente } & \text { Bastante } & \text { Cierto en } & \text { No } \\ \text { extremo } & \text { falso } & \text { falso } & \text { cierto } & \text { Cierto } & \text { Cierto } & \text { Extremo } & \text { aplicable }\end{array}$

\section{HIJO/A:}

64. Tiende a llorar incluso cuando se hace un poco de daño.

$\begin{array}{llllllll}\mathrm{I} & 2 & 3 & 4 & 5 & 6 & 7 & \text { NA }\end{array}$

65. Disfruta mirando los dibujos de los libros.

$\begin{array}{llllllll}\mathrm{I} & 2 & 3 & 4 & 5 & 6 & 7 & \mathrm{NA}\end{array}$

66. Se calma fácilmente cuando está molesto/a.

$\begin{array}{llllllll}\mathrm{I} & 2 & 3 & 4 & 5 & 6 & 7 & \text { NA }\end{array}$

67. Es bueno siguiendo las instrucciones que se le dan.

$\begin{array}{llllllll}\mathrm{I} & 2 & 3 & 4 & 5 & 6 & 7 & \mathrm{NA}\end{array}$

68. Raramente le asustan los "monstruos" que ve en la televisión o en el cine.

$\begin{array}{llllllll}\mathrm{I} & 2 & 3 & 4 & 5 & 6 & 7 & \text { NA }\end{array}$

69. En los columpios, le gusta que se le empuje alto y rápido.

$\begin{array}{llllllll}\mathrm{I} & 2 & 3 & 4 & 5 & 6 & 7 & \mathrm{NA}\end{array}$

70. A veces se aparta tímidamente de las nuevas amistades.

$\begin{array}{llllllll}\text { I } & 2 & 3 & 4 & 5 & 6 & 7 & \text { NA }\end{array}$

71. Cuando juega con un rompecabezas o juego de construcción, se queda concentrado en lo que está haciendo y trabaja durante mucho tiempo.
12

3
4
56
$7 \quad \mathrm{NA}$

72. Le gusta que le canten.

$\begin{array}{llllllll}\mathrm{I} & 2 & 3 & 4 & 5 & 6 & 7 & \mathrm{NA}\end{array}$




$\begin{array}{llllllll}1 & 2 & 3 & 4 & 5 & 6 & 7 & \text { NA } \\ \text { Falso en } & \text { Bastante } & \text { Ligeramente } & \text { Ni falso ni } & \text { Ligeramente } & \text { Bastante } & \text { Cierto en } & \text { No } \\ \text { extremo } & \text { falso } & \text { falso } & \text { cierto } & \text { Cierto } & \text { Cierto } & \text { Extremo } & \text { aplicable }\end{array}$

\section{HIJO/A:}

73. Se acerca lenta y cautelosamente a lugares que le han dicho que son peligrosos.

$\begin{array}{llllllll}\mathrm{I} & 2 & 3 & 4 & 5 & 6 & 7 & \mathrm{NA}\end{array}$

74. Es muy raro que se desanime cuando le cuesta trabajo hacer que algo funcione.

$\begin{array}{llllllll}\mathrm{I} & 2 & 3 & 4 & 5 & 6 & 7 & \mathrm{NA}\end{array}$

75. Es difícil de calmar cuando se disgusta.

$\begin{array}{llllllll}\mathrm{I} & 2 & 3 & 4 & 5 & 6 & 7 & \text { NA }\end{array}$

76. Le gusta el sonido de las palabras, como en las canciones infantiles.

$\begin{array}{llllllll}\mathrm{I} & 2 & 3 & 4 & 5 & 6 & 7 & \mathrm{NA}\end{array}$

77. Sonríe mucho a la gente que quiere.

$\begin{array}{llllllll}\mathrm{I} & 2 & 3 & 4 & 5 & 6 & 7 & \mathrm{NA}\end{array}$

78. Le disgustan los juegos bruscos y toscos.

$\begin{array}{llllllll}\text { I } & 2 & 3 & 4 & 5 & 6 & 7 & \text { NA }\end{array}$

79. A menudo ríe a carcajadas cuando juega con otros niños.

$\begin{array}{llllllll}\mathrm{I} & 2 & 3 & 4 & 5 & 6 & 7 & \mathrm{NA}\end{array}$

80. Raramente se ríe a carcajadas cuando ve comedias en la televisión o en el cine.

$\begin{array}{llllllll}\mathrm{I} & 2 & 3 & 4 & 5 & 6 & 7 & \mathrm{NA}\end{array}$

81. Puede parar fácilmente una actividad cuando se le dice "no".

$\begin{array}{llllllll}\mathrm{I} & 2 & 3 & 4 & 5 & 6 & 7 & \mathrm{NA}\end{array}$




$\begin{array}{llllllll}1 & 2 & 3 & 4 & 5 & 6 & 7 & \text { NA } \\ \text { Falso en } & \text { Bastante } & \text { Ligeramente } & \text { Ni falso ni } & \text { Ligeramente } & \text { Bastante } & \text { Cierto en } & \text { No } \\ \text { extremo } & \text { falso } & \text { falso } & \text { cierto } & \text { Cierto } & \text { Cierto } & \text { Extremo } & \text { aplicable }\end{array}$

\section{HIJO/A:}

82. Es de los últimos niños en intentar una nueva actividad.

$\begin{array}{llllllll}\mathrm{I} & 2 & 3 & 4 & 5 & 6 & 7 & \mathrm{NA}\end{array}$

83. Normalmente no se da cuenta de los olores, como de perfume, humo, olor a guiso, etc.

$\begin{array}{llllllll}\mathrm{I} & 2 & 3 & 4 & 5 & 6 & 7 & \mathrm{NA}\end{array}$

84. Se distrae fácilmente cuando escucha un cuento.

$\begin{array}{llllllll}\mathrm{I} & 2 & 3 & 4 & 5 & 6 & 7 & \text { NA }\end{array}$

85. Está lleno de energía, incluso por la noche.

$\begin{array}{llllllll}\mathrm{I} & 2 & 3 & 4 & 5 & 6 & 7 & \mathrm{NA}\end{array}$

86. Disfruta sentándose en el regazo de sus padres.

$\begin{array}{llllllll}\mathrm{I} & 2 & 3 & 4 & 5 & 6 & 7 & \mathrm{NA}\end{array}$

87. Se enoja cuando se le llama antes de finalizar un juego.

$\begin{array}{llllllll}\mathrm{I} & 2 & 3 & 4 & 5 & 6 & 7 & \text { NA }\end{array}$

88. Disfruta montando en triciclo o bicicleta de forma rápida y arriesgada.

$\begin{array}{llllllll}\mathrm{I} & 2 & 3 & 4 & 5 & 6 & 7 & \mathrm{NA}\end{array}$

89. A veces se queda absorto mirando durante mucho tiempo un dibujo de un libro.

$\begin{array}{llllllll}\mathrm{I} & 2 & 3 & 4 & 5 & 6 & 7 & \text { NA }\end{array}$

90. Está bastante tranquilo/a mientras espera postres como un helado.

$\begin{array}{llllllll}\mathrm{I} & 2 & 3 & 4 & 5 & 6 & 7 & \mathrm{NA}\end{array}$




$\begin{array}{llllllll}1 & 2 & 3 & 4 & 5 & 6 & 7 & \text { NA } \\ \text { Falso en } & \text { Bastante } & \text { Ligeramente } & \text { Ni falso ni } & \text { Ligeramente } & \text { Bastante } & \text { Cierto en } & \text { No } \\ \text { extremo } & \text { falso } & \text { falso } & \text { cierto } & \text { Cierto } & \text { Cierto } & \text { Extremo } & \text { aplicable }\end{array}$

\section{HIJO/A:}

91. Es muy raro que se queje cuando está resfriado.

$\begin{array}{llllllll}\mathrm{I} & 2 & 3 & 4 & 5 & 6 & 7 & \mathrm{NA}\end{array}$

92. Espera con ilusión las salidas familiares, aunque es no se emociona demasiado con ellas.

$\begin{array}{llllllll}\mathrm{I} & 2 & 3 & 4 & 5 & 6 & 7 & \mathrm{NA}\end{array}$

93. Le gusta sentarse tranquilamente, y ver a la gente hacer cosas.

$\begin{array}{llllllll}\mathrm{I} & 2 & 3 & 4 & 5 & 6 & 7 & \text { NA }\end{array}$

94. Disfruta con actividades rítmicas, como mecerse o balancearse.
I 2
2
34
5
$6 \quad 7$
NA

Por favor, asegúrese de haber completado todas las páginas del cuestionario. Muchas gracias por su colaboración. 